\title{
THE HEALTH CARE ENCOUNTERS OF PREGNANT AND POSTPARTUM WOMEN WITH SUBSTANCE USE DISORDERS
}

Kalyn Marie Renbarger

Submitted to the faculty of the University Graduate School in partial fulfillment of the requirements for the degree Doctor of Philosophy in the School of Nursing, Indiana University

June 2020 
Accepted by the Graduate Faculty of Indiana University, in partial fulfillment of the requirements for the degree of Doctor of Philosophy.

Doctoral Committee

Claire Burke Draucker, PhD, RN, FAAN, Chair

Carol Shieh, DNSc, MPH, RNC-OB, FAAN

April 8, 2020

Meg Moorman, PhD, RN

Kenzie Latham-Mintus, $\mathrm{PhD}$ 
(C) 2020

Kalyn Marie Renbarger 


\section{ACKNOWLEDGEMENT}

I am very thankful for the many mentors and nurses who have inspired me to pursue my professional ambitions. I would like to acknowledge my dissertation committee members: Dr. Claire Draucker, Dr. Carol Shieh, Dr. Meg Moorman, and Dr. Kenzie Latham-Mintus. I am appreciative for your expertise and unique perspective you each provided in the completion of this dissertation. I am particularly thankful for the advice, knowledge, and for the guidance of my dissertation committee chair and doctoral program advisor, Dr. Claire Draucker, for whom this dissertation would not be possible. Your mentorship and influence on my research and professional growth has been invaluable. Thank you for always encouraging me and gently pushing me forward in this journey.

I am grateful for the financial support I received to pursue my doctoral education including the Diane McCabe Scholarship, Aycock Scholarship, Meier-Lyon Fellowship, Jonas Scholar Program, and the Joyce Fitzpatrick Research Grant funded through the International Society of Psychiatric Nurses. The financial support was instrumental in funding and completion my education and research.

I would like to thank my family, friends, and colleagues for the support and encouragement throughout this journey. I especially want to thank my loving children, Drew and Maliyah, who were understanding of the many hours of researching and writing. This degree is for you and I hope I have led by example and inspire you to pursue your dreams. 
I am grateful to my participants who bravely shared their stories with me. I am inspired by their stories to further my research and improve health care experiences for both the nurses and the women. 
Kalyn Marie Renbarger

\section{THE HEALTH CARE ENCOUNTERS OF PREGNANT AND POSTPARTUM}

\section{WOMEN WITH SUBSTANCE USE DISORDERS}

Pregnant and postpartum women with substance use disorders (SUDs) are likely to experience adverse health care encounters that contribute to poor health outcomes for them and their infants. The purpose of this dissertation is to describe the health care encounters of pregnant and postpartum women with SUDs. This dissertation includes two studies. The first study is a metasynthesis of published qualitative studies using a metasummary approach to classify the types of health care encounters experienced by pregnant and postpartum women with SUDs. A taxonomy of health care encounters was developed. Five types of adverse encounters were identified and labeled as (a) judgmental, (b) disparaging, (c) scrutinizing, (d) disempowering, and (e) deficient care. Three types of beneficial encounters were identified and labeled as (a) recovery-based, (b) accepting, and (c) effective care. The second study was a qualitative descriptive study conducted to describe factors that influence the formation of trusting relationships between maternity nurses and pregnant and postpartum women with SUDs. Interviews with 15 maternity nurses and 10 pregnant and postpartum women with SUDs were conducted. Content analysis of the participant narratives revealed a number of characteristics of maternity nurses and pregnant and postpartum women with SUDs that helped or hindered trusting relationships. Six characteristics of maternity nurses were identified and labeled as (a) rapport-building with women, (b) demeanor toward women, (c) provision of care, (d) provision of information, (e) attitude toward substance use, and (f) addiction expertise. Five characteristics of the women were identified and labeled as 
(a) engagement with nurses, (b) demeanor toward nurses, (c) acceptance of care, (d) investment in recovery, and (e) bonding with infant. Adverse encounters were often associated with provider stigma related to substance use during pregnancy and limited provider knowledge related to addiction. The findings will contribute to the development of strategies to improve the health care encounters of this population by promoting stigma awareness and communication skills training.

Claire Burke Draucker, PhD, RN, FAAN, Chair 


\section{TABLE OF CONTENTS}

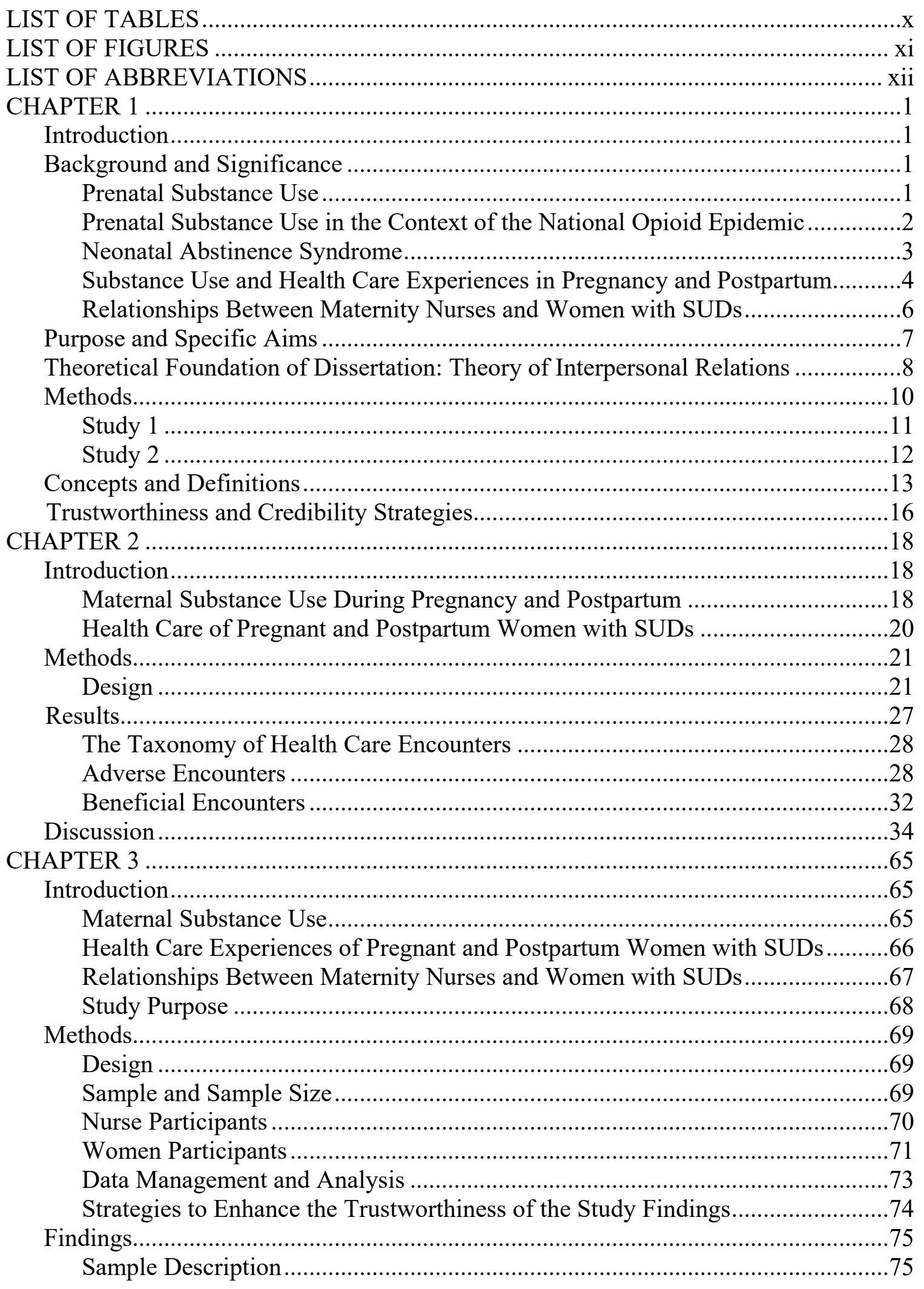




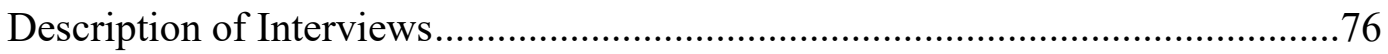

Nurse and Women Characteristics and Trusting Relationships..............................76

Characteristics of Maternity Nurses and Trusting Relationships ..........................77

Characteristics of Women with SUDs and Trusting Relationships .......................87

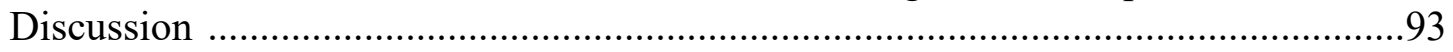

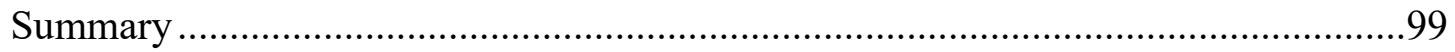

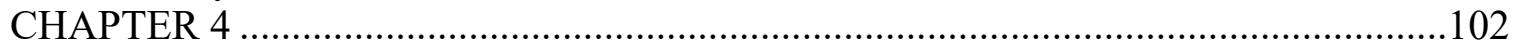

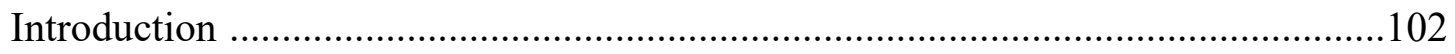

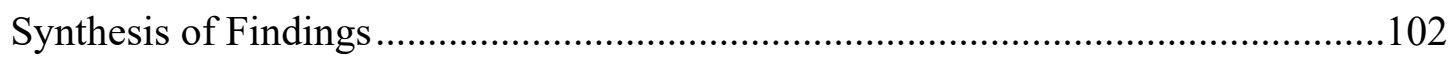

Study Findings and Peplau's Theory of Interpersonal Relations................................106

Strengths and Innovation ...................................................................................107

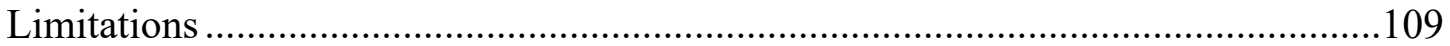

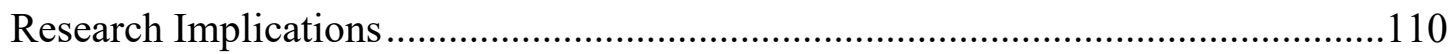

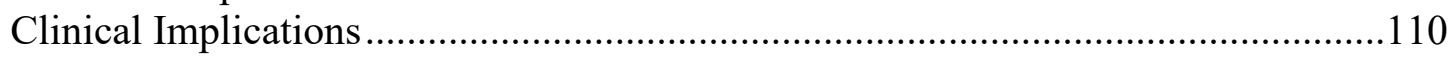

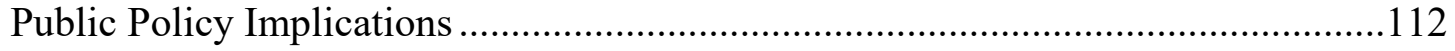

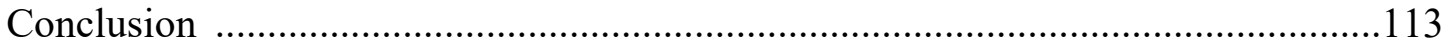

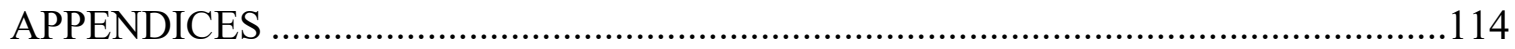

Appendix A Demographic Sheets.....................................................................115

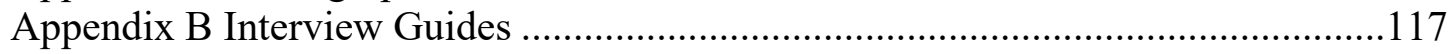

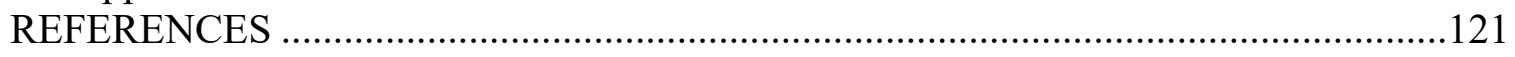

CURRICULUM VITAE 


\section{LIST OF TABLES}

Table 1.1: Terms Related to Substantive Content of Dissertation...................................13

Table 1.2: Terms Related to Methodologies Used in Dissertation ..................................15

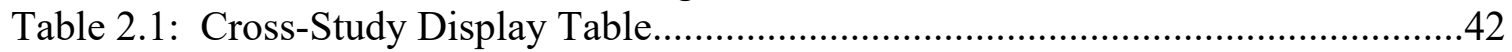

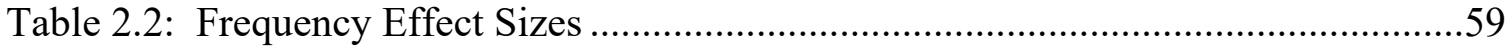

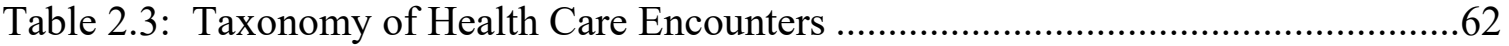

Table 3.1: Facilitators and Barriers to a Trusting Relationship ...................................100 


\section{LIST OF FIGURES}

Figure 1: PRISMA Flow Diagram of Process Selection ...............................................41 


\section{LIST OF ABBREVIATIONS}

\begin{tabular}{|c|c|}
\hline Abbreviation & Term \\
\hline $\mathrm{ACOG}$ & American Congress of Obstetricians and Gynecologists \\
\hline AFCARS & Adoption and Foster Care Analysis and Reporting System \\
\hline AWHONN & Association of Women's Health, Obstetric, and Neonatal Nursing \\
\hline CPS & Child Protective Services \\
\hline HIPAA & Health Information Portability and Accountability Act \\
\hline IRB & Institutional Review Board \\
\hline LDPR & Labor, Delivery, Postpartum, and Recovery \\
\hline MAT & Medication Assisted Treatment \\
\hline MMT & Methadone Maintenance Treatment \\
\hline NAS & Neonatal Abstinence Syndrome \\
\hline NICU & Neonatal Intensive Care Unit \\
\hline NOWS & Neonatal Opioid Withdrawal Syndrome \\
\hline \multirow[t]{2}{*}{ PRISMA } & Preferred Reporting Items for Systematic Reviews and Meta- \\
\hline & Analyses \\
\hline SUDs & Substance Use Disorders \\
\hline
\end{tabular}




\section{CHAPTER 1}

\section{Introduction}

This chapter provides an introduction to the dissertation research, which includes two studies: a metasummary (Study 1) and a qualitative descriptive study (Study 2). The chapter includes a discussion of the background and significance of the research topic, the purpose and specific aims of the studies, a description of the methods of the studies, an overview of the nursing theory most relevant to the dissertation, and a brief summary of chapters 2 through 4.

\section{Background and Significance}

\section{Prenatal Substance Use}

Prenatal substance use is a significant public health problem that has a variety of negative health implications for women and children. In 2018, a U.S. national survey indicated that $11.6 \%$ of pregnant women reported tobacco use, $9.9 \%$ heavy alcohol use, and 5.4\% illicit drug use in the past month (U.S. Department of Health and Human Services, 2019). The type of substance as well as the timing and degree of use in pregnancy affect maternal and infant health outcomes (Forray, 2016).

According to the Diagnostic and Statistical Manual of Mental Disorders, Fifth Edition, substance use disorders (SUDs) are problematic patterns of substance use that result in impairment or distress. SUDs are classified as mild, moderate, or severe. Common SUDs include opioid use disorder, alcohol use disorder, and cannabis use disorder. SUDs are diagnosed based on evidence of 11 symptoms related to impaired control, social impairment, risky use, and pharmacological criteria (American Psychiatric Association, 2013). 
Substance use during pregnancy is linked to a number of maternal, fetal, and neonatal complications. These complications include increased risk of abruption placenta, infant mortality, intrauterine growth restrictions, low infant birth weight, neonate withdrawal symptoms, still birth, and preterm birth (Cook et al., 2017; Forray, 2016; O'Leary et al., 2012; Patrick et. al., 2017; Salihu \& Wilson, 2007; Shankaran et al., 2007; Yazdy et al., 2015). Moreover, substance use during pregnancy is associated with a number of psychosocial consequences for mothers and infants. For example, maternal substance use has been identified as a risk for poor mother-infant attachment, which is associated with child maltreatment (Solis et al., 2012). According to the Adoption and Foster Care Analysis and Reporting System (AFCARS), 269,509 children entered the foster care system in the United States in 2018, and drug abuse by a parent was listed as the main reason for child removal in $36 \%$ of the cases (U.S. Department of Health and Human Services, 2019).

\section{Prenatal Substance Use in the Context of the National Opioid Epidemic}

Opioid use in the United States has become a major public health concern and has contributed to maternal and child health concerns in the United States (Centers for Disease Control and Prevention, 2007). For example, one study found approximately one in five women $(21.6 \%)$ in a sample of over 1.1 million women in 46 states and Washington D.C who were enrolled in Medicaid filled a prescription for an opioid during pregnancy. The rate of filled opioid prescriptions increased from $18.5 \%$ in 2000 to 22.8\% in 2007 (Desai et al., 2014). Between the years of 1999 and 2014, rates of opioid use during pregnancy increased dramatically from 1.5 cases per 1,000 hospital births to 6.5 cases per 1,000 hospital births (Haight et al., 2018). Additionally, during the time 
period between 2000 and 2013, rates of heroin use in women doubled in the United States (Jones et al., 2015). The increase in opioid use during pregnancy has resulted in a dramatic rise in the number of women seeking substance use treatment. From 1992 to 2012, the percent of pregnant women admitted to substance use treatment facilities who reported a history of prescription opioid misuse increased from 2\% to 28\% (Martin et al., 2015).

\section{Neonatal Abstinence Syndrome}

Neonatal abstinence syndrome (NAS) has become a major maternal child health problem as a consequence of the national opioid epidemic. As many as $75-90 \%$ of infants exposed to prenatal opioids will experience NAS. NAS is a set of withdrawal symptoms including irritability, excessive crying, and tremors that are experienced by newborns exposed to opioids and other substances during pregnancy (Hudak \& Tan, 2012). In addition to opioids, withdrawal symptoms can occur in infants with prenatal exposure to benzodiazepines, barbiturates, alcohol, and certain antidepressants. Other substances such as cocaine, amphetamines, and nicotine may increase the severity of NAS symptoms (Hudak \& Tan, 2012). Based on data from hospital births in 28 states in the United States, it was estimated that NAS increased by $300 \%$ between the years of 1999 and 2013. The overall incidence of NAS during this time period was 2.5 cases per 1,000 hospital births. In 1999, the incidence of NAS was 1.5 cases per 1,000 hospital births, and in 2013, the incidence was 6.0 cases per 1,000 hospital births (based on 21 reporting states) (Ko et al., 2016). NAS can result in extended length of hospital stay and increased hospital costs. Between 2004 and 2014, the total hospital costs in the United 
States related to NAS increased from $\$ 65.4$ million to $\$ 462$ million per year (Winkelman et al., 2018).

\section{Substance Use and Health Care Experiences in Pregnancy and Postpartum}

Pregnant and postpartum women with SUDs often report problematic relationships with health care providers. For example, studies have shown that pregnant and postpartum women with SUDs often do not have trusting relationships with health care providers and sometimes opt to avoid health care (Hall \& Teijlingen, 2006; Roberts \& Pies, 2011). Patients' trust that a health care provider cares about them and works in their best interest is considered foundational to the provider-patient relationship and is associated with positive health outcomes (Birkhauer et al., 2017). When pregnant and postpartum women and health care providers do not form trusting relationships, inadequate prenatal care and missed opportunities to improve health outcomes for women and their infants can result (Chan \& Moriarty, 2010; Gilchrist et al., 2012; Leppo, 2012). Two factors that influence the formation of trust between health care providers and pregnant and postpartum women with SUDs are stigma and criminalization of substance use during pregnancy.

Stigma. Pregnant and postpartum women with SUDs experience stigma in their encounters with health care providers (Cleveland \& Bonguli, 2014; Cleveland \& Gill, 2013; Gilchrist et al., 2012; Hall \& van Teijlingen, 2006; Howard, 2015; Leppo, 2012; McGlothen et al., 2018; Paterno et al., 2018). Sociologist Erving Goffman (1963), a leading theorist on stigma, defined stigma as "an attribute that is deeply discrediting" (p. 3) and argued that stigma leads to low self-esteem, depression, and isolation (Goffman, 1963). Health conditions often associated with stigma include skin conditions, epilepsy, 
sexually transmitted diseases, substance use, and mental illness (Knaak et al., 2017; van Boekel et al., 2013; Van Brakel, 2006).

Pregnant women and postpartum women with SUDs experience stigma through judgmental attitudes expressed by health care providers. The women report that because they use substances providers undermine their decision-making, refer to them with negative labels (e.g., "methadone mom") and provide differential treatment for them, thereby the impairing formation of trust (Demirci et al., 2015; Howard, 2015; Howard, 2016; Jessup et al., 2003; Leppo, 2012). Perceived stigma has been associated with increased substance use and dissatisfaction with pregnancy (Best et al., 2014) and decreased utilization of prenatal health care (Gilchrist et al., 2012; Hall \& Teijlingen, 2006). Failure to receive prenatal care can impair health outcomes as health care services and addiction treatment are linked to decreased substance use during pregnancy and positive effects on maternal and newborn health (Goler et al., 2008).

Criminalization. Criminalization of substance use during pregnancy and punitive policies such child removal, arrest, and incarceration can impact the health care experiences of pregnant and postpartum women with SUDs. Most states do not have a statute that directly criminalizes substance use during pregnancy, but existing laws have been used to punish women who use substances while pregnant (Guttmacher Institute, 2019). For example, several states have laws that state an infant exposed prenatally to substances is believed to be abused or neglected and a positive toxicology test can be used as evidence for terminating parental rights (Guttmacher Institute, 2019). Efforts to improve availability and accessibility of substance use treatment programs have often lagged behind efforts to criminalize substance use during pregnancy (Krans \& Patrick, 
2016). Only19 states have created or funded substance use treatment programs for pregnant women (Guttmacher Institute, 2019).

Pregnant and postpartum women with SUDs report fear of criminalization or punishment if their substance use is reported to authorities by health care providers (Chan \& Moriarty, 2010; Gilchrist et al., 2012; Hall \& van Teijlingen, 2006; Harvey et al., 2015; Howard, 2015; Jessup et al., 2003; Leppo, 2012; Stone, 2015). Fear of loss of infant custody, arrest, prosecution, or incarceration can thus impair the formation of trust in the provider-patient relationship, serve as a barrier to the utilization of prenatal care and addiction treatment services, and discourage disclosure of substance use to health care providers (Kruk \& Banga, 2011; Phillips et al., 2007; Roberts \& Nuru-Jeter, 2010; Roberts \& Pies, 2011; Stengel, 2014; Stone, 2015; Van Scoyoc et al., 2016).

\section{Relationships Between Maternity Nurses and Women with SUDs}

Maternity nurses play an important role in the health care of pregnant and postpartum women with SUDs and their infants. Nurses are well situated to create a positive health care experience for women during pregnancy, labor and delivery, and postpartum by establishing a trusting relationship and enhancing the physical and emotional wellbeing of women and their families (Lyndon, 2009). Research shows that new mothers' satisfaction with maternity care is influenced by the quality of their relationships with a nurse (Peterson et al., 2007) and women's perceptions of readiness for discharge in postpartum is linked to the quality of discharge teaching they receive from a nurse (Weiss \& Lokken, 2009).

Despite the importance of the relationships between maternity nurses and pregnant and postpartum women, these relationships may be challenged when the women 
use substances. Maternity nurses may experience frustration towards women with SUDs and remain emotionally distance from them, resulting in workplace stress and burnout (Fraser et al., 2007; Maguire et al., 2012; Murphy-Oikonen et al., 2010; Shaw et al., 2016).

Pregnant and postpartum women with SUDs also have described difficulties in their relationship to maternity nurses. Pregnant and postpartum women with SUDs often report feeling unwelcomed and out of place when entering the neonatal intensive care unit (NICU) to care for their infants and have the sense nurses think the women are bad mothers and resent providing care to them (Cleveland \& Gill, 2013).

\section{Purpose and Specific Aims}

While the quality of provider-patient relationships is central to the care of pregnant and post-partum women with SUDs and influences their health outcomes, few studies have provided an in-depth description of health care encounters between providers and the women. Specifically, little is known about factors that help or hinder the formation of trust between women with SUDs and the maternity nurses who provide a significant amount of their care. Therefore, the purpose of the dissertation project is to describe the health care encounters of pregnant and postpartum women with SUDs, focusing on the formation of trusting relationships between maternity nurses and the women. The specific aims include the following:

Aim 1: Synthesize existing qualitative studies to describe how pregnant and postpartum women with SUDs experience health care encounters in prenatal care, labor and delivery, postpartum, and nursery/NICU settings. 
Aim 2: Identify facilitators of and barriers to the formation of trusting relationships between maternity nurses and pregnant and postpartum women with SUDs from the perspectives of the maternity nurses.

Aim 3: Identify facilitators of and barriers to the formation of trusting relationships between maternity nurses and pregnant and postpartum women with SUDs from the perspectives of the women.

\section{Theoretical Foundation of Dissertation: Theory of Interpersonal Relations}

The theory that provides the theoretical foundation of this dissertation is Hildegard Peplau's theory of interpersonal relations $(1952,1988,1997)$. Hildegard Peplau was a leading nurse theorist who was a pioneer in the field of psychiatric mental health nursing. Peplau (1997) recognized the significance of the nurse-patient relationship in meeting a patient's needs for connection. She argued that the nursepatient relationship is the primary relationship during a patient's hospital stay and considered trust to be an essential component of the nurse-patient relationship. Peplau implored nurses to consider patients as persons rather than as medical conditions. She stressed that nurses could not be effective without having adequate information about what is important to patients. The theory indicates that the unfolding of nurse-patient relationships is unique to each dyad but share a similar structure (Peplau, 1997). The structure, which serves as the basis of the theory, consists of three phases: the orientation phase, working phase, and termination phase.

The first phase of Peplau's theory (1988) is the orientation phase. During this phase, the nurse listens to the patient, gathers health information from the patient, and seeks additional information to get to know the patient as a person. The nurse asks 
questions in an attempt to fully capture the patient's narrative. The nurse guides the interactions to promote a reciprocal, professional relationship with the patient.

Difficulties due to preconceptions of both the nurse and patient in the orientation phase can complicate the nurse-patient relationship. However, the responsibility belongs to the nurse to examine his or her preconceptions about the patient in order to minimize their effects on the nurse-patient relationship.

The second phase of Peplau's theory (1988) is the working phase. The development of the nurse-patient relationship occurs primarily during this phase. The nurse looks for cues of patient readiness to transition from the orientation phase to the working phase. The transition occurs as the nurse begins to focus on the patient's reactions to illness and what the patient must do to improve his or her health condition. Nurses serve several roles in the working phase including providing physical care, health teaching, interviewing, and counseling.

The third phase is the termination phase. This phase represents the end of the professional relationship once the patient's needs have been met (Peplau, 1988). This phase involves summarizing the work that has been accomplished and providing closure to the nurse-patient relationship. Preparing for the termination phase involves completing the discharge planning that began in the working phase.

According to Peplau (1997), the nurse can face many challenges in establishing the nurse-patient relationship. Some of these challenges include unfavorable comparisons of the patient with another person, avoiding rather than dealing with anger or annoyance toward patients, using disrespectful modes of addressing patients, and avoiding discussing emotional topics with patients. 
Peplau's theory of interpersonal relations (1997) provides the contextual and theoretical basis for research on the relationship between maternity nurses and pregnant and postpartum women with SUDs for several reasons. The theory is the best known nursing theory for describing the nurse-patient relationship, which is the central phenomenon explored in this dissertation. Moreover, Peplau addressed facilitators and barriers associated with the formation of trusting nurse-patient relationships, as is consistent with dissertation aims. The theory is also relevant to this work as it reflects how the nurse-patient relationship develops over time and focuses on the common challenges to the relationships.

\section{Methods}

To accomplish the aims of the dissertation, two studies were conducted. Study 1 was a metasummary of published qualitative studies about how pregnant and postpartum women with SUDs experience health care encounters in prenatal care, labor and delivery, postpartum, and nursery/NICU settings. While the focus of the dissertation is on the establishment of trust between maternity nurses and these women, Study 1 was conducted to provide a broader context within which to situate the findings of Study 2 by focusing on encounters with a variety of health care providers. Study 2 was an empirical qualitative descriptive study to identify facilitators and barriers associated with the formation of trusting relationships between pregnant maternity nurses and postpartum women with SUDs. A summary of the methods used to conduct Study 1 and Study 2 are described below. 


\section{Study 1}

Study 1 was conducted to address Aim 1. Qualitative metasummary as described by Sandelowski (2003) was used for this study. Qualitative metasummary is a form of systematic review that combines qualitative findings from published studies to produce a straightforward summary of their findings at a topical or thematic level. Topical and thematic summaries are findings that reflect lower levels of abstraction versus more highly interpretive findings such as those from grounded theories, phenomenologies, and ethnographies (Sandelowski \& Barroso, 2007). Metasummaries produce results that have practical policy and practice implications.

The qualitative metasummary included the following stages. First, research articles that met study criteria (i.e., qualitative methods were used to describe encounters between health care providers and pregnant and postpartum women with SUDs) were retrieved and a cross study display table with basic study information (e.g., citation, purpose, sample, setting) was created. Second, the findings of the studies were extracted. Third, the findings were edited into declarative statements that could be understood independent of the reports. Fourth, the edited findings were grouped and abstracted statements that summarized them were written. Next, effect sizes were used to calculate the frequency with which each finding appeared in the articles. Fifth, a taxonomy of health care encounters was developed to identify types of health care encounters experienced by the participants in the studies. The results and conclusions of Study 1 appear in Chapter 2 of this document. 


\section{Study 2}

Study 2 was conducted to address Aims 2 and 3. A qualitative descriptive method was used for this study. Qualitative description is a research approach used to produce low-interpretive findings that focus on the surface meaning of the participants' words to describe a phenomenon from their perspectives (Sandelowski, 2000). The approach provides a straightforward summary of narrative data in a format that can be used to provide information needed by policy makers and health care providers to address health care concerns (Sandelowski, 2000). Because qualitative description provides a comprehensive summary rather than abstract conceptualizations of data, semi-structured interviews with individuals or groups are commonly used to obtain participant narratives (Neergaard et al., 2009).

Two groups were included in Study 2. The first group included 15 maternity nurses recruited from a local Chapter of the Association of Women's Health, Obstetric, and Neonatal Nursing (AWHONN). AWHONN is a nonprofit, national membership nursing organization that promotes the health of women and newborns. The nurses had at least one year of experience working in a maternity nursing area thereby ensuring they had interactions with pregnant and postpartum women with SUDs. The second group included 10 women recruited from a residential maternal treatment center for substance use located in the Midwest. The treatment center serves women with addictions and allows the women and their children to reside together while the women receive SUD treatment. The women were 18 years or older, used substances during their pregnancy, and had given birth to a living child in the hospital setting within the 2 years prior to the interviews. 
Interviews based on a semi-structured interview guide were conducted with both groups. The participants were asked to describe nurse-patient encounters they had experienced while providing care to women or receiving care from nurses during pregnancy and postpartum, focusing on factors that influenced the development of trust. The interviews were recorded and transcribed.

The findings of interviews from both groups were merged and analyzed using standard content analysis. The analysis included six steps. First, the transcripts were read in their entirety to obtain a holistic understanding of the participants' overall experiences. Second, text units (i.e., meaningful words, phrases, sentences) related to the relationship between the maternity nurses and the women were extracted. Third, a code was assigned to each text unit to capture its essence. Fourth, the codes were displayed in a case-by-topic display table. Fifth, the codes were categorized and summarized. Sixth, a narrative description of each category addressing the study aims was written. The results and conclusions of Study 2 appear in Chapter 3 of this document.

\section{Concepts and Definitions}

The major concepts of this study are defined in Table 1.1 and Table 1.2. Table 1.1 defines terms related to the substantive content of the dissertation, and Table 1.2 defines terms related to the methodological approaches used in Study 1 and Study 2.

Table 1.1

Terms Related to Substantive Content of Dissertation

\begin{tabular}{|l|l|}
\hline Substantive Term & Definition \\
\hline Substance & $\begin{array}{l}\text { Any psychoactive compound that affects } \\
\text { mental processes. Substances may be } \\
\text { legal, illegal, or controlled (World Health } \\
\text { Organization, 2019). }\end{array}$ \\
\hline Substance use & $\begin{array}{l}\text { The use of a substance for nonmedical } \\
\text { purposes that may cause health and social }\end{array}$ \\
\hline
\end{tabular}




\begin{tabular}{|l|l|}
\hline Substantive Term & Definition \\
\hline Substance use disorder & $\begin{array}{l}\text { problems (World Health Organization, } \\
\text { 2019). }\end{array}$ \\
\hline Opioid & $\begin{array}{l}\text { A problematic pattern of substance use } \\
\text { that is diagnosed based on evidence of } \\
\text { impaired control, social impairment, risky } \\
\text { use, and pharmacological criteria } \\
\text { (American Psychiatric Association, 2013) }\end{array}$ \\
\hline Pregnancy/prenatal & $\begin{array}{l}\text { A class of substances derived from the } \\
\text { opium poppy and their synthetic } \\
\text { equivalents that have the ability to relieve } \\
\text { pain and produce euphoria. Opioids } \\
\text { include morphine, heroin, oxycodone, and } \\
\text { methadone (World Health Organization, } \\
\text { 2019). }\end{array}$ \\
\hline Postpartum & $\begin{array}{l}\text { Time period before birth in which a fetus } \\
\text { develops inside a woman's womb or } \\
\text { uterus and usually lasts around 40 weeks } \\
\text { (National Institute of Child Health and } \\
\text { Human Development, 2018). }\end{array}$ \\
\hline Criminalization related to pregnancy & $\begin{array}{l}\text { Time period that begins immediately after } \\
\text { birth when maternal physiological } \\
\text { changes related to pregnancy return to the } \\
\text { non-pregnant state. The end of this period } \\
\text { is less defined and has been considered to } \\
\text { be up to 12 months. (Berens, 2018). }\end{array}$ \\
\hline Maternity nurse & $\begin{array}{l}\text { A nursing professional who provides care } \\
\text { to a pregnant woman and her child before, } \\
\text { during, or after the birth. Maternity nurses } \\
\text { work in prenatal, labor and delivery, } \\
\text { postpartum, and NICU settings. }\end{array}$ \\
$\begin{array}{l}\text { A cluster of withdrawal symptoms that } \\
\text { effect the central nervous, gastrointestinal, } \\
\text { and respiratory systems of newborns } \\
\text { exposed to opioids and other substances } \\
\text { during pregnancy (Hudak \& Tan, 2012). }\end{array}$ \\
$\begin{array}{l}\text { A discrediting attitude by others based on } \\
\text { a person's characteristics or } \\
\text { circumstances (Goffman, 1963, p.3) }\end{array}$ \\
$\begin{array}{l}\text { Incarceration or other punitive legal } \\
\text { actions against women who use } \\
\text { substances during pregnancy (Amnesty } \\
\text { International, 2017). }\end{array}$ \\
\hline a
\end{tabular}




\begin{tabular}{|l|l|}
\hline Substantive Term & Definition \\
\hline Trust in provider-patient relationships & A response to a health care encounter or \\
& relationship in which patient feels that a \\
& provider cares about them and works in \\
& their best interest and/or a provider feels a \\
& patient is reliable and capable of \\
& contributing to his or her own care \\
& (Birkhauer et al., 2017). \\
\hline
\end{tabular}

Table 1.2

Terms Related to Methodologies Used in Dissertation

\begin{tabular}{|c|c|}
\hline Substantive Term & Definition \\
\hline Metasynthesis & $\begin{array}{l}\text { A review approach used to synthesize } \\
\text { findings of studies that are interpretive in } \\
\text { nature. Qualitative meta-synthesis can be } \\
\text { used to aggregate the findings of a variety } \\
\text { of types of studies including } \\
\text { phenomenologies, ethnographies, and } \\
\text { grounded theories (Sandelowski \& } \\
\text { Barroso, 2007). }\end{array}$ \\
\hline Metasummary & $\begin{array}{l}\text { A form of systematic review in a target } \\
\text { domain in which the studies are topical or } \\
\text { thematic summaries of data. Topical } \\
\text { summaries are at a low level of abstraction } \\
\text { and include lists of topics. Thematic } \\
\text { summaries involve more interpretation } \\
\text { and include a description of themes } \\
\text { reflecting underlying patterns in the } \\
\text { participants' responses (Sandelowski \& } \\
\text { Barroso, 2003). }\end{array}$ \\
\hline Qualitative Description & $\begin{array}{l}\text { A qualitative method used for obtaining } \\
\text { straightforward summaries of narrative } \\
\text { data to provide information needed by } \\
\text { policy makers and practitioners to address } \\
\text { clinical concerns (Sandelowski, 2000). }\end{array}$ \\
\hline Content Analysis & $\begin{array}{l}\text { A family of analytic approaches ranging } \\
\text { from impressionistic, intuitive, or } \\
\text { interpretive analyses to systematic, strict } \\
\text { textual analyses (Rosengren, 1981). }\end{array}$ \\
\hline Purposeful Sampling & $\begin{array}{l}\text { A technique used in qualitative research to } \\
\text { identify and select individuals or groups of } \\
\text { individuals who are knowledgeable about } \\
\text { or experienced with a phenomenon of } \\
\text { interest (Creswell \& Plano Clark, 2011). }\end{array}$ \\
\hline
\end{tabular}




\section{Trustworthiness and Credibility Strategies}

Lincoln and Guba (1985) introduced a set of four criteria to ensure the trustworthiness and enhance the soundness of qualitative findings. The criteria are credibility, dependability, confirmability, and transferability. These four criteria provided the framework to enhance the trustworthiness of the findings of the dissertation research.

Credibility is the extent to which findings are closely tied to data and reflect the intended focus of the research (Polit \& Beck, 2012). To enhance credibility, the researcher met regularly with the dissertation chair throughout data collection and analysis of both studies and regularly obtained input from dissertation committee members. Both the perspectives of maternity nurses and pregnant and postpartum women were included in Study 2 to ensure well-balanced findings.

Dependability is the extent to which the researcher can account for changing conditions around the research and the stability of the data over time (Elo et al., 2014). To enhance dependability, the researcher maintained a detailed audit trail that chronicled methodological and analytic decisions made throughout the study.

Confirmability is the extent to which the data accurately represents the information provided by the participants rather than created by the researcher (Polit \& Beck, 2012). To enhance conformability, all interviews were verified by the interviewer. Data analysis was completed in consultation with input from with the dissertation chair and dissertation committee members who periodically compared emerging results with findings from the original studies in Study 1 and the interview transcripts in Study 2. 
Transferability is the extent to which the results can be transferred to other settings or contexts (Marshall \& Rossman, 2016). Transferability is determined by the research consumer based on detailed descriptions of the sample and setting provided by the researcher. To enhance transferability of Study 1, detailed descriptions of the characteristic of the articles in the metasummary were provided. To enhance the transferability of Study 2, the context of this study was thoroughly described with detailed descriptions of the participant characteristics and the settings in which the interviews were conducted. 


\section{CHAPTER 2}

\section{Introduction}

Chapter 2 describes a metasynthesis of published qualitative studies (Study 1) using a metasummary approach to classify types of health care encounters experienced by pregnant and postpartum women with SUDs (Aim 1) (Renbarger et al., 2019).

\section{Maternal Substance Use During Pregnancy and Postpartum}

Maternal substance use in the United States is a significant public health problem associated with a number of adverse fetal, neonatal, and maternal health outcomes. Substance use during pregnancy has been linked to perinatal and neonatal complications such as increased risk for infant mortality, placental abruption, maternal viral infections, intrauterine growth restrictions, low infant birth weight, neonate withdrawal symptoms, stillbirth, and preterm birth (Cook et al., 2017; Kotelchuck et al., 2017; O’Leary et al., 2012; Patrick et al., 2017; Riihim€aki et al., 2017; Yazdy et al., 2015).

In the United States, women are at greater risk for substance use during their reproductive years (ages 18-29 years) than at any other time in their lives (Compton et al., 2007). In 2018, the National Survey on Drug Use and Health revealed that $11.6 \%$ of pregnant women in the United States used tobacco products, $9.9 \%$ reported heavy or binge alcohol use, and 5.4\% used illicit drugs during pregnancy (U.S. Department of Health and Human Services, 2019). Each substance can increase the risk for perinatal and neonatal complications (Forray, 2016). For example, heavy alcohol use has been linked to stillbirth, congenital anomalies, low birthweight, and small for gestational age newborns, whereas smoking has been linked to low birthweight, placental abruption, and 
miscarriage. Risks with cocaine use include preterm birth, low birthweight, premature rupture of membranes, and placental abruption (Forray, 2016).

Maternal substance use during pregnancy has gained increased attention due to the current opioid epidemic. Opioid use during pregnancy more than quadrupled increasing from 1.5 per 1,000 hospital deliveries to 6.5 per 1,000 hospital deliveries between the years of 1999-2014 (Haight et al., 2018). A study of 1.1 million women in 46 states and Washington, D.C. revealed that between the years 2000 and 2007 approximately one in five women (21.6\%) enrolled in Medicaid filled prescriptions for opioids during their pregnancy. The percent of women who filled opioid prescriptions during pregnancy increased from 18.5\% in 2000 to $22.8 \%$ in 2007 (Desai et al., 2014). The percent of women admitted to substance use treatment facilities during pregnancy who reported a history of prescription opioid misuse increased from $2 \%$ in 1992 to $28 \%$ in 2012 (Martin et al., 2015). Maternal hospital admissions related to substance use increased 33\% from 2006 to 2012 - from 13.4 to 17.9 cases per 1,000 admissions (Fingar et al., 2015).

The increase in opioid and other substance use during pregnancy has resulted in a growing number of infants who are experience withdrawal symptoms after birth. NAS is a cluster of withdrawal symptoms that includes irritability, excessive crying, and disturbed sleep patterns and can begin at 24 hours after birth or have a delayed onset of five to seven days. As many as $75-90 \%$ of infants exposed to opioids in utero will experience NAS. Other substances such as cocaine, barbiturates, and nicotine used during pregnancy may increase the severity and length of NAS symptoms in infants (Hudak \& Tan, 2012). The term neonatal opioid withdrawal syndrome (NOWS) is a now 
widely used to refer to infants experiencing withdrawal symptoms specifically from prenatal opioid exposure (Klaman et al, 2017).

The Agency for Healthcare Research and Quality estimates that NAS increased by $300 \%$ between the years of 1999 and 2013 - from 1.5 to 6.0 cases per 1,000 hospital births (Ko et al., 2016). Between 2004 and 2014, the total hospital costs in the United States related to NAS and covered by Medicaid increased from $\$ 65.4$ million in 2004 to \$462 million in 2014 (Winkelman et al., 2018).

\section{Health Care of Pregnant and Postpartum Women with SUDs}

Due to the high incidence of substance use during pregnancy and the associated health-related implications for mothers and infants, health care providers play a key role in maternal child outcomes. Prenatal services and addiction treatment during pregnancy have been linked to better birth outcomes (Cox et al., 2011; Kotelchuck et al., 2017). Pregnant and postpartum women with SUDs, however, often report poor relationships with their health care providers (Chan \& Moriarty, 2010; Gilchrist et al., 2012; Harvey et al., 2015; Leppo, 2012; Radcliffe, 2009). Barriers to positive relationships with health care providers include stigma and criminalization of maternal substance use resulting in women's fears of child removal, arrest, and incarceration (Chan \& Moriarty, 2010; Gilchrist et al., 2012; Harvey et al., 2015; Leppo, 2012). These barriers can impede pregnant and postpartum women with SUDs from receiving high-quality and regular health care, which in turn can negatively affect maternal and infant health outcomes (Chan \& Moriarty, 2010; Gilchrist et al., 2012; Harvey et al., 2015; Leppo, 2012).

Because quality health care encounters that overcome barriers and facilitate trusting relationships between the women and their providers are needed to combat the 
negative effects of substance use during pregnancy, an in-depth understanding of the health care encounters experienced by pregnant and postpartum women is needed. A number of qualitative studies that describe interactions between pregnant and postpartum women with SUDs and health care providers have been conducted, but the findings of these studies have not been well synthesized to provide a comprehensive or nuanced description of the nature of the encounters. Such a description would provide needed information to develop strategies to improve the health care experiences of this population. The purpose of this review, therefore, is to synthesize the findings of published qualitative studies to describe how pregnant and postpartum women with SUDs experience health care encounters in prenatal care, labor and delivery, postpartum, and nursery/NICU settings.

\section{Methods}

\section{Design}

A qualitative metasummary approach as described by Sandelowski and Barroso (2003) was used to conduct the synthesis. This approach is a form of a systematic review that combines qualitative findings from previous studies that produced topical or thematic summaries of data. Topical summaries reflect a low level of abstraction and include lists of topics covered by the research participants. Thematic summaries involve more interpretation and include a description of themes reflecting latent patterns found in participants' responses. Unlike qualitative metasynthesis, which is used to summarize studies that have more abstract findings and yields highly interpretive renderings of the findings, metasummaries yield a straightforward summary of findings at the topic or thematic level of abstraction (Sandelowski \& Barroso, 2007). 
A metasummary approach was chosen for this review for several reasons. First, a preliminary review of the literature on this topic revealed that the many of the studies used qualitative methods. Second, this preliminary review further revealed that most of the qualitative studies had yielded findings at the topical or thematic summary level, and thus called for a metasummary rather than metasynthesis approach. Third, metasummaries produce straightforward summaries that typically have pragmatic policy and practice implications and thus could inform the development of practical strategies to improve the health care encounters of pregnant and postpartum women with SUDs.

The metasummary included several steps: (1) retrieving research reports and creating a cross-study display, (2) extracting the findings, (3) editing the findings, (4) grouping the findings and forming abstracted statements, (5) calculating manifest frequency effect sizes of the abstracted statements, and (6) developing a taxonomy of health care encounters.

Retrieving research reports and creating a cross-study display. First, the researcher retrieved research reports and organized key information from each report using a cross-study display (Sandelowski \& Barroso, 2007). Research studies were eligible for inclusion if they (a) included women who used substances during pregnancy and/or postpartum, (b) described the women's health care encounters in a prenatal care, labor and delivery, postpartum, and/or nursery/NICU setting, (c) contained qualitative findings regardless of whether the researchers identified the study as qualitative or whether the methodology was correctly labeled, (d) were conducted in the United States and included women of any race, ethnicity, nationality or class, (e) were published between January 1, 2000 and December 31, 2018 (f) were published in a peer-reviewed 
journal, and (g) were published in English. Studies were excluded if they (a) did not contain original qualitative findings or (b) used mixed methods and the qualitative findings could not be separated from the quantitative findings.

Pregnancy, labor and delivery, postpartum, and nursery/NICU settings were chosen as the study aim was to describe health care encounters focused on pregnancy, postpartum, and neonatal care as opposed to those focused specifically on substance use treatment. Because cultural differences likely exist in regards to health care encounters of pregnant and postpartum women in different regions of the world and identifying these differences would be beyond the scope of this metasummary, the sample was limited to studies conducted in the United States. Based on the recommendations of Sandelowski and Barroso (2007), studies were not eliminated if the methodology was incorrectly identified in the report. For example, if researchers referred to their methods as grounded theory when in fact they used procedures more consistent with another method, such as qualitative description, these reports were retained in the metasummary as they could contain important findings regardless of how the method was labeled. Only articles written in English were included as it is the primary language of the United States and the shared language of the researcher and dissertation committee members. The starting date of January 1, 2000 was chosen because rates of maternal opioid use in the United States started to rise dramatically at that time (Patrick et al., 2012), bringing an increased focused on substance use by pregnant and postpartum women.

The researcher then searched the electronic databases of CINAHL, PsycINFO, PubMed, and SocIndex with search terms that were consistent with inclusion criteria. The search terms included pregnant OR antenatal OR perinatal OR maternal OR mothers 
AND "substance abuse" OR "substance use" OR "drug abuse" OR "drug use" OR "addiction" OR alcohol OR opioid OR methadone OR Subutex OR Suboxone OR meth OR cocaine OR buprenorphine OR "neonatal abstinence syndrome" AND experience OR perception OR narrative OR belief OR qualitative.

The researcher reviewed the abstracts of the reports revealed in the search to eliminate those that did not meet criteria and then examined the full text of the remaining reports to determine which would be included in the metasummary. The final reports included in the metasummary were uploaded into a file-sharing platform accessed by all team members. The researcher then created a cross-study display table to organize key information from each report (see Table 2.1). This display table includes the following information: author(s), purpose, sample/setting, method, procedures, measures, and findings. The reports were divided among the members of the dissertation committee to verify that (a) the report met study criteria and (b) the findings of the report were best described as topical or thematic summaries. All committee members agreed that the reports met study criteria and that the findings were either topical or thematic summaries as described by Sandelowski and Barroso (2007).

Extracting the findings. The second step included extracting statements of findings in the reports that were relevant to health care encounters. Any statement that described how pregnant and/or postpartum women with SUDs experienced health care encounters in a prenatal care, labor and delivery, postpartum, or nursery/ NICU setting were highlighted and extracted. The statements were placed in a single file by the researcher and confirmed by a dissertation committee member. 
Editing the findings. The third step included editing extracted statements in a format that is understandable to readers who have not read the original report (Sandelowski \& Barroso, 2007). Editing findings involves staying as close as possible to the words of authors to preserve the meanings of the findings. Each of the extracted statements were edited by the researcher into complete declarative sentences that included a subject that described the group of women that were the focus of the reports (e.g., "Recovering Hispanic mothers addicted to substances with an infant in the NICU....") and a predicate that described the health care encounter (e.g., .... were called that "junkie mom" by nurses). A dissertation committee member reviewed the edited statements and made some suggestions for revisions of wording after reviewing the original reports.

Grouping the findings and forming abstracted statements. The fourth step included grouping all edited statements on similar topics together to see if they confirmed, extended, or refuted each other. This process was carried out in an iterative manner by the researcher through discussions with another team member. Several groupings were proposed, discussed, and agreed upon the researcher and a dissertation committee member. All the edited statements in each group were then summarized into abstracted statements that captured the similarities of the edited statements in the group while retaining their divergence and complexity. The abstracted statements were then divided among the dissertation committee members to verify that the abstracted statements were worded in a way that best reflected the edited statements in each group. These dissertation committee members recommended some wording changes that were incorporated into the final abstracted statements. 


\section{Calculating the manifest frequency effect sizes of the abstracted statements.}

The fifth step involved calculating a manifest frequency effect size for each of the abstracted statements (Sandelowski \& Barroso, 2007). This effect size is a quantitative index of the prevalence of each abstracted statement in the reports and is calculated by dividing number of reports containing an abstracted statement by the total number of reports in the metasummary. If two or more studies have common samples that contribute to the same abstracted statement, the reports are counted only once in the numerator and the denominator.

Developing a taxonomy of health care encounters. The last step involved conducting a taxonomic analysis as described by Sandelowski and Barroso (2007) in order to present a parsimonious inventory of the range of findings contained in the reports. The researcher synthesized the abstracted statements by first identifying the fundamental nature of the encounters reflected in each statement. Through revisiting the edited statements and original reports, discussion, and consensus, the researcher with input from dissertation committee members gathered together similar types of encounters and labeled each type with a term that best represented the essence of the participants' experiences in the encounters. The identification, categorization, and labeling of the encounters across the abstracted statements resulted in a taxonomy capturing a variety of different types of health care encounters experienced by pregnant and postpartum women with SUDs. The researcher returned to the original reports to determine how many reports referred to each type of encounter and wrote a narrative description of the types of encounters included in the taxonomy. 


\section{Results}

The results of the search process are summarized in the PRISMA diagram modified from Moher et al. (2009) (Figure 1). The initial search of the databases yielded 3,428 results. A large number $(n=360)$ of reports were removed because they were duplicates. The titles and abstracts of the remaining 3,068 reports were examined based on the review criteria. A total of 3,045 reports were removed because they (a) did not focus on the health care experiences of pregnant and postpartum women with SUDs, (b) were not from the women's perspective, (c) were not published in English, or (d) were conducted outside the United States. Twenty-three reports remained and were included in the metasummary.

As seen in the cross-study display in Table 2.1, 19 unique study samples were represented in the 23 reports. The sample sizes of the reports ranged from 4 to 38 , and the ages of participants ranged from 18 to 56 years at the time of the interview. The participants used a variety of prescription and illicit substances during pregnancy and postpartum including opioids, methadone, marijuana, heroin, alcohol, methamphetamine, cocaine, benzodiazepines, and tobacco. Some participants reported polysubstance use. The majority of the reports $(n=17)$ were identified as qualitative description, whereas the others were identified as phenomenology $(n=2)$, focused ethnography $(n=1)$, grounded theory $(\mathrm{n}=2)$, and mixed methods $(\mathrm{n}=1)$.

The metasummary procedures resulted in 446 edited statements which were grouped into 18 abstracted statements. As seen in Table 2.2, the frequency effect sizes of the abstracted statements ranged from .09 to .53 . This table reveals that the findings with the highest relative prevalence were related to adverse encounters. Over half of the 
reports $(53 \%)$ revealed that participants felt they were treated poorly by health care providers based on providers' behaviors or comments, half (50\%) revealed that participants had a general sense of being judged, almost half (45\%) revealed participants did not get the information they needed, and almost half (43\%) revealed participants felt their care was suboptimal due to their substance use. However, approximately two-fifths of the reports indicated that at least some of the participants had positive relationships with their providers (41\%) and received good medical care (39\%).

\section{The Taxonomy of Health Care Encounters}

The 18 abstracted statements were synthesized into a taxonomy consisting of five types of adverse encounters and three types of beneficial encounters. Table 2.3 displays the types of encounters, the abstracted statements that contributed to the identification of each type, and the number of reports that referred to each type. Each type of encounter is described below. Because some reports described encounters with specific types of health care providers (e.g., perinatal educators, nurse practitioners, nurses, doctors), some referred to providers generically (e.g., health care providers), and some referred to just one type of provider (e.g., NICU nurses), all are referred to as health care providers unless a result can be associated more specifically with one or more types of providers.

\section{Adverse Encounters}

The majority of reports $(\mathrm{n}=22)$ described encounters between participants and health care providers that the participants considered to be adverse. The participants considered these encounters unhelpful or detrimental to their health or well-being or to have involved difficult or contentious interactions with a provider. The participants typically attributed adverse encounters to the fact that they were known by providers to 
be "users." Five types of adverse encounters were identified: judgmental, disparaging, scrutinizing, disempowering, and deficient-care.

Judgmental encounters (\#2). Eleven reports described adverse encounters that were labeled as judgmental. In these encounters, participants sensed that providers disapproved of the participants' substance use and looked down on them because of it. Although the providers did not overtly express their disapproval, the participants nonetheless felt branded as addicts and bad mothers. For example, women on methadone felt providers thought the participants should be able to stop their substance use immediately without medication assisted treatment (MAT). Participants who had infants with NAS sensed blame from physicians and nurses when their infants were withdrawing and as a result were reluctant to visit them. Because the participants believed that their providers thought poorly of them, the participants felt ashamed, frustrated, angry, irritated, and dismissed during health care visits.

Disparaging encounters (\#1, \#16). Fourteen reports described adverse encounters that were labeled as disparaging. In these encounters, participants observed providers engaging in overt behaviors that were blatantly critical or admonishing. Many participants described offensive behaviors or comments by providers. For example, participants reported NICU nurses would roll their eyes, whisper negative comments, and call the participants derogatory names such as "that junkie mom" or "methadone mom." These behaviors led some participants to avoid visiting their infants if an offending nurse was working that day. The participants also revealed that providers said harsh things to them. For example, women prescribed MAT reported being told by nurses that women should be put in jail for using while pregnant, and other participants revealed that doctors 
admonished the participants to "get [their] life together." These encounters were stressful for the participants and resulted in a sense of low self-worth. Some described feeling like a "dirty virus" or "garbage."

Scrutinizing encounters (\#7, \#8, \#9,\#17). Eighteen reports described adverse encounters that were labeled as scrutinizing. In these encounters, participants felt closely observed or monitored by health care providers as a result of being identified as a "drug user." One way in which participants felt scrutinized was through routine drug testing. While some participants realized they would be drug tested at prenatal appointments and in the hospital, others were unaware of this and were alarmed when it occurred. They feared that if they had a positive drug test, it would be reported and they would be placed in jail, lose custody of their children, or be forced to have an abortion. As a result, some avoided prenatal care, skipped appointments, lied about their substance use, scheduled appointments when they had not used substances, switched to other substances before seeking care, or used other women's urine for testing.

Participants also felt scrutinized when they were with their infants. Some participants with infants in the NICU reported they were not allowed to hold their infants or had to ask permission to touch them. When the participants did hold their infants, they suspected the nurses were monitoring the participants to see if they were "high." Participants also felt supervised by the nurses when breastfeeding. For example, some claimed that nurses were pleased when their infants would not latch properly so the infants could be given formula. As a result of this scrutiny, participants were convinced that providers questioned their ability to be mothers and felt unwelcomed and out of place when they visited their infants. Some participants were convinced that their relationships 
with their infants had been damaged because providers had inhibited mother-infant bonding.

Disempowering encounters (\#10,\#12). Ten reports described encounters that were labeled as disempowering. In these encounters, participants felt like they had little control over their own health and that of their infants. The participants indicated that their health care providers often did not believe them, listen to them, or take their healthrelated concerns seriously. Many participants objected to not being included in health care decisions. For example, some participants felt they did not have a voice in the type of SUD treatment they received during pregnancy and some complained that their MAT medication dose was adjusted without their knowledge. Others indicated that their opinions or observations regarding the health of their infants were not considered. For example, some participants recounted instances in which they were worried that something was wrong with their infant but a provider dismissed their concerns. Some participants who experienced fetal loss felt it could have been prevented if providers had listened. Participants wanted their voices to be heard and respected and felt frustrated and angry as a result of disempowering encounters.

Deficient-care encounters (\#3, \#4). Fourteen reports described encounters that were labeled as deficient-care. In these encounters, participants felt like they were receiving low quality care because of their substance use. One aspect of deficient care was not being provided adequate health information by health care providers. Some participants suggested that they were often not given full explanations of their care, and others complained that different providers gave conflicting information. In particular, the participants desired more information about substance use during pregnancy, substance 
use treatment options, and breastfeeding. Participants believed that the limited or contradictory information they received stemmed in part from providers' lack of experience in caring for women with SUDs. For example, some participants reported that they believed that their providers had never before treated a pregnant woman who was taking methadone during pregnancy.

Another aspect of care that the participants felt was deficient was the amount of time the providers spent with them and their infants. Some complained that their appointments were too short or too infrequent and felt this was because of their status as substance users. Others felt nurses did not spend enough time with their infants during withdrawal or treated their infants poorly because of the participants' substance use. In some instances, participants felt providers gave good care to their infants but poor care to the participants. As a result of deficit-care encounters, participants deemed providers to be unsupportive, uncaring, or untrustworthy and often discontinued care.

\section{Beneficial Encounters}

A smaller number of reports $(n=18)$ described encounters between participants and health care providers that the participants considered to be beneficial rather than adverse. The participants considered these encounters to have a positive effect on their health and well-being or that of their infants. Three types of beneficial encounters were identified: recovery-based, accepting, and effective-care.

Recovery-based encounters (\#13, \#14, \#18). Six reports described beneficial encounters that were labeled as recovery-based. In these encounters, participants felt that providers addressed the substance use in a direct but supportive way and encouraged substance use treatment. Instead of only detecting substance use through testing, 
providers invited and encouraged participants to disclose and openly discuss their substance use. These participants accepted that providers should monitor substance use through testing as part of good care. In recovery-based encounters, providers were involved in providing referrals and follow-up for substance use treatment. Recoverybased encounters also included interactions in which providers provided support for participants' substance use treatment. For example, participants appreciated nurses who supported methadone treatment and were understanding when participants had to leave their infants in the NICU each day to attend the methadone clinic. Moreover, participants were grateful when they had "slips" and providers acknowledged that this was often part of the recovery process or when providers gave them "credit" reducing their substance use rather than expecting them to quit immediately. In recovery-based encounters, participants felt they could be honest about their substance use and recovery could be incorporated into their overall care.

Accepting encounters (\#5). Ten reports described beneficial encounters that were labeled as accepting. In these encounters, participants sensed that their providers thought favorably of them despite their substance use. The participants indicated that providers conveyed acceptance by not being judgmental, showing empathy and consideration, communicating with them respectfully, sharing personal information, and treating them the same as patients who did not use substances. For example, participants felt accepted by NICU nurses who performed small but kind gestures such as finding the participants a comfortable place for them to sit or asking them how they were doing. Participants felt especially accepted by providers who acknowledged their identities as 
mothers. Accepting encounters could motivate participants to continue with care despite logistical challenges such as transportation and distance.

Effective-care encounters (\#6, \#11,\#15). Fifteen reports contained encounters that were labeled as effective-care. In these encounters, participants felt that their health care providers were not only accepting but provided care that improved the participants' health and that of their infants in some way. For example, some participants reported that they received helpful information from providers on a variety of health topics such as breastfeeding and drug tests and screening. Another way in which participants felt they were receiving effective care was when providers offered practical assistance and advice. For example, participants on methadone appreciated it when their providers assisted them with breastfeeding. Participants also believed they were receiving effective care when providers provided the opportunity for participants to discuss their concerns. Some participants, for instance, appreciated being able to openly discuss their fears about their infants' health. Other participants noted that their infants received good nursing care. For example, participants were comforted when their infants had their "own nurse" in the NICU, and some participants remarked that good nursing care allowed their infants to require less medicine for withdraw symptoms.

\section{Discussion}

Twenty-three qualitative reports that described the health care encounters of pregnant and postpartum women with SUDs were included in the metasummary. The majority of reports indicated that most women with SUDs perceive health care encounters to be adverse and relationships with providers to be conflictual. Five types of adverse encounters were identified: judgmental, disparaging, scrutinizing, 
disempowering, and deficient-care. The reports also indicated, however, that some pregnant and postpartum women with SUDs perceive their health care encounters to be beneficial and relationships with providers to be positive. Three types of beneficial encounters were identified: recovery-based, accepting, and effective-care.

The findings reveal that pregnant and postpartum women with SUDs believe that adverse encounters with providers are fueled by stigma because providers judge women harshly when they use substances during pregnancy and thus endanger the health of their infants. This finding resonates with much of the literature on substance use and stigma in other health care settings. For example, a systematic review by van Boekel et al. (2013) found that health care providers in Western countries hold negative attitudes towards persons with SUDs and that these attitudes negatively affect treatment outcomes and patients' feelings of empowerment. Moreover, providers perceive that violence, manipulation, and poor motivation hinder the health care of persons with SUDs. The review also revealed that providers often lack education and training to work with this population.

The results indicate that pregnant and postpartum women with SUDs often experience negative communication with providers, which is consistent with prior studies on substance use and communication in patient-provider relationships. For example, many of the problems in adverse encounters described in the reports in the current review stemmed from use of language by providers that the women perceived as judgmental or offensive (i.e., "addict," "methadone mom"). The finding supports research by Ashford et al. (2018) on the impact of word choice on explicit and implicit bias. They found that terms "substance abuser," "addict," "alcoholic," and "opioid addict" are associated with 
negative bias and should not be used, whereas the use of the terms "recurrence of use" and "pharmacotherapy" have positive benefits. The current findings as well as those by Ashford et al. (2018) thus highlight the importance of the use nonbiased language in health care encounters with women with SUDs. The use of derogatory terms is detrimental to the engagement of pregnant and postpartum women with SUDs in health care and thus can lead to negative consequences for both women and their infants.

The current findings revealed that most pregnant and postpartum women with SUDs fear the legal consequences of their substances use, especially losing their children. A study by Holland et al. (2016) found that obstetric providers of women who used marijuana were more likely to focus on the legal rather than the health-related consequences of substance use, such as when providers warned women that child protective services (CPS) could be called at delivery. These findings of the current study and Holland et al. (2016) study, therefore, indicate that health care providers need to carefully consider that discussion on legal consequences may be perceived as threatening by pregnant and postpartum women. Health care providers play a significant role in detecting substance use during pregnancy and referring women to appropriate resources within their community. The American Congress of Obstetricians and Gynecologists (ACOG) recognizes that punitive laws and actions against pregnant women can serve as a barrier to a trusting patient-provider relationship and this may interfere with their care. Health care providers should be open and transparent about any testing and reporting requirements they may have that could potentially lead to legal consequences for pregnant and postpartum women with SUDs. ACOG recommends that urine drug screens be done to confirm substance use and only with consent of the pregnant woman. 
The current findings and those of prior studies thus indicate that interventions that improve communication between providers and women with SUDs may be needed. For example, Weisner and colleagues (2016) developed an intervention (LINKAGE) to link patients receiving addiction treatment to health care. The intervention includes manualguided sessions on patient engagement in health care, the use of health information technology, and facilitated communication with physicians. The positive outcomes of the intervention included greater engagement in health care and increased likelihood of discussing addiction problems with physicians.

The current finding that many pregnant and postpartum women with SUDs desire more control over their health care can be viewed through the lens of the concept of patient activation, which is the ability of patients to actively engage in managing their own health and navigating the health care system (Hibbard et al., 2004). An important aspect of patient activation is shared-decision making, which occurs when providers encourage patients to consider and choose among treatment options based on the best available evidence (Elwyn et al., 2010). Shared decision-making as perceived by patients has been found to improve affective-cognitive outcomes such as satisfaction and less decisional conflict (Shay \& Lafata, 2015).

The findings of this review revealed that women often experience conflicts between pregnancy, postpartum, and neonatal care and substance use treatment. Perinatal health care providers were often not well-informed about addiction and substance use treatment, and recovery professionals were often not sensitive to women's needs during pregnancy and postpartum. These conflicts highlight the need for health systems to provide well-coordinated integrated care. For example, a review by Milligan et al. (2011) 
found that women with SUDs who participated in integrated care were more likely to receive prenatal care and less likely to give birth to premature infants than women who did not. Integrated care included services for pregnancy, parenting, or children in combination with substance use treatment in one setting.

The findings should be considered in the context of the limitations of the review. The level of the findings in all the reports were primarily descriptive and no studies produced highly interpretive or theoretically-based findings based on criteria cited by Sandelowski and Barroso (2007). Because the product of a metasummary is to a straightforward summary of findings, rather than an abstract rendering of them, a theoretical model of how encounters unfold over time was unable to be developed, how encounters vary based on the demographic characteristics of the participants, and how the context of the health care influences the encounters. In addition, the findings of the reports in the review were based on the participants' perspectives and information about the providers' views on the encounters were not collected in the studies. Moreover, participants tended to describe the providers' actions in the encounters but rarely discussed their own actions. Because health care encounters are dynamic interactions between providers and patients, investigating these encounters as dyadic exchanges by using verbatim recordings of encounters and observations of health care visits would yield more nuanced descriptions of adverse and beneficial encounters.

Despite the limitations of the review, several clinical recommendations can be proposed based on the findings. First, the findings clearly indicate that health care providers should reflect on their own biases regarding women who use substances during pregnancy. Providers in prenatal care, labor and delivery, postpartum, and/or 
nursery/NICU settings should be aware of their behaviors, either implicit or overt, that could be perceived as disparaging by women with SUDs, acknowledge the behaviors as harmful, and discontinue them. Second, perinatal providers should be knowledgeable about the complex challenges faced by women with SUDs including the process of substance use recovery. Third, providers should receive education on recognizing and managing implicit biases and improving communication with pregnant and postpartum women with SUDs in order to improve their health care experiences and ensure that they receive regular perinatal care. Fourth, health care providers should actively include the women in health care decisions by promoting patient activation and encouraging shared decision-making. Finally, providers in pregnancy, labor and delivery, postpartum, and nursery/NICU settings should collaborate with substance use treatment providers to devise a treatment plan aimed at providing optimal outcomes for both mother and infant. In summary, the findings of 23 qualitative reports that described the health care encounters of pregnant and postpartum women with SUDs were synthesized using a metasummary approach. While some participants described positive encounters, most felt they were treated poorly by providers due to their substance use. The findings of the review resonate with the findings of prior studies that point to the importance of stigma awareness, therapeutic provider-patient communication, patient activation, and integrated care in this population. The conclusions of the review are based only on the participants' perspectives and future research should examine dyadic interactions between women with SUDs and their providers. The findings indicate that providers should be aware of implicit biases against pregnant and postpartum women with SUDs and provide care 
informed by best practices regarding treating substance use during pregnancy and postpartum. 
Figure 1

PRISMA Flow Diagram of Process Selection

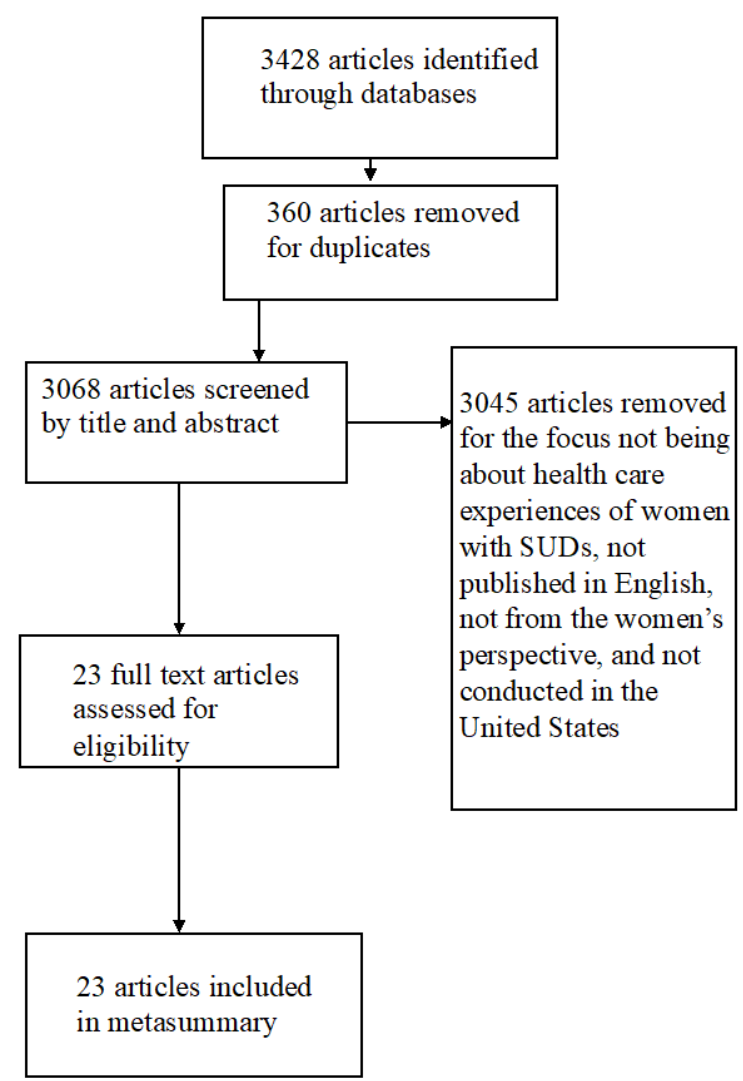


Table 2.1

Cross-Study Display Table

\begin{tabular}{|c|c|c|c|c|c|c|}
\hline Authors & $\begin{array}{c}\text { Purpose } \\
\text { Statement }\end{array}$ & Sample/Setting & Method & Procedures & Measures & Findings \\
\hline $\begin{array}{l}\text { Cleveland } \\
\text { \& Bonugli } \\
(2014)\end{array}$ & $\begin{array}{l}\text { The purpose of } \\
\text { this study was to } \\
\text { explore the } \\
\text { NICU } \\
\text { experiences of } \\
\text { mothers of } \\
\text { infants with } \\
\text { NAS. }\end{array}$ & $\begin{array}{l}\frac{\text { Sample }}{15 \text { mothers of infants with }} \\
\text { NAS } \\
\text { Ages: } 22-40 \text { year, }(M=28) \\
\text { Hispanic } \\
\text { Substance use: } \\
13 \text { participants were } \\
\text { prescribed methadone at the } \\
\text { time of the interview. } \\
\text { Setting } \\
\text { Southwestern Region } \\
\text { United States }\end{array}$ & $\begin{array}{l}\text { Qualitative, } \\
\text { Descriptive }\end{array}$ & $\begin{array}{l}\text { Participants were } \\
\text { recruited from } 2 \\
\text { outpatient } \\
\text { addiction } \\
\text { treatment } \\
\text { facilities. Flyers } \\
\text { were distributed } \\
\text { with contact } \\
\text { information. Staff } \\
\text { were provided } \\
\text { information at a } \\
\text { staff in-service at } \\
\text { each facility. }\end{array}$ & $\begin{array}{l}\text { Semi- } \\
\text { structured } \\
\text { interviews }\end{array}$ & $\begin{array}{l}\text { Participants felt nurses lacked } \\
\text { understanding of addiction. } \\
\text { Participants shared feelings of } \\
\text { guilt and shame when } \\
\text { observing their infants } \\
\text { withdrawing. The participants } \\
\text { felt judged by the nurses and } \\
\text { that feeling judged interfered } \\
\text { with their ability to trust the } \\
\text { nurses. }\end{array}$ \\
\hline $\begin{array}{l}\text { Cleveland } \\
\text { et al., } \\
(2016)\end{array}$ & $\begin{array}{l}\text { We sought to } \\
\text { answer the } \\
\text { following } \\
\text { research } \\
\text { question: "What } \\
\text { are the } \\
\text { mothering } \\
\text { experiences of } \\
\text { women with } \\
\text { SUDs?" }\end{array}$ & $\begin{array}{l}\frac{\text { Sample }}{15 \text { mothers who used }} \\
\text { substances } \\
\text { Ages: } 22-40,(\mathrm{M}=28) \\
\text { Hispanic } \\
\text { Substance use: } \\
13 \text { were enrolled in a } \\
\text { methadone maintenance } \\
\text { program }\end{array}$ & $\begin{array}{l}\text { Qualitative, } \\
\text { Descriptive }\end{array}$ & $\begin{array}{l}\text { Participants were } \\
\text { recruited from } 2 \\
\text { community-based } \\
\text { treatment facilities } \\
\text { in a large urban } \\
\text { city. Flyers were } \\
\text { placed at both } \\
\text { facilities with } \\
\text { contact } \\
\text { information. } \\
\text { Snowball } \\
\text { sampling was also } \\
\text { used. }\end{array}$ & $\begin{array}{l}\text { Semi- } \\
\text { structured } \\
\text { interviews }\end{array}$ & $\begin{array}{l}\text { Five themes were identified } \\
\text { that described the mothering } \\
\text { experiences of the women and } \\
\text { included: 1) facing the reality } \\
\text { of a pregnancy complicated by } \\
\text { substance use, trauma, and loss } \\
\text { 2) finding a higher meaning 3) } \\
\text { dealing with the consequences } \\
\text { 4) managing the details of } \\
\text { daily life 5) looking toward a } \\
\text { future with my children. } \\
\text { Mothers described negative }\end{array}$ \\
\hline
\end{tabular}




\begin{tabular}{|c|c|c|c|c|c|c|}
\hline Authors & $\begin{array}{l}\text { Purpose } \\
\text { Statement }\end{array}$ & $\begin{array}{l}\text { Setting } \\
\text { Southwestern Region } \\
\text { United States }\end{array}$ & Method & Procedures & Measures & $\begin{array}{l}\text { interactions with their nurses in } \\
\text { the hospital. }\end{array}$ \\
\hline $\begin{array}{l}\text { Cleveland } \\
\& \text { Gill, } \\
(2013)\end{array}$ & $\begin{array}{l}\text { To describe the } \\
\text { hospital } \\
\text { experiences of } \\
\text { mother who give } \\
\text { birth to } \\
\text { substance- } \\
\text { exposed infants. }\end{array}$ & $\begin{array}{l}\frac{\text { Sample }}{5 \text { postpartum mothers }(2} \\
\text { weeks to } 2 \text { months) } \\
\text { Ages: } 22-37 \text { years, }(\mathrm{M}=32) \\
\text { Mexican-American } \\
\text { Substance use: methadone } \\
\text { Setting } \\
\text { Southwestern Region } \\
\text { United States }\end{array}$ & $\begin{array}{l}\text { Qualitative, } \\
\text { Descriptive }\end{array}$ & $\begin{array}{l}\text { Participants were } \\
\text { recruited for the } \\
\text { primary study } \\
\text { through a variety } \\
\text { of methods from } \\
\text { community } \\
\text { location in a large } \\
\text { metropolitan area. } \\
\text { Flyers about the } \\
\text { study were posted } \\
\text { throughout the } \\
\text { community, } \\
\text { including clinics } \\
\text { affiliated with a } \\
\text { large tertiary } \\
\text { hospital. }\end{array}$ & Interviews & $\begin{array}{l}4 \text { themes were identified and } \\
\text { included: 1) try not to judge 2) } \\
\text { scoring the baby } 3 \text { ) share with } \\
\text { me and } 4 \text { ) I'm the mother here! } \\
\text { The quality of the relationship } \\
\text { between the mothers and the } \\
\text { nurses in the NICU was a } \\
\text { significant factor of the } \\
\text { mothers' experiences. }\end{array}$ \\
\hline $\begin{array}{l}\text { Demirci et } \\
\text { al., (2015) }\end{array}$ & $\begin{array}{l}\text { In this analysis, } \\
\text { we describe the } \\
\text { experiences and } \\
\text { perceptions } \\
\text { impacting } \\
\text { breastfeeding } \\
\text { decisions among } \\
\text { pregnant and } \\
\text { postpartum } \\
\text { women taking } \\
\text { methadone. }\end{array}$ & 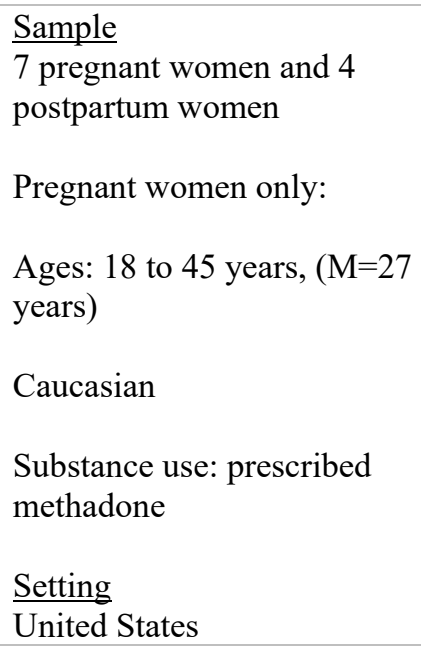 & $\begin{array}{l}\text { Qualitative; } \\
\text { Descriptive }\end{array}$ & $\begin{array}{l}\text { The participants } \\
\text { were part of a } \\
\text { larger study and } \\
\text { recruited through } \\
\text { advertisements at } \\
\text { a local substance } \\
\text { use treatment } \\
\text { center for } \\
\text { pregnant women } \\
\text { and mothers. }\end{array}$ & $\begin{array}{l}\text { Semi- } \\
\text { structured } \\
\text { interviews and } \\
\text { focus groups }\end{array}$ & $\begin{array}{l}\text { Three major themes were } \\
\text { identified and included: 1) } \\
\text { fears, barriers, and } \\
\text { misconceptions 2) motivation } \\
\text { and perceived benefits of } \\
\text { breastfeeding; and 3) sources } \\
\text { of information, support, and } \\
\text { anxiety. Participants believed } \\
\text { health care providers were } \\
\text { unknowledgeable about } \\
\text { breastfeeding and methadone } \\
\text { use. Participants described } \\
\text { negative interactions with their } \\
\text { nurses. }\end{array}$ \\
\hline
\end{tabular}




\begin{tabular}{|c|c|c|c|c|c|c|}
\hline Authors & $\begin{array}{c}\text { Purpose } \\
\text { Statement }\end{array}$ & Sample/Setting & Method & Procedures & Measures & Findings \\
\hline $\begin{array}{l}\text { Falleta et } \\
\text { al., (2018) }\end{array}$ & $\begin{array}{l}\text { This current } \\
\text { study takes a } \\
\text { qualitative } \\
\text { approach to } \\
\text { understand } \\
\text { currently or } \\
\text { recently } \\
\text { pregnant } \\
\text { women's } \\
\text { perceptions of } \\
\text { CPS. }\end{array}$ & 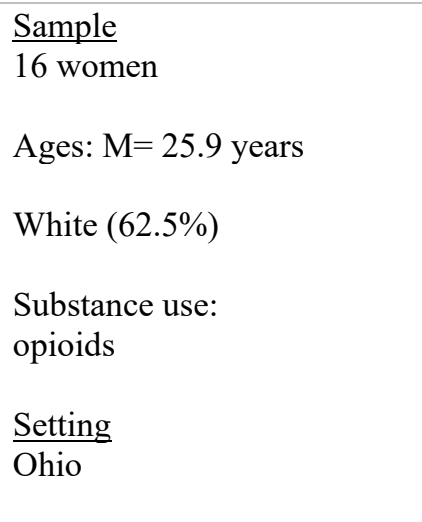 & $\begin{array}{l}\text { Qualitative, } \\
\text { Descriptive }\end{array}$ & $\begin{array}{l}\text { Participants were } \\
\text { recruited for the } \\
\text { study by program } \\
\text { staff at a substance } \\
\text { use treatment } \\
\text { facility in } 2012 \text {. } \\
\text { Interviews with } \\
\text { study participants } \\
\text { were conducted } \\
\text { individually by a } \\
\text { trained clinical } \\
\text { psychology PhD } \\
\text { candidate. }\end{array}$ & $\begin{array}{l}\text { Semi- } \\
\text { structured } \\
\text { interviews }\end{array}$ & $\begin{array}{l}\text { Participants identified both } \\
\text { positive and negative feelings } \\
\text { and attitudes about CPS. } \\
\text { Participants identified useful } \\
\text { qualities of CPS. Fear can } \\
\text { serve as a barrier to women } \\
\text { receiving care. }\end{array}$ \\
\hline $\begin{array}{l}\text { Fallin- } \\
\text { Bennett \& } \\
\text { Ashford, } \\
(2017)\end{array}$ & $\begin{array}{l}\text { To collect } \\
\text { formative } \\
\text { information to } \\
\text { design a tailored } \\
\text { tobacco } \\
\text { treatment } \\
\text { intervention for } \\
\text { women with } \\
\text { newborns treated } \\
\text { or evaluated for } \\
\text { neonatal } \\
\text { abstinence } \\
\text { syndrome and to } \\
\text { explore current } \\
\text { tobacco use } \\
\text { behaviors and } \\
\text { facilitators and } \\
\text { barriers to } \\
\text { smoking } \\
\text { cessation. }\end{array}$ & $\begin{array}{l}\text { Sample } \\
11 \text { mothers of newborns who } \\
\text { were treated or evaluated for } \\
\text { neonatal abstinence } \\
\text { syndrome at birth within the } \\
\text { preceding } 3 \text { months. } \\
\text { Ages } 22-36 \text { years } \\
\text { Substance use: } \\
\text { opioids } \\
\text { smoking } \\
\text { Setting } \\
\text { United States }\end{array}$ & $\begin{array}{l}\text { Qualitative, } \\
\text { Descriptive }\end{array}$ & $\begin{array}{l}\text { Participants took } \\
\text { part in semi- } \\
\text { structured } \\
\text { individual } \\
\text { interviews that } \\
\text { lasted } \\
\text { approximately } 1 \\
\text { hour. Interviews } \\
\text { were } \\
\text { professionally } \\
\text { transcribed and } \\
\text { analyzed using } \\
\text { content analysis }\end{array}$ & $\begin{array}{l}\text { Semi- } \\
\text { structured } \\
\text { interviews }\end{array}$ & $\begin{array}{l}\text { Five themes were identified } \\
\text { and included: 1) strategizing } \\
\text { to reduce risk } 2 \text { ) desire to quit } \\
\text { smoking in the future } 3 \text { ) } \\
\text { holding on to smoking while } \\
\text { working through recovery 4) } \\
\text { feeling judged by nurses and 5) } \\
\text { feeling supported and } \\
\text { empowered by nurses. } \\
\text { Most participants described } \\
\text { positive experiences and were } \\
\text { supported by health care } \\
\text { providers. }\end{array}$ \\
\hline
\end{tabular}




\begin{tabular}{|c|c|c|c|c|c|c|}
\hline Authors & $\begin{array}{c}\text { Purpose } \\
\text { Statement }\end{array}$ & Sample/Setting & Method & Procedures & Measures & Findings \\
\hline $\begin{array}{l}\text { Hicks et al., } \\
(2018)\end{array}$ & $\begin{array}{l}\text { This study } \\
\text { utilized a cross- } \\
\text { sectional } \\
\text { qualitative and } \\
\text { quantitative } \\
\text { interview-based } \\
\text { survey to } \\
\text { capture the } \\
\text { infant feeding } \\
\text { practices and } \\
\text { barriers to } \\
\text { exclusive } \\
\text { breastfeeding for } \\
\text { women in } \\
\text { methadone } \\
\text { maintenance } \\
\text { therapy. }\end{array}$ & $\begin{array}{l}\frac{\text { Sample }}{30 \text { women in methadone }} \\
\text { maintenance treatment } \\
\text { Substance use: methadone } \\
\text { Ages: } 22-41 \text { years } \\
\text { Setting } \\
\text { Southeastern Region } \\
\text { United States }\end{array}$ & Mixed Methods & $\begin{array}{l}\text { A convenience } \\
\text { sample of women } \\
\text { in treatment } \\
(\mathrm{n}=30) \text { were } \\
\text { interviewed using } \\
\text { an adapted } \\
\text { instrument } \\
\text { designed to } \\
\text { capture decisions } \\
\text { and intentions to } \\
\text { formula feed or } \\
\text { breastfeed; } \\
\text { support from } \\
\text { friends and } \\
\text { family; hospital } \\
\text { experience; } \\
\text { support from } \\
\text { health care } \\
\text { personnel; and } \\
\text { maternal } \\
\text { knowledge of } \\
\text { breastfeeding } \\
\text { while taking } \\
\text { methadone. }\end{array}$ & Interviews & $\begin{array}{l}\text { Out of the } 24 \text { women who } \\
\text { initiated breastfeeding, } 11 \\
\text { reported that they discontinued } \\
\text { because of issues related to } \\
\text { infant's neonatal intensive care } \\
\text { unit (NICU) stay. Eleven } \\
\text { women reported that their } \\
\text { health care providers did not } \\
\text { discuss breastfeeding with } \\
\text { them. Women who were } \\
\text { encouraged to breastfeed by } \\
\text { health care staff were more } \\
\text { likely to breastfeed for longer } \\
\text { durations. }\end{array}$ \\
\hline $\begin{array}{l}\text { Howard, } \\
(2015)\end{array}$ & $\begin{array}{l}\text { This qualitative } \\
\text { study was } \\
\text { undertaken to } \\
\text { examine the } \\
\text { experiences of } \\
\text { opioid- } \\
\text { dependent } \\
\text { women during } \\
\text { their prenatal }\end{array}$ & $\begin{array}{l}\frac{\text { Sample }}{20 \text { postpartum women within }} \\
6 \text { months of delivery } \\
\text { Ages: } 18-44 \text { years } \\
\text { Substance use: Prescription } \\
\text { opioids } \\
\text { Setting }\end{array}$ & $\begin{array}{l}\text { Qualitative, } \\
\text { Phenomenology }\end{array}$ & $\begin{array}{l}\text { Recruitment of the } \\
\text { postpartum } \\
\text { patients was } \\
\text { accomplished } \\
\text { through } 5 \\
\text { substance use } \\
\text { treatment centers. } \\
\text { Flyers were } \\
\text { displayed in } \\
\text { public restrooms, }\end{array}$ & Interviews & $\begin{array}{l}\text { Themes developed around } \\
\text { internal stigma of shame and } \\
\text { guilt. The majority of women } \\
\text { reported external stigma from } \\
\text { health care providers. }\end{array}$ \\
\hline
\end{tabular}




\begin{tabular}{|c|c|c|c|c|c|c|}
\hline Authors & $\begin{array}{c}\text { Purpose } \\
\text { Statement }\end{array}$ & Sample/Setting & Method & Procedures & Measures & Findings \\
\hline $\begin{array}{l}\text { Howard, } \\
\text { (2016) }\end{array}$ & $\begin{array}{l}\text { The aim of the } \\
\text { study was to } \\
\text { understand the } \\
\text { lived } \\
\text { experiences of } \\
\text { pregnant and } \\
\text { postpartum } \\
\text { women who } \\
\text { have an opioid } \\
\text { use disorder. }\end{array}$ & $\begin{array}{l}\text { Sample } \\
20 \text { postpartum women within } \\
6 \text { months of delivery } \\
\text { Ages: } 20-38 \text { years } \\
\text { Substance use: } \\
\text { Prescription opioids } \\
\text { Setting } \\
\text { Maine, Massachusetts, and } \\
\text { Rhode Island }\end{array}$ & $\begin{array}{l}\text { Qualitative, } \\
\text { Phenomenology }\end{array}$ & $\begin{array}{l}\text { Recruitment of the } \\
\text { postpartum } \\
\text { patients was } \\
\text { accomplished } \\
\text { through } 5 \\
\text { substance use } \\
\text { treatment centers. } \\
\text { Flyers were } \\
\text { displayed in } \\
\text { public restrooms, } \\
\text { waiting areas, and } \\
\text { informational } \\
\text { bulletin boards at } \\
\text { the treatment } \\
\text { locations. }\end{array}$ & Interviews & $\begin{array}{l}\text { Themes included: 1) decision } \\
\text { making about treatment } \\
\text { choices during pregnancy 2) } \\
\text { fear of CPS and 3) feeling } \\
\text { under surveillance. }\end{array}$ \\
\hline $\begin{array}{l}\text { Jarlenski et } \\
\text { al., (2016) }\end{array}$ & $\begin{array}{l}\text { This study } \\
\text { explored how } \\
\text { pregnant women } \\
\text { who use } \\
\text { marijuana obtain } \\
\text { and understand } \\
\text { information } \\
\text { about perinatal } \\
\text { marijuana use. }\end{array}$ & $\begin{array}{l}\frac{\text { Sample }}{26 \text { pregnant women }} \\
\text { Ages: } 19-36 \text { years } \\
\text { Substance use: } \\
\text { marijuana } \\
\underline{\text { Setting }} \text { United States }\end{array}$ & Qualitative & $\begin{array}{l}\text { Interviews } \\
\text { assessed women's } \\
\text { sources of } \\
\text { information about } \\
\text { risks of perinatal } \\
\text { marijuana use and } \\
\text { perceptions } \\
\text { regarding the } \\
\text { usefulness of such } \\
\text { information. } \\
\text { Interview data } \\
\text { were coded } \\
\text { independently by } \\
\text { two coders who } \\
\text { iteratively refined }\end{array}$ & $\begin{array}{l}\text { Semi- } \\
\text { structured } \\
\text { interviews }\end{array}$ & $\begin{array}{l}\text { Few women reported receiving } \\
\text { helpful information from a } \\
\text { health care provider or social } \\
\text { worker. Women described a } \\
\text { lack of evidence about harms } \\
\text { of perinatal marijuana use, and } \\
\text { reported being dissatisfied with } \\
\text { the quality of information. } \\
\text { Most women said they desired } \\
\text { information about the effects } \\
\text { of perinatal marijuana use on } \\
\text { infant health. }\end{array}$ \\
\hline
\end{tabular}




\begin{tabular}{|c|c|c|c|c|c|c|}
\hline Authors & $\begin{array}{c}\text { Purpose } \\
\text { Statement }\end{array}$ & Sample/Setting & Method & Procedures & Measures & Findings \\
\hline & & & & $\begin{array}{l}\text { the codes and } \\
\text { reviewed } \\
\text { transcripts for } \\
\text { themes. }\end{array}$ & & \\
\hline $\begin{array}{l}\text { Jessup et } \\
\text { al., (2003) }\end{array}$ & $\begin{array}{l}\text { To examine } \\
\text { extrinsic barriers } \\
\text { to substance use } \\
\text { treatment } \\
\text { programs by } \\
\text { drug dependent } \\
\text { women. }\end{array}$ & $\begin{array}{l}\text { Sample } \\
12 \text { pregnant women and } 24 \\
\text { women who had a child } \\
\text { within the previous year } \\
\text { Ages: } 24.4-36 \text { years } \\
\text { Substance use: } \\
\text { Crack/powder cocaine } \\
\text { Alcohol } \\
\text { Heroin } \\
\text { Methamphetamine } \\
\text { Cocaine/marijuana cigarettes } \\
\text { Psychedelics } \\
\text { Setting } \\
\text { California }\end{array}$ & $\begin{array}{l}\text { Qualitative, } \\
\text { Life History } \\
\text { Analysis }\end{array}$ & $\begin{array}{l}\text { Participants were } \\
\text { recruited from } 15 \\
\text { residential } \\
\text { substance use } \\
\text { treatment } \\
\text { programs for } \\
\text { pregnant and } \\
\text { parenting women. } \\
\text { Flyers with a toll- } \\
\text { free telephone } \\
\text { number were } \\
\text { posted in the } \\
\text { programs and a } \\
\text { telephone- } \\
\text { screening } \\
\text { interview was } \\
\text { conducted. }\end{array}$ & $\begin{array}{l}\text { Life history } \\
\text { interviews }\end{array}$ & $\begin{array}{l}\text { Participants fear and worry } \\
\text { about loss of infant custody, } \\
\text { arrest, prosecution, and } \\
\text { incarceration. Participants } \\
\text { feared presenting for care and } \\
\text { feared } \\
\text { not presenting for care. }\end{array}$ \\
\hline $\begin{array}{l}\text { Kramlich et } \\
\text { al., (2018) }\end{array}$ & $\begin{array}{l}\text { This focused } \\
\text { ethnography } \\
\text { aimed to address } \\
\text { the } \\
\text { missing voice of } \\
\text { pregnant and } \\
\text { parenting } \\
\text { women with } \\
\text { SUDs in rural } \\
\text { areas. }\end{array}$ & $\begin{array}{l}\text { Sample } \\
13 \text { women within } 5 \text { weeks of } \\
\text { delivery while infants were } \\
\text { receiving treatment for NAS } \\
\text { Ages: } 22-40 \text { years } \\
\text { Substance use: prescribed } \\
\text { MAT prescription opioids } \\
\text { illicit opioid use } \\
\text { Setting }\end{array}$ & $\begin{array}{l}\text { Qualitative, } \\
\text { Focused } \\
\text { Ethnography }\end{array}$ & $\begin{array}{l}\text { Women were } \\
\text { recruited for study } \\
\text { participation in } \\
\text { two ways, either } \\
\text { through } \\
\text { informational } \\
\text { flyers } \\
\text { shared by their } \\
\text { prenatal providers } \\
\text { or by the inpatient } \\
\text { perinatal social }\end{array}$ & $\begin{array}{l}\text { Interviews, } \\
\text { participant } \\
\text { observations, } \\
\text { and media } \\
\text { artifacts }\end{array}$ & $\begin{array}{l}\text { Several themes were identified } \\
\text { as: 1) challenges of getting } \\
\text { treatment and care (service } \\
\text { availability, } \\
\text { distance/geographic location, } \\
\text { transportation, provider } \\
\text { collaboration/coordination, } \\
\text { physical and emotional } \\
\text { safety), 2) opportunities to } \\
\text { bond (proximity, information), } \\
\text { and 3) importance of }\end{array}$ \\
\hline
\end{tabular}




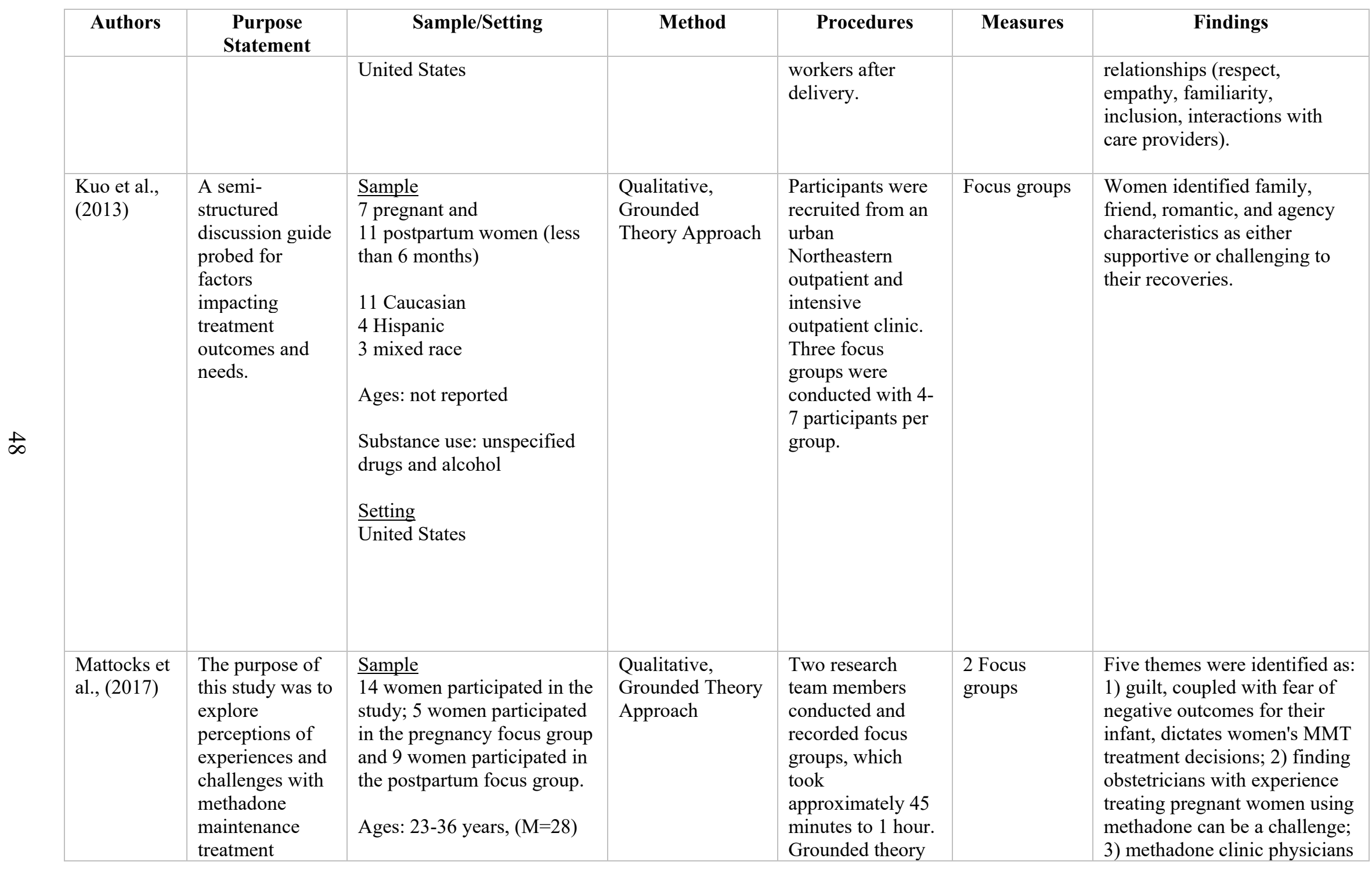




\begin{tabular}{|c|c|c|c|c|c|c|}
\hline Authors & $\begin{array}{c}\text { Purpose } \\
\text { Statement }\end{array}$ & Sample/Setting & Method & Procedures & Measures & Findings \\
\hline & $\begin{array}{l}\text { (MMT) and } \\
\text { obstetrical care } \\
\text { among pregnant } \\
\text { and postpartum } \\
\text { women enrolled } \\
\text { in a methadone } \\
\text { maintenance } \\
\text { program. }\end{array}$ & $\begin{array}{l}\text { 80\% Caucasian, } \\
20 \% \text { Hispanic/Latino. } \\
\text { Substance use: methadone } \\
\text { Setting } \\
\text { United States }\end{array}$ & & $\begin{array}{l}\text { was used to guide } \\
\text { data analysis and } \\
\text { open coding, } \\
\text { where transcripts } \\
\text { were reviewed } \\
\text { line by line to } \\
\text { create code } \\
\text { definitions as } \\
\text { concepts emerged } \\
\text { inductively from } \\
\text { the data. }\end{array}$ & & $\begin{array}{l}\text { are instrumental in helping } \\
\text { women find the right } \\
\text { methadone dose during } \\
\text { pregnancy; 4) some women } \\
\text { had strong preferences for } \\
\text { methadone over } \\
\text { buprenorphine; and 5) women } \\
\text { face substantial substance use } \\
\text { treatment challenges after } \\
\text { delivery. }\end{array}$ \\
\hline $\begin{array}{l}\text { McGlothen } \\
\text { et al., } \\
\text { (2018) }\end{array}$ & $\begin{array}{l}\text { This study } \\
\text { aimed to } \\
\text { describe what } \\
\text { influences the } \\
\text { infant-feeding } \\
\text { decisions of } \\
\text { women taking } \\
\text { medication } \\
\text { assisted } \\
\text { treatment for } \\
\text { opioid use } \\
\text { disorder. }\end{array}$ & 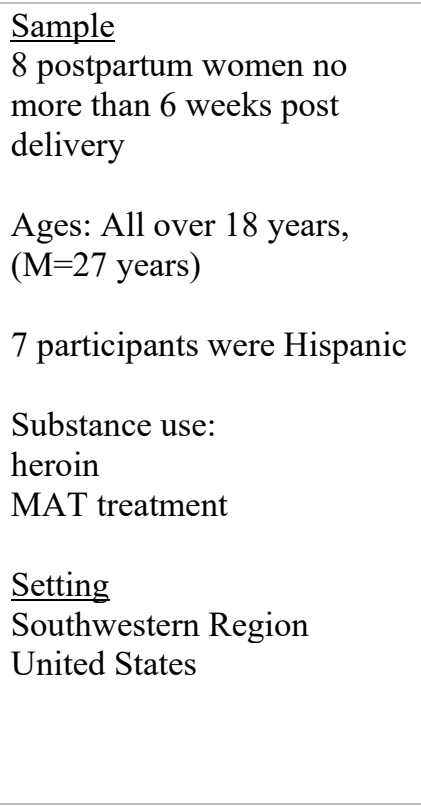 & $\begin{array}{l}\text { Qualitative, } \\
\text { Descriptive }\end{array}$ & $\begin{array}{l}\text { Purposeful } \\
\text { sampling was used } \\
\text { to recruit } \\
\text { postpartum } \\
\text { women. } \\
\text { Participants were } \\
\text { provided with a } \\
\text { recruitment flyer } \\
\text { about the study } \\
\text { during prenatal } \\
\text { classes at the } \\
\text { treatment center. } \\
\text { Flyers were also } \\
\text { posted in the } \\
\text { newborn nursery, } \\
\text { neonatal intensive } \\
\text { care unit, and } \\
\text { mother-baby unit } \\
\text { of a county } \\
\text { hospital. }\end{array}$ & $\begin{array}{l}\text { Semi- } \\
\text { structured } \\
\text { interviews }\end{array}$ & $\begin{array}{l}\text { Two themes were identified as: } \\
\text { 1) what I heard about } \\
\text { breastfeeding and 2) doing } \\
\text { what I feel is best for my baby. } \\
\text { Participants felt there was } \\
\text { social stigma and that nurses } \\
\text { undermined their infant- } \\
\text { feeding decision. }\end{array}$ \\
\hline
\end{tabular}




\begin{tabular}{|c|c|c|c|c|c|c|}
\hline Authors & $\begin{array}{c}\text { Purpose } \\
\text { Statement }\end{array}$ & Sample/Setting & Method & Procedures & Measures & Findings \\
\hline $\begin{array}{l}\text { Paterno et } \\
\text { al., (2018) }\end{array}$ & $\begin{array}{l}\text { The purpose of } \\
\text { this study was to } \\
\text { describe the } \\
\text { experiences of } \\
\text { addiction in } \\
\text { pregnancy, } \\
\text { recovery, and } \\
\text { subsequently } \\
\text { serving as a peer } \\
\text { mentor to other } \\
\text { pregnant women } \\
\text { with active SUD } \\
\text { among women } \\
\text { in recovery in a } \\
\text { rural setting. }\end{array}$ & $\begin{array}{l}\frac{\text { Sample }}{5 \text { women who served as peer }} \\
\text { mentors with lived } \\
\text { experience of perinatal } \\
\text { SUDs. } \\
\text { Ages: } 31-56 \text { years } \\
\text { White } \\
\text { Setting } \\
\text { United States }\end{array}$ & $\begin{array}{l}\text { Qualitative, } \\
\text { Narrative Inquiry }\end{array}$ & $\begin{array}{l}\text { Peer mentors were } \\
\text { recruited by word- } \\
\text { of-mouth with } \\
\text { assistance from } \\
\text { one peer mentor } \\
\text { who served as key } \\
\text { informant. The } \\
\text { key informant } \\
\text { notified other peer } \\
\text { mentors about the } \\
\text { study and gave } \\
\text { them the contact } \\
\text { information for } \\
\text { project principal } \\
\text { investigator. }\end{array}$ & $\begin{array}{l}\text { Digital } \\
\text { storytelling } \\
\text { and semi- } \\
\text { structure } \\
\text { interviews }\end{array}$ & $\begin{array}{l}\text { The mentors faced significant } \\
\text { stigma from health care } \\
\text { providers and fear during their } \\
\text { pregnancy. The mentors had } \\
\text { each done "inside work" to } \\
\text { successfully complete } \\
\text { recovery. They maintained } \\
\text { recovery by staying balanced. }\end{array}$ \\
\hline $\begin{array}{l}\text { Roberts \& } \\
\text { Nuru-Jeter, } \\
(2010)\end{array}$ & $\begin{array}{l}\text { Explore } \\
\text { women's } \\
\text { perspectives on } \\
\text { being identified } \\
\text { as a pregnant } \\
\text { alcohol or drug } \\
\text { user through } \\
\text { screening and } \\
\text { the influence on } \\
\text { prenatal care } \\
\text { attendance and } \\
\text { engagement. }\end{array}$ & $\begin{array}{l}38 \text { low-income pregnant and } \\
\text { parenting women } \\
\text { Substance use: } \\
\text { alcohol methamphetamine } \\
\text { Setting } \\
\text { California }\end{array}$ & $\begin{array}{l}\text { Qualitative, } \\
\text { Descriptive }\end{array}$ & $\begin{array}{l}\text { Purposive } \\
\text { sampling strategy } \\
\text { was used. } \\
\text { Participants were } \\
\text { recruited from } \\
\text { programs serving } \\
\text { low-income } \\
\text { women. Staff at } \\
\text { participating sites } \\
\text { recruited women } \\
\text { through posted } \\
\text { flyers and a } \\
\text { standardized } \\
\text { script. Interviews } \\
\text { lasted } \\
\text { approximately } 60 \\
\text { minutes. }\end{array}$ & $\begin{array}{l}20 \text { semi- } \\
\text { structured } \\
\text { interviews and } \\
\text { two focus } \\
\text { groups }\end{array}$ & $\begin{array}{l}\text { Most participants were } \\
\text { opposed to having drug but not } \\
\text { alcohol use identified by health } \\
\text { care providers. } \\
\text { Participants were mistrustful of } \\
\text { health care providers' efforts to } \\
\text { discover substance use and } \\
\text { expected legal, psychological, } \\
\text { and social consequences from } \\
\text { being identified. Some } \\
\text { participants avoided and } \\
\text { disengaged from prenatal care } \\
\text { and attempted to stop using } \\
\text { substances on their own. }\end{array}$ \\
\hline $\begin{array}{l}\text { Roberts \& } \\
\text { Pies, (2011) }\end{array}$ & $\begin{array}{l}\text { To understand } \\
\text { how drug use } \\
\text { and factors }\end{array}$ & $\begin{array}{l}\frac{\text { Sample }}{38 \text { pregnant and parenting }} \\
\text { women }\end{array}$ & $\begin{array}{l}\text { Qualitative, } \\
\text { Exploratory }\end{array}$ & $\begin{array}{l}\text { Women were } \\
\text { recruited from } \\
\text { substance use }\end{array}$ & $\begin{array}{l}20 \text { semi- } \\
\text { structured } \\
\text { interviews and }\end{array}$ & $\begin{array}{l}\text { Most participants avoided } \\
\text { prenatal care or attempted to } \\
\text { stop using substances before }\end{array}$ \\
\hline
\end{tabular}




\begin{tabular}{|c|c|c|c|c|c|c|}
\hline Authors & $\begin{array}{c}\text { Purpose } \\
\text { Statement }\end{array}$ & Sample/Setting & Method & Procedures & Measures & Findings \\
\hline & $\begin{array}{l}\text { associated with } \\
\text { drug use } \\
\text { influence } \\
\text { women's } \\
\text { prenatal care use }\end{array}$ & $\begin{array}{l}\text { Substance use: } \\
\text { methamphetamine } \\
\text { crack/cocaine } \\
\text { alcohol } \\
\text { Setting } \\
\text { California }\end{array}$ & & $\begin{array}{l}\text { treatment, a home- } \\
\text { visiting program, } \\
\text { and the Women, } \\
\text { Infants, and } \\
\text { Children program } \\
\text { by phone or when } \\
\text { she was onsite. }\end{array}$ & $\begin{array}{l}2 \text { focus groups } \\
\text { were } \\
\text { conducted. } \\
\text { Case-studies, } \\
\text { a cross-case } \\
\text { study, and } \\
\text { typology were } \\
\text { also used. }\end{array}$ & $\begin{array}{l}\text { attending prenatal care because } \\
\text { of fear of CPS. A few } \\
\text { participants attended in spite of } \\
\text { their fear of CPS because they } \\
\text { prioritized their baby's health. }\end{array}$ \\
\hline $\begin{array}{l}\text { Salmon et } \\
\text { al., (2000) }\end{array}$ & $\begin{array}{l}\text { The purpose of } \\
\text { this study was to } \\
\text { explore } \\
\text { perceptions of } \\
\text { pregnant and } \\
\text { parenting } \\
\text { substance- } \\
\text { abusing women } \\
\text { in an outpatient } \\
\text { drug treatment } \\
\text { program } \\
\text { regarding } \\
\text { provider and } \\
\text { social support. }\end{array}$ & 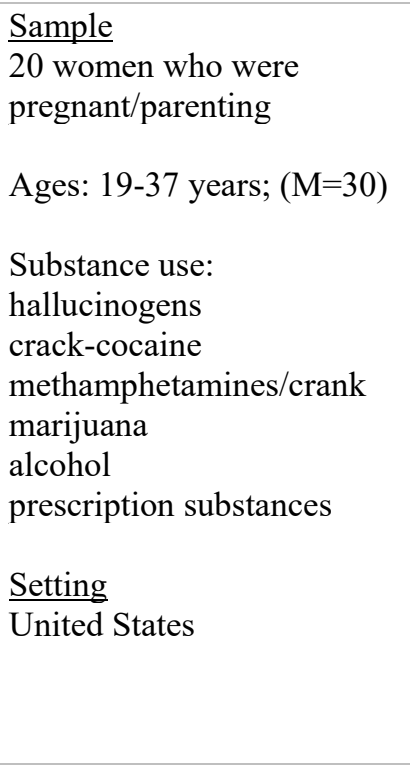 & $\begin{array}{l}\text { Qualitative, } \\
\text { Descriptive }\end{array}$ & $\begin{array}{l}\text { Participants were } \\
\text { recruited through } \\
\text { an advertisement } \\
\text { posted at the } \\
\text { agency. Interviews } \\
\text { were held in a } \\
\text { private office of } \\
\text { an } \\
\text { outpatient } \\
\text { substance use } \\
\text { treatment program } \\
\text { serving pregnant } \\
\text { and parenting } \\
\text { substance-using } \\
\text { women, designed } \\
\text { to promote the } \\
\text { health and normal } \\
\text { development of } \\
\text { the children. }\end{array}$ & Interviews & $\begin{array}{l}\text { The majority of participants } \\
\text { felt the support received from } \\
\text { medical providers was not } \\
\text { adequate. The majority of } \\
\text { participants reported receiving } \\
\text { no information on risks of } \\
\text { substance use in pregnancy } \\
\text { from their health care } \\
\text { providers. }\end{array}$ \\
\hline $\begin{array}{l}\text { Scott et al., } \\
(2017)\end{array}$ & $\begin{array}{l}\text { To explore care } \\
\text { experiences of } \\
\text { women who } \\
\text { used prescription } \\
\text { or illicit opioids } \\
\text { and experienced }\end{array}$ & $\begin{array}{l}\frac{\text { Sample }}{11 \text { women who experienced }} \\
\text { fetal or infant loss } \\
\text { Ages: } 18-36 \text { years }\end{array}$ & $\begin{array}{l}\text { Qualitative, } \\
\text { Description with } \\
\text { secondary data } \\
\text { analysis }\end{array}$ & $\begin{array}{l}\text { The interviews } \\
\text { were conducted by } \\
\text { nurses who } \\
\text { received training } \\
\text { on how to conduct } \\
\text { an interview. }\end{array}$ & 11 interviews & $\begin{array}{l}\text { Participants felt frustration and } \\
\text { anger of not being heard by } \\
\text { their health care providers. } \\
\text { Participants felt minimized and } \\
\text { overwhelmed experienced a } \\
\text { profound sense of grief and }\end{array}$ \\
\hline
\end{tabular}




\begin{tabular}{|c|c|c|c|c|c|c|c|}
\hline & Authors & $\begin{array}{c}\text { Purpose } \\
\text { Statement }\end{array}$ & Sample/Setting & Method & Procedures & Measures & Findings \\
\hline & & $\begin{array}{l}\text { fetal or infant } \\
\text { loss. }\end{array}$ & $\begin{array}{l}\text { White }(\mathrm{n}=8) \\
\begin{array}{l}\text { Substance use: } \\
\text { opioids } \\
\text { polysubstance use }\end{array} \\
\text { Setting } \\
\text { Midwest Region } \\
\text { United States }\end{array}$ & & & & $\begin{array}{l}\text { coping over the loss of their } \\
\text { children. }\end{array}$ \\
\hline$\dot{N}$ & $\begin{array}{l}\text { Stone, } \\
(2015)\end{array}$ & $\begin{array}{l}\text { To gain a greater } \\
\text { understanding of } \\
\text { the way } \\
\text { substance-using } \\
\text { women navigate } \\
\text { the health and } \\
\text { justice systems } \\
\text { in order to avoid } \\
\text { criminal justice } \\
\text { consequences } \\
\text { and to access } \\
\text { needed health } \\
\text { and social } \\
\text { support } \\
\text { resources. }\end{array}$ & $\begin{array}{l}\frac{\text { Sample }}{30 \text { pregnant or recently }} \text { pregnant women (within } 12 \\
\text { months postpartum) } \\
\text { Ages: } 19-41 \text { years } \\
\text { Substance use: } \\
\text { alcohol } \\
\text { marijuana } \\
\text { prescription medications } \\
\text { cocaine methamphetamine } \\
\text { heroin } \\
\text { hallucinogens } \\
\underline{\text { Setting }} \\
\text { United States }\end{array}$ & $\begin{array}{l}\text { Qualitative, } \\
\text { Descriptive }\end{array}$ & $\begin{array}{l}\text { Purposive } \\
\text { sampling with } \\
\text { recruitment flyers } \\
\text { posted in the } \\
\text { maternity wards of } \\
\text { local hospitals and } \\
\text { substance use } \\
\text { treatment centers, } \\
\text { community } \\
\text { centers, and } \\
\text { service enrollment } \\
\text { offices. Women } \\
\text { who completed } \\
\text { the interviews } \\
\text { were invited to } \\
\text { refer others to the } \\
\text { study. }\end{array}$ & $\begin{array}{l}\text { In-depth life } \\
\text { history } \\
\text { interviews and } \\
\text { loosely- } \\
\text { structured } \\
\text { interview } \\
\text { schedule of } \\
\text { open-ended } \\
\text { questions. }\end{array}$ & $\begin{array}{l}\text { Participants feared detection } \\
\text { during pregnancy, losing } \\
\text { custody of their children, and } \\
\text { experiencing criminal justice } \\
\text { consequences. } \\
\text { More than half of the } \\
\text { participants avoided prenatal } \\
\text { care. Participants skipped } \\
\text { visits, scheduled appointments } \\
\text { around substance use, or } \\
\text { avoided prenatal care } \\
\text { completely. }\end{array}$ \\
\hline & $\begin{array}{l}\text { Suarez et } \\
\text { al., (2018) }\end{array}$ & $\begin{array}{l}\text { This qualitative } \\
\text { interview study } \\
\text { provides insight } \\
\text { into the } \\
\text { experience of } \\
\text { becoming a } \\
\text { mother for }\end{array}$ & $\begin{array}{l}\frac{\text { Sample }}{4 \text { women with children aged }} \\
14-20 \text { months } \\
\text { Substance use: } \\
\text { Opiates }\end{array}$ & $\begin{array}{l}\text { Qualitative, } \\
\text { Narrative } \\
\text { Approach }\end{array}$ & $\begin{array}{l}\text { Mothers in a } \\
\text { larger scale study } \\
\text { of the impact of } \\
\text { combined } \\
\text { occupational and } \\
\text { music therapies } \\
\text { were invited to }\end{array}$ & $\begin{array}{l}\text { Semi- } \\
\text { structured } \\
\text { interviews }\end{array}$ & $\begin{array}{l}\text { Themes were identified and } \\
\text { include 1) deep love for the } \\
\text { baby, 2) the baby as a } \\
\text { motivation to stay sober } 3 \text { ) and } \\
\text { the determination to make the } \\
\text { relationship between mother } \\
\text { and child different from the }\end{array}$ \\
\hline
\end{tabular}




\begin{tabular}{|c|c|c|c|c|c|c|}
\hline Authors & $\begin{array}{c}\text { Purpose } \\
\text { Statement }\end{array}$ & Sample/Setting & Method & Procedures & Measures & Findings \\
\hline & $\begin{array}{l}\text { women in opiate } \\
\text { recovery. }\end{array}$ & $\begin{array}{l}\text { Setting } \\
\text { United States }\end{array}$ & & $\begin{array}{l}\text { complete } \\
\text { interviews. All } \\
\text { four participants } \\
\text { were in an opiate } \\
\text { substance use } \\
\text { recovery program } \\
\text { and had a baby } \\
\text { born with NAS. }\end{array}$ & & $\begin{array}{l}\text { one the mother had } \\
\text { experienced with her own } \\
\text { mother. Participants described } \\
\text { stigma from health care } \\
\text { providers. }\end{array}$ \\
\hline $\begin{array}{l}\text { Van } \\
\text { Scoyoc, et } \\
\text { al., (2016) }\end{array}$ & $\begin{array}{l}\text { To answer the } \\
\text { question of why } \\
\text { pregnant women } \\
\text { continue to use } \\
\text { illicit substances } \\
\text { without } \\
\text { accessing } \\
\text { treatment despite } \\
\text { acknowledging } \\
\text { the risks to their } \\
\text { developing } \\
\text { babies. }\end{array}$ & 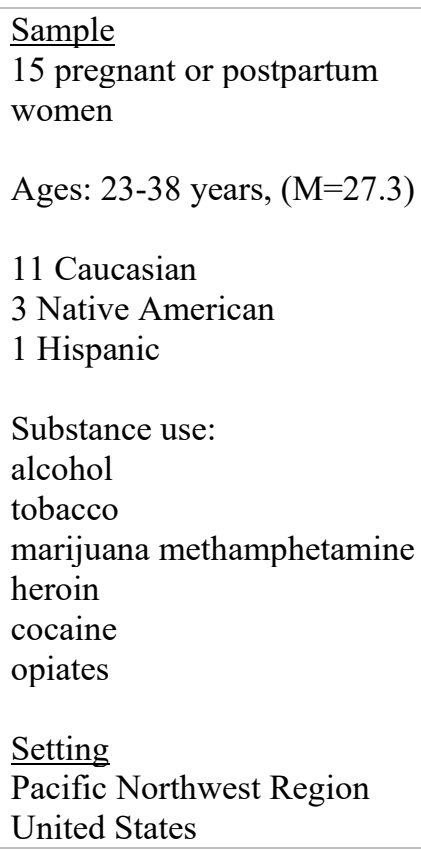 & $\begin{array}{l}\text { Qualitative, } \\
\text { Descriptive }\end{array}$ & $\begin{array}{l}\text { Women were } \\
\text { recruited through } \\
\text { announcements in } \\
\text { parenting classes, } \\
\text { referrals by } \\
\text { treatment staff, } \\
\text { and flyers posted } \\
\text { at the treatment } \\
\text { center. }\end{array}$ & Interviews & $\begin{array}{l}\text { Many participants reported } \\
\text { having concerns about } \\
\text { disclosing their addiction to } \\
\text { health care providers. } \\
\text { Participants also described } \\
\text { trying to quit or weaning off } \\
\text { substances themselves. }\end{array}$ \\
\hline
\end{tabular}


Table 2.2

Frequency Effect Sizes

\begin{tabular}{|c|c|}
\hline Abstracted Statement & Effect Size \\
\hline $\begin{array}{l}\text { 1. Many pregnant and postpartum women with SUDs feel they are } \\
\text { treated poorly by health care providers as evidenced by their } \\
\text { disparaging comments and behaviors. (Cleveland et al., 2016; } \\
\text { Cleveland \& Bonugli, 2014; Cleveland \& Gill, 2013; Howard, } \\
\text { 2015; Howard, 2016; Jarlenski et al., 2016; Kramlich et al., } \\
\text { 2018; McGlothen et al., 2018; Roberts \& Nuru-Jeter, 2010; } \\
\text { Roberts \& Pies, 2011; Salmon et al., 2000; Scott et al., 2017; } \\
\text { Stone 2015; Suarez et al., 2018) }\end{array}$ & .53 \\
\hline $\begin{array}{l}\text { 2. During encounters with health care providers, many pregnant } \\
\text { and postpartum with SUDs women feel judged because of their } \\
\text { substance use. (Cleveland \& Bonugli, 2014; Cleveland \& Gill, } \\
\text { 2013; Demirci et al., 2015; Fallin-Bennett \& Ashford, 2017; } \\
\text { Kramlich et al., 2018; Mattocks et al., 2017; McGlothen et al., } \\
\text { 2018; Paterno et al., 2018; Roberts \& Nuru-Jeter, 2010; Salmon } \\
\text { et al., 2000; Suarez et al., 2018) }\end{array}$ & .50 \\
\hline $\begin{array}{l}\text { 3. Many pregnant and postpartum women with SUDs do not } \\
\text { receive the information they need to manage their health care, } \\
\text { often because their providers lack knowledge about substance } \\
\text { use and pregnancy. (Cleveland \& Bonugli, 2014; Demirci et al., } \\
\text { 2015; Howard 2015; Jarlenski et al., 2016; Kramlich et al., 2018; } \\
\text { Mattocks et al., 2017; McGlothen et al., 2018; Roberts \& Nuru- } \\
\text { Jeter, 2010; Roberts \& Pies, 2011; Salmon et al., 2000; Scott et } \\
\text { al., 2017; Stone, 2015) }\end{array}$ & .45 \\
\hline $\begin{array}{l}\text { 4. Pregnant and postpartum women with SUDs feel providers do } \\
\text { not provide optimal care, spend enough time with them, or act in } \\
\text { a manner that is compassionate, trustworthy, and supportive. } \\
\text { (Cleveland \& Bonugli 2014; Cleveland \& Gill, 2013; Howard, } \\
\text { 2016; Kramlich et al., 2018; Kuo et al., 2013; Mattocks et al., } \\
\text { 2017; Roberts \& Nuru-Jeter, 2010; Roberts \& Pies, 2011; } \\
\text { Salmon et al., 2000; Scott et al., 2017; Stone, 2015) }\end{array}$ & .43 \\
\hline $\begin{array}{l}\text { 5. Some pregnant and postpartum women with SUDs have positive } \\
\text { relationships with their health care providers and feel the } \\
\text { providers do not judge or treat the women differently than } \\
\text { women without SUDs. (Cleveland \& Bonugli, 2014; Cleveland } \\
\text { \& Gill, 2013; Fallin-Bennett \& Ashford, 2017; Howard 2015; } \\
\text { Kramlich et al., 2018; Mattocks et al., 2017; Roberts \& Nuru- } \\
\text { Jeter, 2010; Salmon et al., 2000; Stone, 2015; Suarez et al., } \\
\text { 2018) }\end{array}$ & .41 \\
\hline $\begin{array}{l}\text { 6. Some pregnant and postpartum women with SUDs feel health } \\
\text { care providers provide good medical care, emotional support, } \\
\text { and helpful health-related information. (Demirci et al., 2015; } \\
\text { Fallin-Bennett \& Ashford, 2017; Hicks 2018; Howard, 2016; }\end{array}$ & .39 \\
\hline
\end{tabular}




\begin{tabular}{|c|c|}
\hline Abstracted Statement & Effect Size \\
\hline $\begin{array}{l}\text { McGlothen et al., 2018; Roberts \& Nuru-Jeter, 2010; Salmon et } \\
\text { al., 2000; Scott et al., 2017; Suarez et al., 2018) }\end{array}$ & \\
\hline $\begin{array}{l}\text { 7. Pregnant and postpartum women with SUDs feel nurses monitor } \\
\text { the women when they are with their infants or take over the } \\
\text { infants' care. (Cleveland et al., 2016; Cleveland \& Bonugli, } \\
\text { 2014; Cleveland \& Gill, 2013; Demirci et al., 2015; Fallin- } \\
\text { Bennett \& Ashford, 2017; Howard, 2015; Kramlich et al., 2018; } \\
\text { McGlothen et al., 2018; Salmon et al., 2000; Stone 2015) }\end{array}$ & .36 \\
\hline $\begin{array}{l}\text { 8. Some pregnant and postpartum women with SUDs limit } \\
\text { substance use before health care appointments, hide substance } \\
\text { use from providers, and delay or avoid prenatal care to avoid } \\
\text { detection. (Falletta et al., 2018; Jessup et al., 2003; Kramlich et } \\
\text { al., 2018; Mattocks et al., 2017; Roberts \& Nuru-Jeter, 2010; } \\
\text { Roberts \& Pies, 2011; Stone, 2015; Van Scoyoc et al., 2017) }\end{array}$ & .31 \\
\hline $\begin{array}{l}\text { 9. Many pregnant and postpartum women with SUDs fear that } \\
\text { encounters with health care providers could lead to negative } \\
\text { legal and social consequences stemming from their substance } \\
\text { use, especially the loss of the women's children. (Howard, 2015; } \\
\text { Howard, 2016; Jarlenski et al., 2016; Jessup et al., 2003; Roberts } \\
\text { \& Nuru-Jeter, 2010; Roberts \& Pies, 2011; Stone, 2015; Van } \\
\text { Scoyoc et al., 2017) }\end{array}$ & .28 \\
\hline $\begin{array}{l}\text { 10. Some pregnant and postpartum women with SUDs feel health } \\
\text { care providers fail to include the women in decisions about their } \\
\text { health. (Howard, 2016; Kramlich et al., 2018; McGlothen et al., } \\
\text { 2018; Roberts \& Nuru-Jeter, 2010; Scott et al., 2017; Stone, } \\
\text { 2015) }\end{array}$ & .26 \\
\hline $\begin{array}{l}\text { 11. Some pregnant and postpartum women with SUDs feel that } \\
\text { health care providers give good care of their infant. (Cleveland } \\
\& \text { Bonugli, 2014; Fallin-Bennett \& Ashford, 2017; Mattocks et } \\
\text { al., 2017; McGlothen et al., 2018; Salmon et al., 2000; Suarez et } \\
\text { al., 2018) }\end{array}$ & .26 \\
\hline $\begin{array}{l}\text { 12. Pregnant and postpartum women with SUDs often feel their } \\
\text { health care providers do not believe, listen to, or consider the } \\
\text { women's concerns about their health and that of their infants. } \\
\text { (Howard, 2015; Paterno et al., 2018; Roberts \& Nuru-Jeter, } \\
\text { 2010; Roberts \& Pies, 2011; Salmon et al., 2000; Scott et al., } \\
\text { 2017) }\end{array}$ & .23 \\
\hline $\begin{array}{l}\text { 13. Some pregnant and postpartum women appreciate it when health } \\
\text { care providers address their substance use and encourage SUD } \\
\text { treatment. (Kramlich et al., 2018; Mattocks et al., 2017; Roberts } \\
\text { \& Nuru-Jeter, 2010; Salmon et al., 2000; Suarez et al., 2018) }\end{array}$ & .22 \\
\hline $\begin{array}{l}\text { 14. Some pregnant and postpartum women with SUDs feel it is best } \\
\text { if their health care providers are aware of their substance use. }\end{array}$ & .17 \\
\hline
\end{tabular}




\begin{tabular}{|l|l|}
\hline Abstracted Statement & Effect Size \\
\hline $\begin{array}{l}\text { (Kramlich et al., 2018; Roberts \& Nuru-Jeter, 2010; Stone, 2015; } \\
\text { Suarez et al., 2018) }\end{array}$ & \\
\hline $\begin{array}{l}\text { 15. Pregnant and postpartum women with SUDs who seek prenatal } \\
\text { health care do so primarily because they are concerned about } \\
\text { their infants' health. (Cleveland et al., 2016; Jessup et al., 2003; } \\
\text { Roberts \& Pies, 2011; Stone, 2015) }\end{array}$ & .17 \\
\hline $\begin{array}{l}\text { 16. Some pregnant and postpartum women with SUDs feel like } \\
\text { nurses in the NICU treat the women's infants differently or } \\
\text { poorly because of the women's substance use. (Cleveland et al., } \\
\text { 2016; Cleveland \& Bonugli, 2014; Cleveland \& Gill, 2013; } \\
\text { Howard, 2015; Kramlich et al., 2018) }\end{array}$ & .14 \\
\hline $\begin{array}{l}\text { 17. Most pregnant and postpartum women with SUDs are concerned } \\
\text { about drug testing procedures during health care encounters. } \\
\text { (Jessup et al., 2003; Roberts \& Nuru-Jeter, 2010; Stone, 2015) }\end{array}$ & .13 \\
\hline $\begin{array}{l}\text { 18. Some pregnant and postpartum women with SUDs see the } \\
\text { benefits of drug testing. (Roberts \& Nuru-Jeter, 2010; Stone, } \\
\text { 2015) }\end{array}$ & .09 \\
\hline
\end{tabular}


Table 2.3

Taxonomy of Health Care Encounters

\begin{tabular}{|c|c|c|}
\hline & $\begin{array}{l}\text { The abstracted statements (numbered in } \\
\text { Table 2.2) that contributed to the } \\
\text { identification of each type of encounter }\end{array}$ & $\begin{array}{l}\text { Number of } \\
\text { reports in } \\
\text { the sample } \\
\text { that } \\
\text { discussed } \\
\text { each type of } \\
\text { encounter }\end{array}$ \\
\hline \multicolumn{3}{|l|}{$\begin{array}{l}\text { Adverse } \\
\text { Encounters }\end{array}$} \\
\hline $\begin{array}{l}\text { 1. Judgmental } \\
\text { encounters }\end{array}$ & $\begin{array}{l}\text { \# 2: During encounters with health care } \\
\text { providers, many pregnant and postpartum with } \\
\text { SUDs women feel judged because of their } \\
\text { substance use. }\end{array}$ & 11 \\
\hline $\begin{array}{l}\text { 2. Disparaging } \\
\text { encounters }\end{array}$ & $\begin{array}{l}\text { \# 1: Many pregnant and postpartum women with } \\
\text { SUDs feel they are treated poorly by health care } \\
\text { providers as evidenced by their disparaging } \\
\text { comments and behaviors. } \\
\text { \#16: Some pregnant and postpartum women with } \\
\text { SUDs feel like nurses in the NICU treat the } \\
\text { women's infants differently or poorly because of } \\
\text { the women's substance use. }\end{array}$ & 14 \\
\hline $\begin{array}{l}\text { 3. Scrutinizing } \\
\text { encounters }\end{array}$ & $\begin{array}{l}\text { \#7: Pregnant and postpartum women with SUDs } \\
\text { feel nurses monitor the women when they are } \\
\text { with their infants or take over the infants' care. } \\
\text { \#8: Some pregnant and postpartum women with } \\
\text { SUDs limit substance use before health care } \\
\text { appointments, hide substance use from providers, } \\
\text { and delay or avoid prenatal care to avoid } \\
\text { detection. } \\
\text { \#9: Many pregnant and postpartum women with } \\
\text { SUDs fear that encounters with health care } \\
\text { providers could lead to negative legal and social } \\
\text { consequences stemming from their substance } \\
\text { use, especially the loss of the women's children. } \\
\text { \#17: Most pregnant and postpartum women with } \\
\text { SUDs are concerned about drug testing } \\
\text { procedures during health care encounters. }\end{array}$ & 18 \\
\hline
\end{tabular}




\begin{tabular}{|c|c|c|}
\hline & $\begin{array}{l}\text { The abstracted statements (numbered in } \\
\text { Table 2.2) that contributed to the } \\
\text { identification of each type of encounter }\end{array}$ & $\begin{array}{l}\text { Number of } \\
\text { reports in } \\
\text { the sample } \\
\text { that } \\
\text { discussed } \\
\text { each type of } \\
\text { encounter }\end{array}$ \\
\hline \multicolumn{3}{|l|}{$\begin{array}{l}\text { Adverse } \\
\text { Encounters }\end{array}$} \\
\hline $\begin{array}{l}\text { 4.Disempowering } \\
\text { encounters }\end{array}$ & $\begin{array}{l}\text { \#10: Some pregnant and postpartum women with } \\
\text { SUDs feel health care providers fail to include } \\
\text { the women in decisions about their health. } \\
\text { \#12: Pregnant and postpartum women with } \\
\text { SUDs often feel their health care providers do } \\
\text { not believe, listen to, or consider the women's } \\
\text { concerns about their health and that of their } \\
\text { infants. }\end{array}$ & 10 \\
\hline $\begin{array}{l}\text { 5. Deficient-care } \\
\text { encounters }\end{array}$ & $\begin{array}{l}\text { \# 3: Many pregnant and postpartum women with } \\
\text { SUDs do not receive the information they need } \\
\text { to manage their health care, often because their } \\
\text { providers lack knowledge about substance use } \\
\text { and pregnancy. } \\
\text { \#4: Pregnant and postpartum women with SUDs } \\
\text { feel providers do not provide optimal care, spend } \\
\text { enough time with them, or act in a manner that is } \\
\text { compassionate, trustworthy, and supportive. }\end{array}$ & 14 \\
\hline \multicolumn{3}{|l|}{$\begin{array}{l}\text { Beneficial } \\
\text { Encounters }\end{array}$} \\
\hline $\begin{array}{l}\text { 1. Recovery- } \\
\text { based encounters }\end{array}$ & $\begin{array}{l}\text { \#13: Some pregnant and postpartum women } \\
\text { appreciate it when health care providers address } \\
\text { their substance use and encourage SUD } \\
\text { treatment. } \\
\text { \#14: Some pregnant and postpartum women with } \\
\text { SUDs feel it is best if their health care providers } \\
\text { are aware of their substance use. } \\
\text { \#18: Some pregnant and postpartum women with } \\
\text { SUDs see the benefits of drug testing. }\end{array}$ & 6 \\
\hline $\begin{array}{l}\text { 2. Accepting } \\
\text { encounters }\end{array}$ & $\begin{array}{l}\# 5: \text { Some pregnant and postpartum women with } \\
\text { SUDs have positive relationships with their } \\
\text { health care providers and feel the providers do }\end{array}$ & 10 \\
\hline
\end{tabular}




\begin{tabular}{|c|c|c|}
\hline & $\begin{array}{l}\text { The abstracted statements (numbered in } \\
\text { Table 2.2) that contributed to the } \\
\text { identification of each type of encounter }\end{array}$ & $\begin{array}{l}\text { Number of } \\
\text { reports in } \\
\text { the sample } \\
\text { that } \\
\text { discussed } \\
\text { each type of } \\
\text { encounter }\end{array}$ \\
\hline \multicolumn{3}{|l|}{$\begin{array}{l}\text { Beneficial } \\
\text { Encounters }\end{array}$} \\
\hline & $\begin{array}{l}\text { not judge or treat the women differently than } \\
\text { women without SUDs. }\end{array}$ & \\
\hline $\begin{array}{l}\text { 3. Effective-care } \\
\text { encounters }\end{array}$ & $\begin{array}{l}\text { \#6: Some pregnant and postpartum women with } \\
\text { SUDs feel health care providers provide good } \\
\text { medical care, emotional support, and helpful } \\
\text { health-related information. } \\
\text { \#11: Some pregnant and postpartum women with } \\
\text { SUDs feel that health care providers give good } \\
\text { care of their infant. } \\
\text { \#15: Pregnant and postpartum women with } \\
\text { SUDs who seek prenatal health care do so } \\
\text { primarily because they are concerned about their } \\
\text { infants' health. }\end{array}$ & 15 \\
\hline
\end{tabular}




\section{CHAPTER 3}

\section{Introduction}

Chapter 3 describes a qualitative descriptive study (Study 2) conducted to identify facilitators of and barriers to the formation of trusting relationships between maternity nurses and pregnant and postpartum women with SUDs (Aims 2 and 3).

\section{Maternal Substance Use}

Substance use during pregnancy is a growing maternal-child health concern in the United States. In a recent national survey by the U.S. Department of Health and Human Services (2019), 11.6\% of pregnant women reported tobacco use, $9.9 \%$ alcohol use, $4.7 \%$ marijuana use, and 5.4\% illicit substance use while pregnant. Particularly concerning is the number of women and children being affected by the current opioid crisis in the United States. Opioid use during pregnancy increased 333\% between 1999 and 2014 from 1.5 cases per 1,000 hospital births in 1999 to 6.5 cases per 1,000 hospital births in 2014 (Haight et al., 2018).

Substance use during pregnancy has been linked to variety of maternal, fetal and neonatal complications. Alcohol use during pregnancy is associated microcephaly, hydrocephaly, oral clefts, and attention deficit disorder (Pereira et al., 2018). Tobacco use during pregnancy is linked to fetal growth restriction and maternal complications such as placenta abruption and hemorrhage (Pereira et al., 2018; Pineles et al., 2016). Opioid use in pregnancy is associated with oral clefts, ventricular septal defects, and atrial defects (Lind et al., 2017).

NAS is a common complication experienced by infants who are exposed to prenatal substances. NAS is a cluster of withdrawal symptoms that can involve the 
central nervous, respiratory, and gastrointestinal systems and includes irritability, excessive crying, and tremors. While most infants exposed to prenatal opioids will experience NAS, a variety of other substances such as benzodiazepines, barbiturates, alcohol, and nicotine can contribute to symptoms (Hudak \& Tan, 2012). Between 2009 and 2012, the incidence of NAS increased exponentially in the United States from 3.4 cases per 1,000 hospital births to 5.8 cases per 1,000 hospital births (Patrick et al., 2015).

Given the prevalence and serious complications resulting from substance use during pregnancy, it is vital to understand the health care experiences of pregnant and postpartum women with SUDs. It is especially important to understand the formation of trust between the women and the maternity nurses who provide much of their care.

\section{Health Care Experiences of Pregnant and Postpartum Women with SUDs}

Health care services and addiction treatment improve health outcomes for women who use substances during pregnancy and their infants. Prenatal care can decrease the risk of neonatal complications including premature delivery, low infant birth weight, and small for gestational age in term infants (El-Mohandes et al., 2003). Substance use treatment integrated with prenatal care is associated with lower rates of preterm delivery, placental abruption, and intrauterine fetal demises (Goler et al., 2008).

A trusting provider-patient relationship occurs when patients feel that their providers care about them and work in their best interest, and when providers feel that their patients are capable of assuming responsibility for their care (Birkhauer et al., 2017). Provider-patient trust has been linked to positive health outcomes such as higher quality of life and patient satisfaction (Birkhauer et al., 2017). Yet pregnant and postpartum women with SUDs do not trust providers if the women feel judged because of 
their substance use. Women with SUDs have described stigmatizing health care encounters in which a provider undermined their decision-making, assigned them offensive labels, and provided them differential treatment (Howard, 2015; Howard, 2016; Jessup et al., 2003; Leppo, 2012). As a result, many women with SUDs forego prenatal care (Cleveland \& Bonguli, 2014; Cleveland \& Gill, 2013; Gilchrist et al., 2012; Howard, 2015; Leppo, 2012; McGlothen et al., 2018; Paterno et al., 2018).

\section{Relationships Between Maternity Nurses and Women with SUDs}

Maternity nurses can positively influence the health care experiences of pregnant and postpartum women with SUDs. Maternity nurses care for women during pregnancy, labor and delivery, and postpartum as well as care for their infants after birth. More than other health care providers, maternity nurses provide direct physical and emotional care to women and their infants and are well poised to offer support, ensure women's safety, and provide education (Lyndon, 2009).

As with other health care providers, however, relationships between maternity nurses and pregnant and postpartum women can be fraught with difficulties when women have used substances during pregnancy. Maternity nurses report concerns that women with SUDs are not truthful their substance use, cannot properly care for their infants, and blame nurses for their infants' problems (Fraser et al., 2007; Maguire et al., 2012; Murphy-Oikonen et al., 2010; Shaw et al., 2016). Moreover, some maternity nurses report having experienced abusive and threatening behavior from parents and family members of infants with NAS (Maguire et al., 2012).

Pregnant and postpartum women with SUDs similarly describe difficulties in their relationships with maternity nurses. Postpartum women with SUDs resent it when nurses 
judge them and consider them to be "bad" mothers because of their substance use or when nurses take over the care of their infants (Cleveland \& Gill, 2013). For example, some postpartum women with SUDs report feeling unwelcomed and out of place when entering the NICU to care for their infants and believe nurses want to care for infants but not mothers who used substances (Cleveland \& Gill, 2013).

The lack of trusting relationships between the women and maternity nurses is a significant health care problem. Nurse theorists have long stressed the importance of trust in nurse-patient relationships. For example, Peplau (1997) recognized the importance of meeting a patient's needs for connection through a trusting nurse-patient relationship. The absence of trust in the nurse-patient relationships may compromise health outcomes for pregnant and postpartum women with SUDs. Despite the importance of trust in nurse-patient relationships in this population, few studies have provided in-depth descriptions of factors that influence its development.

\section{Study Purpose}

The purpose of this study, therefore, is to identify facilitators and barriers associated with the formation of trusting relationships between maternity nurses and pregnant and postpartum women with SUDs. To comprehensively describe these barriers and facilitators, it is necessary to explore the relationships from the perspectives of both maternity nurses and women with SUDs. This information can guide the development of strategies to be used by maternity nurses to strengthen relationships with pregnant or postpartum women with SUDs who receive nursing care. 


\section{Methods}

\section{Design}

A qualitative descriptive approach was used to conduct this study. Qualitative description is a low-interpretive approach in which researchers focus on the surface meaning of the participants' words to describe a phenomenon from their perspectives (Sandelowski, 2000). Qualitative description produces a straightforward summary of narrative data to provide information needed by policy makers and practitioners to solve health-related problems (Sandelowski, 2000). Because qualitative description provides a comprehensive and focused summary of narrative data rather than more abstract conceptualizations, semi-structured interviews with individuals or groups are often used to collect data (Neergaard et al., 2009) and content analysis is used to analyze the data (Sandelowski, 2000). Because the goal of the current study is to provide a straightforward description of common barriers and facilitators associated with the formation of trusting relationships between pregnant or postpartum women with SUDs and maternity nurses that can readily inform practice, qualitative description was determined to be the most appropriate method.

\section{Sample and Sample Size}

Because the study aimed to identify barriers and facilitators associated with the development of trusting relationships from the perspectives of both maternity nurses and pregnant and postpartum women with SUDs, the sample included both of these two groups. Sullivan-Bolyai et al. (2005) indicated that most qualitative descriptive studies have a moderate sample size of at least 20 participants, although a final sample size depends on how many participants are needed to provide ample data to address the 
research aims. Therefore, 25 participants (15 nurses, 10 women) were recruited for this study. Approval was obtained from the Indiana University Purdue University at Indianapolis Institutional Review Board (IRB), and administrative permissions were obtained from the Association of Women's Health, Obstetric, and Neonatal Nursing (AWHONN), which facilitated the recruitment of the nurses, and the maternal treatment center where the women were recruited.

\section{Nurse Participants}

Inclusion criteria. The inclusion criteria for the nurse participants were as follows: 1) had experience working with pregnant and/or postpartum women with SUDs, 2) held a registered nurse license, and 3) had at least one year of experience working in a maternity nursing area including a prenatal office, labor and delivery unit, postpartum unit, or a NICU. The criterion of having at least one year of working experience ensured the nurse participants had a variety of interactions with pregnant and postpartum women with SUDs.

Recruitment. A convenience sample of 15 maternity nurses from the Midwest was recruited by purposeful sampling. Recruitment was done through the local Chapter of AWHONN, which is a 501c3 nonprofit, national membership nursing organization that supports and promotes the health of women and newborns. E-mail messages were sent to all members of the local section of AWHONN by their Chapter Coordinator. In addition, an announcement of the study was posted on the Facebook page of the local section of AWHONN. The e-mail and Facebook announcement briefly described the study and invited interested maternity nurses to contact the researcher by cell phone or email. 
Data collection. The researcher conducted phone interviews with the first 15 nurses who contacted her as all met inclusion criteria. A brief demographic questionnaire was administered before beginning the interview (see Appendix A). Nurse participants were asked to discuss their experiences working with pregnant and postpartum women with SUDs; describe positive, negative, and typical interactions they had had with the women; and identify what helped and hindered the formation of trust using a semistructured interview guide (see Appendix B). The interviews, which lasted between 20 and 30 minutes, were audiotaped and transcribed. Each participant was given a $\$ 30$ gift card after completing the interview as compensation for their time.

\section{Women Participants}

Inclusion criteria. The inclusion criteria for the women participants were as follows: 1) 18 years of age or older, 2) used substances during pregnancy, 3) hospitalized for labor/delivery or postpartum care or during their infant's NICU stay, 3) able to speak and write in English, and 4) within two years of giving birth to a living child at a hospital. The criterion of having given birth at the hospital was to ensure the participants had interactions with maternity nurses they could reflect back on, and the criterion of within two years of giving birth was to increase the likelihood the participants would recall those interactions.

Recruitment. Women participants were recruited from a residential maternal treatment center for substance use located in the Midwest. While the residential center is located in a rural setting, clients were from rural, urban, and suburban areas around the Midwest. The treatment center admits women with addictions to opioids and other substances such as methamphetamines, marijuana, and cocaine. Women can have up to 
two of their children ages five and younger live with them during their stay. Stays at the treatment facility may last up to several months. Treatment can include individual counseling, group therapy, and MAT.

Purposeful sampling techniques were used to recruit a convenience sample of 10 women. The researcher met with the unit manager of the residential treatment center to review inclusion criteria and study procedures. The unit manager identified and approached women in the treatment center who met eligibility criteria, briefly explained the study, and gave them a study brochure. The unit manager obtained verbal consent from the women to be contacted by the researcher. The researcher then approached women interested in participating in the study, explained the study procedures, and, if the women were interested, set up a time to conduct the interview.

Data collection. Interviews were held with the first 10 women who expressed an interest in participating as all met study criteria. The interviews were conducted in a private conference room at the residential treatment center. After the women completed a brief demographic questionnaire (see Appendix A), the researcher, who is an experienced maternity nurse, conducted the individual interviews using a semi-structured interview guide (see Appendix B). Women participants were asked to describe their experiences with maternity nurses; describe some positive, negative, and typical interactions with them; and identify what helped and hindered forming trust. The interviews, which lasted between 20 and 30 minutes, were audio-recorded and transcribed. Participants were given a $\$ 30$ gift card after completing the interviews as compensation for their time. 


\section{Data Management and Analysis}

All the interviews were transcribed by an IRB-approved professional transcriptionist. All participant information was de-identified and labeled with a study identification number.

The data from both groups were analyzed jointly. Data analysis was completed by the researcher with the assistance of her dissertation chair and input from the dissertation committee members. A conventional content analysis, in which codes are formed inductively from the data, rather than a directed content analysis, in which a set of preexisting codes were used to organize the data (Hsieh \& Shannon, 2005), was conducted in several steps.

Step 1: Transcript Review. The researcher read through all transcripts several times to become immersed in the data and obtain a thorough understanding of the nature of the relationship between the maternity nurses and the pregnant and postpartum women with SUDs.

Step 2: Extraction of Text Units. The researcher highlighted and extracted each text unit (e.g., phrase, sentence, story) related to the relationships between the maternity nurses and the pregnant and postpartum women with SUDs.

Step 3: Coding. Each text unit was assigned a code by the researcher. The codes were verified by the dissertation chair.

Step 4. Data display. These codes were placed into a case-by-topic table as described by Miles et al. (2013). The case-by-topic table is structured so that the cases are presented on the vertical axis and topics of interest are presented on the horizontal axis. This table was used to organize, condense and display codes according to each 
topic. For example, participants were listed on the vertical axis with their assigned ID number (e.g., 001, 002) and topics related to the research aims were displayed on the horizontal axis (e.g., positive, negative, and typical aspects of the nurse-patient relationships, facilitators of trust, barriers to trust).

Step 5: Categorization. The researcher, with input from the dissertation chair, categorized and summarized the codes in each column.

Step 6: Narrative summary. A narrative description of each column, with the use of exemplars taken from the transcripts, were constructed by the researcher to answer the study aims. The summaries were reviewed by the dissertation chair and refinements were made. The summaries were then verified by dissertation committee members who independently reviewed a subset of the transcripts to ensure the findings were consistent with the data.

\section{Strategies to Enhance the Trustworthiness of the Study Findings}

Several procedures were used to establishing the trustworthiness of the findings as described by Lincoln and Guba (1985). To ensure the findings were sound, both maternity nurses and pregnant and postpartum women with SUDs were included in the sample so that both perspectives were represented. The interview guides were structured such that participants were invited to discuss both positive and negative relationships. The researcher became immersed in the data, presented emerging analytic ideas to her dissertation chair, and routinely returned to the data to test emerging hypotheses. The narratives that described the barriers and facilitators were reviewed the dissertation committee members. To ensure that the findings were dependable and could be repeated, the researcher maintained an audit trail that chronicled all methodological and analytic 
decisions made throughout the study. A detailed description of the sample is provided so that consumers of the research can determine the transferability of the findings to their own settings and context.

\section{Findings}

\section{Sample Description}

Fifteen maternity nurses participated in the study. All identified as female.

Fourteen were White, and one was Black. They were between the ages of 31 to 55 years with the mean age of 41 years; one did not disclose her age. They had worked in a maternal specialty area for an average of 14.2 years of experience, with a range of 2 to 30 years. The nurse participants had current or past experiences working in the following settings: antenatal $(\mathrm{n}=4)$, labor and delivery unit $(\mathrm{n}=12)$, postpartum unit $(\mathrm{n}=11)$, maternal/fetal transport $(n=1)$, nursery $(n=10)$, NICU or special care nursery $(n=7)$, and labor and delivery, postpartum, and recovery unit $(\mathrm{LDPR})(\mathrm{n}=2)$. They were currently working in a variety of roles: staff nurse $(n=7)$, charge nurse $(n=1)$, nurse practitioner $(\mathrm{n}=2)$, lactation consultant $(\mathrm{n}=2)$, management $(\mathrm{n}=1)$, and education $(\mathrm{n}=2)$.

Eight of the 10 women participants completed a demographic questionnaire, and 2 refused. The following information, therefore, refers to the eight women who provided demographic information. The women were between the ages of 23 and 37 years with a mean age of 29 years. Six were White, one was Black, and one was Hispanic. They had between 2 and 7 children ranging from 8 days to 19 years old. As required by inclusion criteria, all had a child under the age of 2 years old. The women reported using the following substances during their most recent pregnancy: nicotine, methamphetamines, opioid pain relievers differently than prescribed or without a prescription, heroin, 
marijuana, Subutex with and without a prescription, benzodiazepines, and cocaine. All had used more than one substance. The primary substances for which women received treatment were opioids $(n=4)$ and methamphetamine $(n=4)$.

\section{Description of Interviews}

Overall, both nurse and women participants were able to recall a number of positive and negative nurse-patient interactions. The majority were forthcoming and described specific details about their interactions. Only a few participants had difficulty recalling particular interactions and spoke in more generalized terms. Nearly all of the participants appeared eager for the opportunity to discuss their experiences. Several participants became upset or angry when discussing behaviors and attitudes of the other group.

\section{Nurse and Women Characteristics and Trusting Relationships}

In describing the nurse-patient encounters they had experienced, the participants focused on the characteristics of nurses and characteristics of women that affected the formation of trusting relationships. For this paper, characteristics were considered attitudes, common behaviors, and proficiencies or deficiencies that each person brings to a relationship. For each characteristic, the participants identified either positive manifestations of the characteristic that helped the development of trust (facilitators) or negative manifestations of the characteristic that hindered the development of trust (barriers). The characteristics and related facilitators and barriers are listed in Table 3.1 and described below. In some cases, the characteristics of the nurses and the women were corresponding or complementary (e.g., demeanor toward women - demeanor 
toward nurses; provision of care - acceptance of care) and are therefore displayed on the same row in the table.

The participants discussed characteristics of both their own group (i.e., women or nurses) and that of the other group that affected the formation of trusting relationships. Not surprisingly, however, nurse participants were more focused on the women's characteristics and women participants were more focused on the nurses' characteristics. The findings below represent a merger of the perspectives of both groups, but viewpoints are attributed to the nurse participants, the women participants, or both groups combined (referred to only as "participants") when indicated.

\section{Characteristics of Maternity Nurses and Trusting Relationships}

The participants identified six characteristics of maternity nurses that were manifested in ways that could either help or hinder the formation of trusting relationships with pregnant and postpartum women with SUDs. The characteristics included rapportbuilding with women, demeanor toward women, provision of care, provision of information, attitude toward substance use, and addiction expertise (see Table 3.1).

Rapport-building with women. The findings indicated that rapport-building by maternity nurses affected the formation of trusting relationships with pregnant and postpartum women with SUDs. Participants indicated that rapport-building was manifested by creating a personal connection with the women or keeping a personal distance from them.

Creating a personal connection. Women participants indicated that trusting relationships were facilitated when a nurse created a personal connection with them. Women participants described instances when a nurse sat with them, spent extra time 
with them, shared personal information, and heard their stories. As a result, they saw the nurse as "a supportive friend," "a mother figure," or "like a grandma." One woman participant stated, "Like she'd [her nurse] sit in there, all night with me, and just talk."

The nurse participants also described instances when they made a personal connection with a woman by sharing personal information, spending ample time with her, and relating to her as both a "woman and a mother." One nurse who worked in labor and delivery and postpartum described such a connection:

My real mother was actually; I was born to a drug-addicted mom. So, I try to show people that you don't have to stay that way.... You can turn yourself around. I try to use, not my own personal struggle, but I try to use my story ... to message to other people.

Another nurse participant who worked in labor and delivery and postpartum made a personal connection to a woman, and, after hearing her story of addiction, realized "that could be me."

Keeping a personal distance. Conversely, women participants indicated that a barrier to a trusting relationship occurred when a maternity nurse kept a personal distance from them. The women participants described instances in which a nurse provided basic care but did not make an effort to talk to them, spend extra time with them, or get to know them. One described such an experience: "“[The nurse would say] 'Let me see your wristband." And then 'That's it ... type, type, type, out of room. That's it." Women participants described times when a nurse cared for their infant but did interact with them. One stated, "She [a nurse] didn't really ask about me or anything. Just kind of paid no attention to me, which yeah check on my baby."

Nurse participants also discussed a number of instances in which they did not form a personal connection with women for whom they provided care. In some cases, 
the nurse participants attributed this to the women's substance use. A nurse participant who worked in labor and delivery and postpartum stated, "The mom that was high when she came in, I think part of it was because she was high when she got to us. I feel like trying to communicate with her was not possible." Nurse participants also described having a distant relationship with a woman if they had too many tasks to do or other patients to care for at the same time.

Demeanor toward women. The findings indicate that the demeanor (outward behaviors) of maternity nurses toward pregnant and postpartum women with SUDs affected the formation of a trusting relationship. The participants suggested that the demeanor of maternity nurses was manifested by caring or cruel gestures they made toward the women.

Making caring gestures. Women participants indicated that caring gestures by nurses facilitated trusting relationships. These gestures were small acts that a nurse did to make them feel comfortable and cared for while in the hospital. The women participants, for example, appreciated it when a nurse spoke kindly toward them, checked on them frequently, and accompanied them out of the hospital after discharge. Women participants were especially grateful for caring gestures involving their infants. For example, one women participant said, "She (the nurse) actually set it up to where I could see him (infant) on video from (another hospital) to my phone."

Nurse participants similarly described making caring gestures toward a woman such as giving her a massage, rubbing her back, and giving her a glass of water. One nurse participant described the caring gesture of not always wearing gloves so a woman 
would not feel dirty: "Obviously, I washed my hands, but if I hand her [the patient] a remote, it wasn't like, 'Oh my gosh, it just eww, that's nasty."'

Making cruel gestures. Conversely, the women participants indicated that nurses made cruel gestures that obviously hindered trusting relationships. These gestures were acts by a nurse that left them feeling degraded and disheartened. They described instances in which a nurse engaged in eye rolling, made disparaging comments, or withheld pain medication in a punitive way. The women participants also described times when a nurse treated them unkindly because their babies were withdrawing. For example, nurses are responsible for completing a scale to score the severity of infants' withdrawal symptoms, and several women participants indicated a nurse had scored their infants poorly to retaliate against the women for their substance use. One stated, "She [a nurse] was lying is what she was doing. The day before she scores a one, but now she's scoring an eight, and then the next day she's scoring a one or a zero." The women participants also mentioned instances when a nurse refused to allow them to see, hold, or feed their infant. One woman participant stated, "So, I would drive up [to the NICU], and I would stay one to two hours, and I'd ask to feed her [infant] and hold her. I was told I could not hold my baby.”

The nurse participants described times they felt angry and frustrated toward a woman who used substances. However, they did not mention engaging in cruel gestures such as those described by the women participants.

Provision of care. The findings indicate that how maternity nurses provide care affected the formation of a trusting relationship with pregnant and postpartum women 
with SUDs. Participants indicated that provision of care is manifested as either providing effective care or limiting care.

Providing effective care. Women participants indicated that trusting relationships were facilitated when a nurse effectively met their care needs. They described instances when a nurse started their IVs easily, provided helpful assistance with breastfeeding, and assisted them with walking and showering after they delivered their infant. In some instances, their care needs were life-threatening. One woman participant shared such an instance:

So she [the nurse] was just really quick about getting me taken back there [the delivery room] and getting my IV and all that stuff in, to try to get me back to the anesthesiologist as soon as possible, which I did make it, barely, but she, I guess, stands out for me in that way. She made things get done.

In regards to providing effective care, the nurse participants often focused on pain management. They stressed the importance of advocating for women so their pain would be well managed, telling women when pain medications were due, and bringing their medications on time. One nurse participant who worked in labor and delivery and postpartum stated, "Keep their [patients'] medications going, on time, but if you miss a dose, even by 30 minutes, that's going to alter your relationship with them."

Limiting care. Women participants indicated a barrier to trusting relationships occurred when a nurse limited the care they provided to women because of their substance use. The women participants described instances in which a nurse did not bring needed infant supplies, failed to change their bedding, did not respond quickly when they asked for help, had difficulty starting their IVs, or withheld their pain medication. One woman participant stated, 
I had a seizure, well I had three back-to-back seizures. They [the nurses] let me just lay in the bed and they had my fiancé hold one of those tongue depressors down on my tongue and let me just, they just let him take care of me is what they were doing.

Another woman participant claimed she had to "fight tooth and nail" to get a nurse to give the woman pain medication.

The nurse participants acknowledged instances when they did only "the basics" when caring for a woman who used substances. One nurse participant who worked in labor and delivery recalled feeling angry with a woman who had been "partying" and delivered her infant in a toilet. The nurse participant stated,

I basically would get in and out of her room. Make sure she was stable and do the basics, but I didn't go above and beyond......... I think it was, I think from the provider, myself, I think we were kind of washing our hands, I hate to say it.

Another nurse participant who worked in labor and delivery stated, "I definitely cared for the baby, but I was not going overboard to try to give special care or anything to the mother, at that point."

Provision of information. The findings indicate that provision of information by maternity nurses affected the formation of trusting relationships with pregnant or postpartum women with SUDs. Participants indicated that provision of information is manifested as either keeping women well informed or leaving them in the dark.

Keeping women informed. Women participants indicated that trust was facilitated when a nurse provided information on a variety of topics such as breastfeeding and substance use, infant withdrawal, infant care, and medications given for substance use. They especially appreciated it when a nurse made an extra effort to provide personalized education. For example, one woman participant was particularly grateful when a nurse 
provided a tailored hand written diet plan rather than "something that she printed off the computer." However, women participants stressed that a nurse should present information as non-judgmental guidance rather than "telling a woman what to do."

The nurse participants also indicated that providing information promoted trust. One who worked as a lactation consultant described a positive encounter with a woman who used marijuana. The nurse described the effects of marijuana in breastmilk but did not insist the woman not breastfeed. She asserted, "I can't tell you [woman] what to do. I can tell you what will happen."

Keeping women in the dark. Women participants indicated that a barrier to a trusting relationship occurred when a nurse did not provide enough information. They resented it when a nurse did not communicate with them about their care or report on their infants' progress. Some described an instance in which a nurse just did her "job" and then left the room. One woman participant claimed, "I would ask questions and they [the nurses] would just get up and leave." Another woman participant was not told if her infant had been taken to the nursery or the NICU. She stated, "They [the nurses] didn't notify me of anything... I was really left in the dark about a lot of things."

The nurse participants did not describe instances in which they purposely withheld information but did describe instances when they felt that providing education was difficult or impossible. For example, several nurse participants described difficulty in providing education to women who were high when they came to deliver the infant. One nurse participant stated, "I felt like parenting education for her [patient] was not going to help her, that she was kind of just so far gone.” 
Attitude toward substance use. The findings indicate that the attitudes of maternity nurses toward substance use affected the formation of trusting relationships with pregnant and postpartum women with SUDs. The participants indicated that maternity nurses' attitude toward substance use, especially in regard to women's culpability for their addiction, was manifested by remarks that either absolved or condemned women for their substance use during pregnancy.

Absolving women for substance use. Women participants indicated trusting relationships were facilitated if a nurse made remarks that absolved women in some way for their substance use. They tended to "beat [themselves] up" for their substance use and its effects on their infants and appreciated nurses who made comments that helped eased the women's guilt. The women participants described times when a nurse reassured them they were not bad mothers, that any harm done to their babies was "not so bad," they were doing a good job with their baby, and they could make positive changes in their lives. One woman participant indicated her nurse said,

It's not just because you've done that [used substances], that doesn't mean you're a bad parent. There's parents out there beating their kids and doing all kinds of crazy stuff.... [Your substance use] doesn't mean you're bad or there's no hope for you.

Nurse participants also suggested that trust was enhanced if they helped ease a woman's guilt. One nurse participant who worked as a lactation consultant recalled working with a woman who was distraught that her baby tested positive for opioids and was experiencing withdraw symptoms. The nurse participant stated, "We counseled her and talked to her a lot and.... counseling to help her overcome her feelings of blame and blaming herself for all of this [baby withdrawing]." 
Condemning women for substance use. Conversely, women participants indicated that any remark by a nurse that condemned them for their substance use was a barrier to a trusting relationship. They were clear they could not trust a nurse who criticized them for their substance use or lifestyle or who lectured them about how they could have harmed their baby. These messages annoyed them because they were well aware of this danger. One woman participant said, "It really upset me, because I'm already in the situation I put myself in, so I don't need the nurse to remind me, because I already know."

Nurse participants admitted that they had at times condemned a woman for her substance use, especially because she had endangered the health of her infant. One nurse participant working with a woman in labor and delivery described her frustration when having difficulty starting an IV. The nurse participant explained,

I just remember it being frustrating, and I'm sure I wasn't the nicest nurse to that patient either. I was so frustrated that I couldn't get an IV site in, because she had destroyed her veins, and I love doing IVs.

This nurse participant revealed succumbing to the adage "treat her and street her." Other nurse participants referred to women who use substances during pregnancy as "methadone moms," "Suboxone moms," and "addicts."

Addiction expertise. The findings indicate that the addiction expertise of maternity nurses affected the formation of trusting relationships with pregnant and postpartum women with SUDs. The participants distinguished maternity nurses who had addiction expertise from those who did not.

Having addiction expertise. Women participants suggested that trusting relationships were facilitated when a nurse had knowledge about addictions and experience caring for women who struggled with addiction. They indicated a nurse with 
addictions expertise understood the women's difficulties and was more likely to support addiction treatment. For example, they described incidents in which a nurse praised them for entering treatment and assured them that this was "the right step." One woman participant stated, "When I left the hospital with him [her infant], they [the nurses] knew that I was going to treatment and they were just really supportive about it." The women participants suggested that nurses who had a family member with addiction were more compassionate because that nurse truly "understood" addiction.

Lacking addiction expertise. Some women participants indicated that a nurse's lack of addiction expertise was a barrier to a trusting relationship because the nurse could not to understand women's struggles. One woman participant stated, “They [nurses] don't understand. Some of them, I think they should be trained for addiction. That would be really nice." They suggested that pain management was especially problematic when a nurse lacked addiction expertise. One nurse had offered a woman participant an opioid pain medication instead of a preferable alternative pain management approach. The participant stated, "She [the nurse] was giving me Dilaudid and everything else, so that's just bad all around. And she still brought it. So, I wasn't going to turn it down, but I wish she would have said no."

The nurse participants also recognized that nurses often lacked addiction expertise. Many indicated they had not had any formal addiction training. Realizing it was important, a few had sought training outside of their place of employment. One nurse who worked in LDPR unit said, "You have to hope that your nurse knows that methadone and Nubain will react the way that [they] will, because several nurses have given it, even knowing the patient was on methadone." 


\section{Characteristics of Women with SUDs and Trusting Relationships}

The participants identified five characteristics of pregnant and postpartum women with SUDs that were manifested in ways that could either help or hinder the formation of trusting relationships with maternity nurses. The characteristics included engagement with nurses, demeanor towards nurses, acceptance of care, investment in recovery, and bonding with infant (see Table 3.1).

Engagement with nurses. The findings indicate that engagement by pregnant and postpartum women with SUDs with maternity nurses affected the formation of a trusting relationship. Participants suggested that engagement with maternity nurses was manifested by women either being open and forthcoming, especially about their substance use, or by being closed and distant.

Being open and forthcoming. Women participants indicated that trusting relationships were facilitated when they were able to engage with a nurse by "sharing their stories" and having the nurse do the same. One women participant stated, "We [she and the nurse] were connected, we were able to sit and have like heart-to-heart conversations." Another woman participant stated, "We [she and a nurse] sat down and cried together for two hours. Because she'd share a story about her daughter, and I'd share a story about myself."

The nurse participants felt they were better able to engage with a woman who used substances if she was open, honest, and forthcoming about her substance use and her situation. One nurse participant who worked in LDPR described a woman who was particularly open about her substance use. The participant said, "And just to have that trust between us, like she's telling me something that she knows could be an issue." 
Another nurse participant stated, "She [woman who used substances] was open and a lot of the nurses, I think at that point, our mind frame kind of shifted as far as what we thought about the [typical woman with addictions]."

Being closed and distant. Women participants did not mention instances when they were closed or distant in a way that hindered a relationship with a nurse. However, nurse participants indicated a woman's detachment served as a barrier to forming trust. The nurse participants describe instances in which a woman did not talk, make eye contact, or interact with them or requested they leave the room. One nurse participant who worked in labor and delivery recalled a woman she cared for during a cesarean section: "She just had this blank look on her face, and I remember her kind of rolling her eyes, [as if to say] "like whatever." Another nurse participant who worked in postpartum explained,

It was as if you [a nurse] would walk in and say, 'Hey, good morning. How are you? Can I get you anything?' And it was just as if the end of the world was near, and you had done the worst possible thing to them, and they didn't want to be bothered, and they didn't want to talk, and it was just [like they felt], 'Do what you need to do and get out, or do you have to do this? Can I refuse this? Get out.

Demeanor toward nurses. The findings indicate that the demeanor of pregnant and postpartum women toward maternity nurses affected the development of trusting relationships. Participants suggested that women's demeanor was manifested in either pleasant behaviors or hostile behaviors.

Displaying pleasant behaviors. The women participants did not mention times when they displayed pleasant behaviors that furthered trust in their relationships with a nurse. Nurse participants, however, did describe how it was easier to form a trusting relationship when a woman engaged in pleasant behaviors. They described instances 
when a woman was thankful for the care she received, behaved in a manner that was amiable, displayed a positive attitude, and did not complain. One nurse participant who worked in postpartum recalled offering to watch a woman's baby so she could walk around the hospital unit to relieve her pain. She stated, "And when she [woman] called me to bring her baby back, she was expressing how grateful she was." Another nurse participant who worked as a lactation consult stated, "She [woman] said, "Thanks for giving me the information,' and she was positive about it........ I felt good about that answer, because at least she wasn't being awful and rude and upset."

Displaying hostile behaviors. The women participants did not mention engaging in hostile behaviors that impeded a trusting relationship with a nurse. The nurse participants, however, discussed having difficulty establishing a trusting relationship with a woman who appeared hostile. They described instances in which a woman was argumentative, cursed, lied, attacked them, or acted "hateful." One nurse participant who worked in labor and delivery recalled working with a woman who was transferred to a psychiatric unit. The participant stated, "She [the woman] looked up at me, and I was behind the glass window. She looked up at me and if looks could kill, oh my gosh." Another nurse participant who worked in labor and delivery recalled an incident in which a woman's aggressive behavior had dire consequences:

She [woman] was out of control, came in and delivered precipitously. I went to give her IM Pitocin after delivery and I gave it to her and she swatted at me and I ended up poking myself. That was my first dirty needle stick.

The nurse participant disclosed that woman had hepatitis $\mathrm{C}$ and that the participant had to have lab draws for a year following the incident. 
Acceptance of care. The findings indicate that the attitudes of pregnant and postpartum women toward receiving help was important in the development of trusting relationships with maternity nurses. Participants suggested that these attitudes were manifested by women either accepting or rejecting help offered by a nurse.

Accepting help. Women participants did not mention times when accepting help from a nurse fostered trust. Nurse participants, however, described times when a trusting relationship was facilitated when a woman accepted their help. They described being pleased when a woman was "compliant" with her MAT for substance use, was open to receiving help, and did "what she was asked to do." One nurse participant who worked in postpartum stated, "She [woman] was very compliant, there all the time [at hospital visiting her infant]. She was kind of what I gauged everything moving forward on." Another nurse who worked in a LDPR spoke fondly of a woman who "never refused anything from me. I took care of her multiple times. She just did what she was told and took whatever medicines we were giving her that she was supposed to....."

Rejecting help. The woman participants did not mention instances when a trusting relationship with a nurse was impeded because they refused help. Nurse participants, however, indicated that they were unlikely to form a trusting relationship with a woman who rejected their help. They described instances in which a woman was not "compliant" or refused care. One nurse participant who worked in labor and delivery stated, "That [caring for a woman who was high] was not a great experience, because she was so far gone that she did not want help." Another nurse described a "typical" woman who was not receptive to the participant's help: "She was always wanting this and 
wanting that, or not listening to what I had to say, not letting me to do what I need to do as far as taking care of her."

Investment in recovery. The findings indicate that pregnant and postpartum women's investment in recovery affected the development of trusting relationships with maternity nurses. Participants suggested that women were either committed to recovery or they continued to actively use substances.

Commitment to recovery. Woman participants described times when their relationship with a nurse was facilitated if they showed a committed to recovery. For example, one woman participant stated, "They [the nurses] were all encouraging when they found out that I was coming to rehab..."

Nurse participants confirmed that they were more likely to form a trusting relationship with a woman who expressed a desire for sobriety, attempted to stop using substances, stopped using street substances, or sought treatment for substance use. In these situations, the nurse participants typically responded with praise and encouragement. A nurse participant who worked in LDPR stated, "So I felt like she [patient] was very brave and very in-tune with her body, and in control of her body, and she was willing to do whatever it took to fix this, whereas most people aren't." Another nurse participant who worked in labor and delivery described feeling proud of a woman who decided to seek help for her substance use: "I think she was using pain pills or something like that, and she knew that she had a problem. She got herself going to the methadone clinic."

Actively using substances. Women participants did not describe instances when their active substance use interfered with their relationship with a nurse. Nurse 
participants, however, described having difficulty trusting women who were actively using substances. They described times when a woman used substances in her hospital room, left the nursing unit to get high, was high when she delivered her infant, did not attempt to stop her substance use, and did not demonstrate a willingness to change her current situation. The nurse participants described how these behaviors made them angry, distrustful, and dismissive of the woman. One nurse participant who worked in labor and delivery described a situation in which a woman left the hospital unit and came back with "pills in her pocket." The nurse participant stated, "But the fact that she, I couldn't give her anything because I didn't know what she took downstairs. That's all I can say about that. I lost trust with her, definitely." Another nurse participant described a woman who hid heroin in the back of the toilet. She stated, "So, you get anxious around those patients, and clearly, they're lying to you, so you don't trust them."

Bonding with infant. The findings indicate that how pregnant and postpartum women bonded with their infants affected the development of a trusting relationship with maternity nurses. Participants suggested that how women bonded with their infants was manifested by how the women showed concern or lack of concern for their infants.

Showing concern for infant. Women participants did not suggest that showing concern for their infants facilitated a trusting relationship with a nurse. Nurse participants, however, described how a trusting relationship with a woman was facilitated if she showed love for her infant, participated in her infant's care, showed interest in her infant, wanted to comfort her infant, breastfed her infant, or showed remorse for her infant's withdrawal symptoms. One nurse participant who worked in labor and delivery stated, "She [women who used substances] loved her baby, the way I loved my babies, so 
I could identify with that." She went on to say, "She was trying to take care of herself and take care of her baby and she didn't want to lose the relationship [with her husband] over it, so I felt like a connection there."

Showing lack of concern for infant. Women participants did not discuss not showing concern for their infants. Nurse participants, however, commented that some women did not show concern for their infants and this impeded the formation of trust. The nurse participants described instances when a woman left her infant in the NICU or nursery, did not comfort her infant, did not visit her infant in the NICU, did not participate in the care of her infant, or left her infant at the hospital for CPS to find the infant a home. These behaviors made it difficult for the nurse participants to connect with the women. One nurse participant who worked in labor and delivery, postpartum, and nursery stated,

It was just difficult to watch and try to encourage [the woman] to spend time [with infant], but she was one that had a brick wall up and she would leave her room and go outside for a cigarette or whatever and then come back, but just not really want to take care of her baby.

Another nurse participant who worked in labor and delivery described a woman who did not visit her infant in the NICU. She stated,

There was a mom, we would try to call her and call her and call her, and she just wouldn't answer or she'd answer and have kind of a weak excuse for not being able to get to the hospital. It would just be frustrating.

\section{Discussion}

Fifteen maternity nurses and 10 women with SUDs during pregnancy and postpartum were interviewed to identify facilitators and barriers to the development of trusting nurse-patient relationships. The findings revealed that six characteristics of maternity nurses and five characteristics of the pregnant and postpartum women with 
SUDs influenced the building of trust. The six nurse characteristics are (1) rapportbuilding with women, (2) demeanor toward women, (3) provision of care, (4) provision of information, (5) attitude toward substance use, and (6) addiction expertise. The five women characteristics are (1) engagement with nurses, (2) demeanor toward nurses, (3) acceptance of care, (4) investment in recovery, and (5) bonding with infant.

A primary finding was that pregnant and postpartum women with SUDs trusted maternity nurses who showed caring, both by connecting with the women in a personal way (rapport-building with women) and engaging in caring acts (demeanor towards women), and distrusted nurses who did not show such caring. This finding echoes the findings of other published studies with general patient populations. For example, a literature review on trust in nurse-patient relationships by Dinc and Gastmans (2013) found that trust is a relational phenomenon associated with nurses showing a "sensitive and caring attitude" (p. 509). Similar to the current findings, this review revealed that the depersonalization of the patient hinders the development a trusting nurse-patient relationship. Also consistent with the current findings, a review of literature by Shattell (2004) found that patients describe positive experiences when their nurses make eye contact, are enthusiastic, and are willing to talk about their own lives. A systematic review by Rørtveit et al. (2015) also revealed that trust was experienced by patients who felt a nurse cared about them, accepted them as people, created a sense of belonging, and did not diminish them.

Another major finding of the current study was that trust developed when the maternity nurses provided competent care for pregnant and postpartum women with SUDs, both in carrying out direct care activities (provision of care) and in providing 
education (provision of information), and trust was hindered if the women perceived care to be incompetent. This also resonates with published studies with general patient populations. The literature review by Dinc and Gastmans (2013) revealed that trust develops when nurses have the ability to anticipate and meet care needs of patients, are prompt, follow through meeting care needs, and provide good advice. As found in the current study, this review also revealed that nurses' lack of knowledge or practice skills serves as a barrier to forming a trusting relationship. Rørtveit et al. (2015) also found that trust is facilitated when patients felt their nurses were competent and knowledgeable.

A third major finding of the current study was that pregnant and postpartum women trusted nurses who incorporated an understanding of addictions in providing care because they had experience working with patients with addictions (addiction expertise) and did not blame the women for their substance use (attitude toward substance use), and did not trust nurses who did not incorporate an understanding of addictions in their care. Other studies have shown that nurses' lack of addiction knowledge negatively influenced their relationships with pregnant and postpartum women with SUDs (Cleveland \& Bonguli, 2014; Demirci et al., 2015). Conversely, several studies have found that women who use substances were comfortable with nurses who had an understanding of the complex issues that surround addiction (Cleveland \& Bonguli, 2014; Mattocks et al., 2017; Suarez et al., 2017).

The results of the current study contribute to the literature by providing examples of how characteristics of patients who use substances affect nurse-patient relationships, an issue that has not been widely addressed. The findings suggest that trusting nursepatient relationships are more likely to occur when pregnant and postpartum women with 
SUDs are open (engagement with nurses) and amiable (demeanor toward nurses), viewed by nurses as "compliant" (acceptance of care), and committed to giving up substances (commitment to recovery). Nurses are more likely to detach from women are distant, hostile, "non-compliant" with care, or actively using substances. These results echo a review of literature by Shattell (2004) on nurse-patient interactions that found nurses distanced themselves and provided lower quality of care with patients that they viewed as "bad" or "difficult."

Some limitations need to be considered in regards to the findings. First, a limitation of the study is that the data were obtained retrospectively as both women and nurse participants in the study were asked to recall nurse-patient interactions that occurred in the past and might not have been able to recall some details due to the lapses in time and memory. Despite this potential limitation, with the exception of a few participants who did struggle to recall specific interactions, most were able to provide robust details of the interactions that they recalled, likely because the interactions were important to them. Moreover, the findings were limited by the convenience sampling strategy as the women participants and nurse participants were both recruited from single venues (i.e., AWHONN, treatment center). As a result, the lack of diversity within each sample limited conclusions that could be drawn. For example, because the majority of participants from both groups were White, no conclusions can be made in regards to the effects of ethnicity on the formation of trusting relationships. In addition, all the women participants were in treatment and it is possible that women who do not choose treatment may have had different relationships with nurses than those that do. Similarly, the nurse participants were all members of AWHONN and thus may have more knowledgeable 
about addictions and committed to professional advancement than nurses who do not belong to professional organizations. Another limitation of this study is that not surprisingly both groups, but especially the women, were more likely to reflect on how the characteristics of the other group, rather than their own, influenced trust.

Because of these limitations, future research on nurse-patient relationships in this population should be prospective; include larger, more diverse samples; examine the health care experiences of women throughout the period of perinatal care; include women who do not receive addiction treatment; and recruit maternity nurses from a variety of venues. Moreover, to more objectively describe nurse-patient encounters in this population, future studies should include a component in which encounters are observed, recorded, and analyzed to gain a more nuanced description of how the encounters unfold in real time.

The findings suggest three clinical implications for maternity nurses. First, they should consider how the nurse characteristics outlined in these findings are evidenced in their own nursing care of pregnant and postpartum women with SUDs. In working with this population, maternity nurses need to be attuned to how they might best use caring, empathetic, and nonjudgmental approaches. There were a few women in our sample who trusted their maternity nurses fully and experienced no barriers to care, and their experiences provide examples of best practices in providing care for this population. Our findings suggest, however, that some nurses may need to enhance their interpersonal skills when working with this population. Delaney, Shattell, and Johnson (2017) identified a model of interpersonal engagement based on Peplau's theory of interpersonal skills that includes six core elements: centering yourself, sending intent to listen, 
displaying empathy, becoming attuned to the patient, decoding and understanding the patient's story, and crafting a response. The goal of the model is to understand and validate the patient's experience and could serve as a framework for interacting with women with SUDs. Alexander (2017) suggested that providing compassionate care for women with addictions is enhanced by listening to their stories, reflecting on their stories, and affirming the women.

Second, maternity nurses should be knowledgeable about the challenges surrounding addiction and pregnancy through formal certification programs and professional development opportunities. Organizations that offer such education include the International Nurses Society on Addictions (n.d.), the Substance Abuse Mental Health Services Administration (U.S. Department of Health and Human Services, n.d.), and the American Psychiatric Nurses Association (2019). Schools of nursing need to include comprehensive addiction training especially related to the provision of care for pregnant and postpartum women with SUDs.

Third, maternity nurses may need professional role support to overcome barriers to caring for pregnant and postpartum women with SUDs - especially barriers encountered in caring for women who do not fit the norm of the "good patient." Support from other nurses and inter-professional colleagues can help nurses confront any biases that interfere caring for patients with SUDs (Neville \& Roan, 2014). Maternity nurses need opportunities to develop strategies to form trusting relationships with pregnant and postpartum women with SUDs and to improve the quality of care they provide for them and their infants. 


\section{Summary}

A qualitative descriptive approach (Sandelowski, 2000) was used to identify facilitators and barriers associated with the formation of trust between pregnant and postpartum women with SUDs and maternity nurses. Interviews were held with 10 women who had used substances during pregnancy and 15 nurses who worked in a variety of maternity settings. Using content analysis, six characteristics of nurses and five characteristics of women that either facilitated or hindered a trusting relationship were identified. Consistent with prior studies, findings revealed that trust was facilitated by maternity nurses who formed a caring connection, provided quality nursing care, and had expertise in addiction care and impeded by maternity nurses who did not have these characteristics. Trusting relationships were hindered when the women did not connect well with the nurses, rejected care, and showed little interest in recovery or connecting with their infants. The primary limitations of the study include the retrospective nature of data collection and the convenience sampling strategies. The findings suggest that maternity nurses should be provided opportunities to examine their biases related to the use of substances during pregnancy, develop strategies to provide the most compassionate and effective care to this population, and obtain education related to addictions in pregnancy. 
Table 3.1

Facilitators and Barriers to a Trusting Relationship

\begin{tabular}{|c|c|c|c|c|c|}
\hline $\begin{array}{l}\text { Nurse } \\
\text { Characteristics }\end{array}$ & Facilitators & Barriers & $\begin{array}{l}\text { Women } \\
\text { Characteristics }\end{array}$ & Facilitators & Barriers \\
\hline $\begin{array}{l}\text { Rapport- } \\
\text { building with } \\
\text { women }\end{array}$ & $\begin{array}{l}\text { Creating a } \\
\text { personal } \\
\text { connection }\end{array}$ & $\begin{array}{l}\text { Keeping a } \\
\text { personal } \\
\text { distance }\end{array}$ & $\begin{array}{l}\text { Engagement } \\
\text { with nurses }\end{array}$ & $\begin{array}{l}\text { Being open } \\
\text { and } \\
\text { forthcoming }\end{array}$ & $\begin{array}{l}\text { Being closed } \\
\text { and distant }\end{array}$ \\
\hline $\begin{array}{l}\text { Demeanor } \\
\text { toward women }\end{array}$ & $\begin{array}{l}\text { Making } \\
\text { caring } \\
\text { gestures }\end{array}$ & $\begin{array}{l}\text { Making cruel } \\
\text { gestures }\end{array}$ & $\begin{array}{l}\text { Demeanor } \\
\text { toward nurses }\end{array}$ & $\begin{array}{l}\text { Displaying } \\
\text { pleasant } \\
\text { behaviors }\end{array}$ & $\begin{array}{l}\text { Displaying } \\
\text { hostile } \\
\text { behaviors }\end{array}$ \\
\hline Provision of care & $\begin{array}{l}\text { Providing } \\
\text { effective care }\end{array}$ & Limiting care & $\begin{array}{l}\text { Acceptance of } \\
\text { care }\end{array}$ & $\begin{array}{l}\text { Accepting } \\
\text { help }\end{array}$ & $\begin{array}{l}\text { Rejecting } \\
\text { help }\end{array}$ \\
\hline $\begin{array}{l}\text { Provision of } \\
\text { information }\end{array}$ & $\begin{array}{l}\text { Keeping } \\
\text { women } \\
\text { informed }\end{array}$ & $\begin{array}{l}\text { Keeping } \\
\text { women in } \\
\text { the dark }\end{array}$ & & & \\
\hline $\begin{array}{l}\text { Attitude } \\
\text { toward } \\
\text { substance use }\end{array}$ & $\begin{array}{l}\text { Absolving } \\
\text { women for } \\
\text { substance use }\end{array}$ & $\begin{array}{l}\text { Condemning } \\
\text { women for } \\
\text { substance } \\
\text { use }\end{array}$ & $\begin{array}{l}\text { Investment in } \\
\text { recovery }\end{array}$ & $\begin{array}{l}\text { Commitment } \\
\text { to recovery }\end{array}$ & $\begin{array}{l}\text { Actively } \\
\text { using } \\
\text { substances }\end{array}$ \\
\hline \multirow[t]{2}{*}{$\begin{array}{l}\text { Addiction } \\
\text { expertise }\end{array}$} & $\begin{array}{l}\text { Having } \\
\text { addiction } \\
\text { expertise }\end{array}$ & $\begin{array}{l}\text { Lacking } \\
\text { addiction } \\
\text { expertise }\end{array}$ & & & \\
\hline & & & $\begin{array}{l}\text { Bonding with } \\
\text { infant }\end{array}$ & $\begin{array}{l}\text { Showing } \\
\text { concern for } \\
\text { infant }\end{array}$ & $\begin{array}{l}\text { Showing } \\
\text { lack of } \\
\text { concern for } \\
\text { infant }\end{array}$ \\
\hline
\end{tabular}




\section{CHAPTER 4}

\section{Introduction}

The purpose of this dissertation was to explore the health care experiences of women with SUDs during pregnancy and postpartum. Two studies were conducted. Study 1 (Chapter 2) was a metasynthesis of qualitative literature conducted to develop a taxonomy of health care encounters experienced by pregnant and postpartum women with SUDs. Study 2 (Chapter 3) was an empirical study conducted to more specifically examine the relationship between pregnant and postpartum women with SUDs and maternity nurses, focusing on facilitators and barriers associated with the development of trust in these relationships. This chapter contains a synthesis of the findings of Study 1 and Study 2, a discussion of how the findings link to Peplau's theory of interpersonal relationships, a description of strengths and limitations of the two studies, and a summary of implications for future research, theory, clinical practice, and policy.

\section{Synthesis of Findings}

The findings of Study 1 included eight types of health care encounters experienced by pregnant and postpartum women with SUDs. The findings of Study 2 built upon these findings by identifying six nurse characteristics and five patient characteristics that influenced the development of trust in encounters between maternity nurses and pregnant and postpartum women with SUDs. While Study 1 examined encounters with health care providers in general, and Study 2 examined encounters with maternity nurses in particular, there was resonance across both sets of findings. Therefore, the findings of both studies can be synthesized into three key findings. These key findings are discussed below. 
Key Finding 1: Adverse encounters between health care providers and pregnant and postpartum women with SUDs are common, but not universal, and often reflect stigma associated with substance use.

Four types of encounters identified in Study 1 - judgmental, disparaging, scrutinizing, and disempowering - were associated with perceived stigma related to substance use. The women suggested that providers looked down on them, were overtly critical of them, closely monitored them, and denied them control over their health care decisions because they used substances when pregnant. Study 2 expanded upon these findings by identifying behaviors of maternity nurses that hindered trust and were associated with stigma, including keeping a personal distance from the women and making cruel gestures toward them. Study 2 also expanded on the findings of Study 1 by identifying behaviors of the women that inhibited trust and exacerbated stigmatizing encounters, including being closed and distant and displaying hostility toward nurses. These behaviors seemed to fit the nurses' negative stereotypes of persons who use substances. Taken together, the findings of both studies indicate that stigma related to substance use influences health care encounters in profound ways.

However, one type of encounter identified in Study 1 - accepting encounters indicates that some women did not feel providers looked down on them because of their substance use. These women indicated that their health care providers did not judge them, communicated with them respectfully, shared personal information with them, and treated them the same as other patients who did not use substances. Study 2 built on these findings by revealing some maternity nurses created a personal connection and made caring gestures toward the women and some women were open and forthcoming 
with nurses and displayed pleasant behaviors. Together these findings indicate that, although less common, some health care encounters between pregnant and postpartum are marked by good interpersonal connections rather than stigma.

Key Finding 2: Adverse encounters between health care providers and pregnant and postpartum women with SUDs often, but not always, include not only negative interpersonal interactions but perceived lower quality of care.

One type of encounter identified in Study 1 - deficient-care encounters - was associated with compromised care. The women indicated that providers spent less time with them because they used substances and gave them less information than other women. Study 2 supported this finding by revealing maternity nurses often limited the care they provided the women and kept them in dark about their health, and women with SUDs often rejected the help nurses offered them. These findings jointly suggest that the health care outcome of lower perceived quality care is an important problem in this population.

Of note, however, one type of encounter identified in Study 1 - effective-care encounters - indicates that at least some women did not feel their care was compromised because they used substances. These women indicated they were informed about their care and that of their infants, provided with useful health information, given practical assistance and advice, and provided with the opportunity to discuss their concerns. Similarly, Study 2 revealed that some women felt maternity nurses provided effective care and kept them informed and some women readily accepted the help nurses offered them. Both sets of findings indicate some pregnant and postpartum women do perceive 
their care is effective, although not as commonly as women feel their care is compromised because of their substance use.

Key Finding 3: The addiction expertise of health care providers influence the types of encounters experienced between health care providers and pregnant and postpartum women with SUDs.

The extent to which providers had expertise in addictions influenced all the types of encounters identified in Study 1. The women believed that encounters with providers without addiction expertise were more likely to be stigmatizing and to result in poor care. Study 2 expanded upon this finding by revealing that some maternity nurses lacked addiction expertise and condemned women for their substance use and this was exacerbated when women were actively using substances. Findings from both studies thus indicate that providers' lack of addiction expertise related to the care of pregnant and postpartum women with SUDs is an important workforce issue.

However, one type of encounter identified in Study 1- recovery-based - indicates that some women felt supported by providers who addressed the women's substance use in a direct manner and encouraged them to attend substance use treatment. Study 2 findings were consistent as results revealed that some maternity nurses had addiction expertise and helped women resolve the guilt they felt for using substances, especially if the women were committed to recovery. Taken together, these findings indicate that some providers do have addiction expertise that positively influences their encounters with pregnant and postpartum women with SUDs. 


\section{Study Findings and Peplau's Theory of Interpersonal Relationship}

The findings of this dissertation study support several premises of Peplau's $(1952,1988,1997)$ theory of interpersonal relations. One of the major premises is that trust in essential in establishing the nurse-patient relationship. Consistent with this premise, the findings of Study 2 revealed that pregnant and postpartum women with SUDs were able to form a trusting relationship with maternity nurses who created a personal connection with women, made caring gestures toward them, provided effective care, kept them informed, absolved them of guilt associated with substance use, and had addiction expertise. Another major premise of the theory was that nurses should view their patients as people rather than as medical conditions, and nurses need to have knowledge about what is important to patients. Study 2 indicated that pregnant and postpartum women with SUDs developed trusting relationships with nurses who created a personal connection with the women, spent extra time with them, shared personal information with them, and listened to their stories. These activities reflected efforts by nurses to get to know the women not just as patients who used substances but as women with unique life experiences, needs and struggles. A third major premise of the theory that is reflected in the study findings is that nurses face challenges that can interfere with establishing the nurse-patient relationship. Study 2 uncovered several of these challenges; some nurses held negative attitudes toward the women because of their substance use, avoided dealing their difficult behaviors, used disrespectful or judgmental modes of addressing them, and avoided making a personal connection with them.

Some of the findings of the studies, however, extended beyond the main premises of the theory of interpersonal relationships $(1952,1988,1997)$. For example, the theory 
focused on nurse-patient relationships that occur in stages over time, whereas many of the encounters described by the participants, especially in Study 2, were brief or one-time interactions. In addition, Peplau's theory (1997) does not address extensively how the patients' behaviors contribute to the nurse-patient interactions and these behaviors were an important focus of Study 2. These limitations have implications for further theory development as will be discussed below.

\section{Strengths and Innovation}

The findings of this dissertation expand the current literature by providing indepth descriptions of types of health care encounters experienced by pregnant and postpartum women with SUDS and a delineation of the facilitators of and barriers to the development of trusting relationships with maternity nurses. These descriptions contribute to our understanding of how women's substance use during pregnancy can impact these encounters and affect the women's health care experiences due to the stigma associated with substance use in general and, more specifically, substance use during pregnancy.

The findings of Study 1 contribute to the literature by providing a synthesis of existing qualitative study findings of how pregnant and postpartum women experience health care encounters in prenatal care, labor and delivery, postpartum, and nursery/NICU setting. Sandelowski and Barroso (2007) argued that the findings of qualitative studies are underutilized because the findings of individual studies on the same topic are often not linked in a systematic way and therefore interpretations that can be drawn from any one study are limited. Linking the findings of multiple studies through systematic qualitative metasynthesis increases their interpretive value and can 
make a greater contribution to evidence-based practice. The taxonomy developed in Study 1 is based on many studies with samples of varying sizes and therefore provides a more solid foundation from which to draw conclusions than any one study on its own. Because a metasummary approach was used, the study produced straightforward narrative descriptions of the types of encounters and these descriptions can be used to inform policy, practice, and research.

The findings of Study 2 will also contribute to the literature in important ways. Study 2 is the first study to explore in-depth the development of trust between maternity nurses and pregnant and postpartum women with SUDs. Including the perspectives of both the women and maternity nurses allowed for a balance of perspectives and a rich discussion related to trust in the nurse-patient relationship. Despite the sensitive topic, both the women and the nurses were easily recruited to the study, seemingly because the topic was of concern to them. The researcher's background as a maternity nurse also seemed to promote rapport with the participants. Most all of the participants of the interview study were open and freely shared their experiences and thus the findings are based on rich and informative descriptions of health care encounters. The structure of the interview guide, which ensured participants were invited to discuss both positive and negative experiences, added to the comprehensiveness of the findings. Other methodological strengths of both studies included extensive peer debriefing with the researcher's dissertation chair and committee, which enriched the findings and enhanced the validity of the study. 


\section{Limitations}

The findings of this dissertation are best understood within the context of limitations. The data sets of Study 1 or Study 2 were not large and/or heterogeneous enough to draw conclusions about group influences on the health care experiences of the participants. Because most of the primary studies in the metasummary of Study 1 did not routinely address sociodemographic variation in their samples, and the two samples of Study 2 were relative homogenous and drawn from single venues, the studies did not account for how the health care experiences were influenced by demographic characteristics such as age, race, religion, and other factors or by type of maternity setting (e.g., labor and delivery versus postpartum).

Additional limitations of the Study 1 were as follows: (a) The findings in all the reports were primarily descriptive versus theoretical or interpretive, thereby limiting the opportunity to advance theory regarding the phenomenon, and (b) The findings of the primary reports were based solely on women's perspectives and did not include providers' perspectives thus limiting an understanding of how providers viewed the women's contributions to the encounters.

Additional limitations for Study 2 were as follows: (a) Data were obtained retrospectively which increased the risk of recall bias, (b) Because of our recruitment strategies, conclusions cannot be made about the views of maternity nurses who do not participate in a professional organizations or pregnant and postpartum with SUDs who are not in treatment for their substance use, and (c) Both the nurse and women participants were more likely to reflect on the characteristics of the other group rather 
than their own characteristics which restricted our description of some of the barriers and facilitators.

\section{Research Implications}

Future studies should be conducted that address the limitations of the studies of this dissertation. The next step in this research trajectory is to conduct studies that (a) include larger samples with more diverse demographic characteristics, (b) explore differences among different maternity settings, and (c) observe or record health care encounters in real-time. Studies aimed at developing a theoretical framework that describes how health care encounters unfold over time is needed. Such a framework could be used to develop interventions aimed at improving the quality of relationships between health care providers and pregnant and postpartum women with SUDs. Once these interventions are developed, research would focus on evaluating their efficacy and effectiveness.

\section{Clinical Implications}

While more research is needed to develop theoretically based interventions to improve the health care encounters of pregnant and postpartum women with SUDs, the findings of this dissertation do support a number of clinical implications for health care providers. The following recommendations are based on the three key findings.

First, because the findings indicate that pregnant and postpartum women often experience adverse encounters due to the stigma associated with the use of substances during pregnancy, all health care providers who work with this population should reflect on the influence of stigma on their own attitudes and behaviors. Providers should first examine whether their interactions women who use substances could be perceived as 
disapproving or judgmental by the women. As biases against women who use substances may be unconscious and difficult to recognize, providers should seek educational and training programs on ways to mitigate the influence of implicit bias in their practice and improve patient-provider communication related to the sensitive topic of substance use during pregnancy. For example, the intervention LINKAGE, which was developed by Weisner and colleagues (2016), has been shown to improve patient engagement and communication with physicians who work with patients with SUDs.

Second, because findings indicate that many pregnant and postpartum women with SUDs perceive their care to be compromised because they use substances, providers should evaluate their own practices and seek out supervision and peer support to ensure they are not compromising the care they provide to the women and their infants. Quality care needs to include fully informing woman of their health status and care plan, empowering them to make decisions regarding their care and promoting activation, spending adequate time when caring for them, and carrying out all care tasks, such as starting IVs and managing the women's pain, in a professional and efficient manner. Providers in pregnancy, labor and delivery, postpartum, and nursery/NICU settings should collaborate with substance use treatment providers to devise a treatment plan aimed at providing optimal outcomes for mother and infant.

Third, because findings indicate that lack of provider expertise in addiction care contributes to adverse encounters and deficient maternity care, providers should obtain this expertise through a variety of venues. Professional school curricula should include comprehensive content on addictions and provide adequate clinical opportunities in all maternity settings for students to obtain the knowledge and skills needed to provide 
addiction care. Practicing health care providers should seek opportunities to learn more about addictions through professional certifications such as offered by Substance Abuse Mental Health Services Administration (U.S. Department of Health and Human Services, n.d.) and other health organizations. Moreover, providers should also be aware of addiction resources that are available to women during pregnancy and postpartum including community substance use treatment centers, MAT providers, and other local programs that provide recovery support.

\section{Public Policy Implications}

Study findings indicate that policies such as the criminalization of substance use during pregnancy and the removal of children by CPS can affect women's relationships with health care providers. Women distrust providers who the women fear might report their substance use and, in some instances, avoid care because of this. Health care providers should advocate for policies that protect and promote the health of pregnant and postpartum women with SUDs and improve maternal-child health outcomes. Policies should support recovery rather than punishment, encourage women to disclose their substance use during pregnancy, and support women who seek substance use treatment while pregnant. Treatment for SUDs during pregnancy should be readily accessible to women and should be coordinated with their maternity care. Because treatment programs are not readily available for all women, providers need to advocate for funding for these recovery programs, especially residential maternal treatment programs where women can live with their children during their recovery. 


\section{Conclusion}

The findings of this dissertation reveal that pregnant and postpartum women with SUDs often experience a number of different types of adverse and beneficial health care encounters with their health care providers. The adverse encounters are often influenced by the stigma related to use of substances during pregnancy. The findings also reveal that a variety of characteristics of maternity nurses and pregnant and postpartum women either help or hinder the development of trusting nurse-patient relationships. The findings of this dissertation study support Peplau's $(1952,1988,1997)$ theory of interpersonal relations, which focuses on the importance of trust, personal connection, and knowledge of the person in the provider-patient relationship. Additional research on the health care experiences of pregnant and postpartum women with SUDs is needed to build theory and development interventions to improve the health care of this population. Clinical recommendations include education, training, supervision, and support in mitigating implicit bias, improving communication skills, and providing addictions care. Advocating for public policies that support recovery and promote the optimal health care outcomes for women and their infants is recommended. 


\section{APPENDICES}

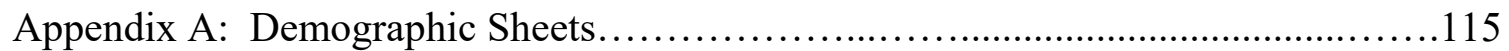

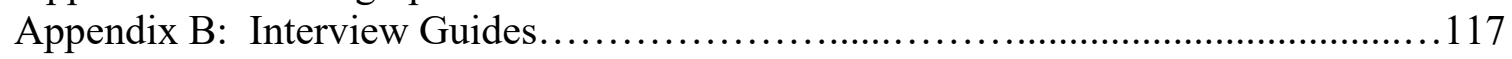


Appendix A

Demographic Sheets

\section{Nurse Participants}

1. What is your age?

2. What is your ethnicity?

3. Do you affiliate with a religious group? If so, which religion?

4. What is your gender?

5. What is your estimated annual household income?

6. What setting do you work in currently?

7. What is your role? (e.g., staff nurse, charge nurse, office nurse?)

8. What areas of maternity nursing have you worked in in the past?

9. How many years of experience do you have working in a maternity area?

10. How many years of nursing experience have you had? 


\section{Women Participants}

1. How old are you?

2. What is your race or ethnicity?

3. What was the highest level of education that you have completed?

4. How many children do you have?

5. How old are your children?

6. Did you use any of the following during your pregnancy?

\begin{tabular}{|c|c|c|c|}
\hline Opioids & Yes & No & Unsure/ No answer \\
\hline Methamphetamine & Yes & No & Unsure/ No answer \\
\hline Nicotine & Yes & No & Unsure/ No answer \\
\hline Heroin & Yes & No & Unsure/No answer \\
\hline Cocaine & Yes & No & Unsure/ No answer \\
\hline $\begin{array}{l}\text { Prescription pain } \\
\text { killers without a } \\
\text { prescription }\end{array}$ & Yes & No & Unsure/No answer \\
\hline $\begin{array}{l}\text { Prescription pain } \\
\text { killers differently } \\
\text { than prescribed }\end{array}$ & Yes & No & Unsure/No answer \\
\hline Benzodiazepines & Yes & No & Unsure/No answer \\
\hline Alcohol & Yes & No & Unsure/No answer \\
\hline Marijuana & Yes & No & Unsure/No answer \\
\hline $\begin{array}{l}\text { Methadone: } \\
\text { with a prescription } \\
\text { without a prescription }\end{array}$ & $\begin{array}{l}\text { Yes } \\
\text { Yes }\end{array}$ & $\begin{array}{l}\text { No } \\
\text { No }\end{array}$ & $\begin{array}{l}\text { Unsure/ No answer } \\
\text { Unsure/No answer }\end{array}$ \\
\hline $\begin{array}{l}\text { Suboxone: } \\
\text { with a prescription } \\
\text { without a prescription }\end{array}$ & $\begin{array}{l}\text { Yes } \\
\text { Yes }\end{array}$ & $\begin{array}{l}\text { No } \\
\text { No }\end{array}$ & $\begin{array}{l}\text { Unsure/No answer } \\
\text { Unsure/No answer }\end{array}$ \\
\hline $\begin{array}{l}\text { Subutex: } \\
\text { with a prescription } \\
\text { without a prescription }\end{array}$ & $\begin{array}{l}\text { Yes } \\
\text { Yes }\end{array}$ & $\begin{array}{l}\text { No } \\
\text { No }\end{array}$ & $\begin{array}{l}\text { Unsure/No answer } \\
\text { Unsure/No answer }\end{array}$ \\
\hline Other (please list): & Yes & No & Unsure/ No answer \\
\hline
\end{tabular}


Appendix B

Interview Guides

\section{Maternity Nurse Interview Guide}

-Hi, my name is Kalyn and I am registered nurse and a PhD student at Indiana School of Nursing. I want to thank you for participating in this study. I am interested in understanding the nature of relationships between maternity nurses and pregnant and postpartum women with SUDs. The answers you provide will be useful in identifying ways in which we as nurses can improve our relationships with pregnant and postpartum women with SUDs. As you know, I am going to ask you questions about your relationship with pregnant and postpartum women with SUDs when working as a maternity nurse.

-You have experience working in a [prenatal, labor and delivery, postpartum, or NICU setting]. Tell me about your experiences working with [pregnant and/or postpartum] women with SUD's.

-Our nursing research has indicated that nurses can have positive, not so positive, and typical interactions with pregnant/postpartum women with SUDs. I am going to ask you to talk about a positive interaction, a not so positive interaction, and typical or routine interaction with women with SUDs while working as their nurse. Without telling me the women's names, I am going to ask you think back to some specific pregnant or postpartum women with SUDs for whom you provided care and the interactions you had with them.

-I would like you to think of an interaction that you had with pregnant or postpartum women that you would consider positive. Describe that interaction how did it begin, what happened during the interaction, what was most memorable about it, what made it positive? What substances can you recall that this patient had been identified as using in pregnancy? (Ask if there are other positive interactions the participant would like to discuss and repeat the same questions.)

-I would like you to think of an interaction that you had with pregnant or postpartum women that was not so positive. Describe that interaction - how did it begin, what happened during the interaction, what was most memorable about it, what made it not so positive? What substances can you recall that this patient had been identified as using in pregnancy? (Ask if there are other not so positive interactions the participant would like to discuss and repeat the same questions.)

-I would like you to think of an interaction that you had with pregnant or postpartum women that you might consider typical - not necessarily positive or negative but routine. Describe that interaction - how did it begin, what happened during the interaction, what was most memorable about it, what made it typical? 
What substances can you recall that this patient had been identified as using in pregnancy? (Ask if there are typical interactions the participant would like to discuss and repeat the same questions.)

-We believe it is important that maternity nurses and women develop trusting relationships but are not quite sure what helps the development of trusting relationships. Thinking back to the relationships you had with pregnant and postpartum women you have cared for, were there certain things that helped you develop trust with them?

-Were there certain things that got in the way of you developing trust with them?

-Are there any ways in which the women's substance use influenced your relationships with them? If so, give me some examples of when this occurred.

-Are there any things that you believe would be important for maternity nurses to know that would help them provide better care for women during pregnancy and postpartum?

-What type of addiction training or education have you received while working as a nurse? 


\section{Women Participant Interview Guide}

-Hi, my name is Kalyn and I am registered nurse and a $\mathrm{PhD}$ student at Indiana School of Nursing. I want to thank you for participating in this study. I am interested in understanding interactions that new mothers have with nurses before, during, and after the birth of a child. The answers you provide will be useful in identifying ways nurses can be more helpful when working with new mothers. As you know, I am going to ask you questions about your relationship with your maternity nurses when [baby's name] was born.

-[Baby’s name] is now __ months old. Tell me about [baby's name].

-Take me back to the time when [baby's name] was born. Tell me about what your hospital experience was like when [baby's name] was born.

-We are really interested in understanding all sorts of experiences mothers have with their maternity nurses. We would like to hear about several interactions that you had with your nurses. Sometimes new mothers' interactions with their nurses are positive, while others are not so positive, and others are typical or routine. Take a moment to think back to your health care experiences surrounding your pregnancy and birth of [baby's name]. I would like you to think of an interaction that you had with a maternity nurse that you would consider positive. Describe that interaction - how did it begin, what happened during the interaction, what was most memorable about it, what made it positive? (Ask if there are other positive interactions the participant would like to discuss and repeat the same questions.)

-Now I would like you to think back to an interaction that you had with a nurse that was not so positive - for any reason. Describe that interaction - how did it begin, what happened during the interaction, what was most memorable about it, what made it not so positive? (Ask if there are other not so positive interactions the participant would like to discuss and repeat the same questions.)

-Now I would like you to think back to an interaction that you had with a nurse that was neither especially positive or not so positive - one that was routine or typical. Describe that interaction - how did it begin, what happened during the interaction, why would you describe it as typical, what made it typical? (Ask if there are other routine or typical interactions the participant would like to discuss and repeat the same questions.)

We believe it is important that maternity nurses and women develop trusting relationships but are not quite sure what helps the development of trusting relationships. Thinking back to the relationships you had with your nurses, were there certain things that helped you develop trust in your nurses?

-Were there certain things that got in the way of you developing trust in your nurses? 
-As you know, we are conducting this study with women who used substances during pregnancy or postpartum. Were there any ways in which your substance use influenced your relationships with your nurses? If so, give me some examples of when this occurred.

-Are there any things that you believe would be important for maternity nurses to know that would help them provide better care for women during pregnancy and postpartum? 


\section{REFERENCES}

Alexander, K. (2017). A call for compassionate care. Journal of Addictions Nursing, 4, 220-223. https://doi.org/10.1097/JAN.000 0000000000198

American Congress of Obstetricians and Gynecologists (n.d.). Toolkit on state legislation: Pregnant women and prescription drug abuse, dependence and addiction. Available at: http://www.acog.org/ /media/Departments

American Psychiatric Association. (2013). Diagnostic and statistical manual of mental disorders (5th ed.). American Psychiatric Publishing.

American Psychiatric Nurses Association, APNA eLearning Center (2019). https://e-learning.apna.org/

Amnesty International (2017). Criminalizing Pregnancy: Policing pregnant women who use drugs in the USA. https://www.amnesty.org/download/Documents/AMR5162032017ENGLISH.pdf

Ashford, R., Brown, A., \& Curtis, B. (2018). Substance use, recovery, and linguistics: The impact of word choice on explicit and implicit bias. Drug Alcohol Dependency (189), 131-138. https://doi.org/10.1016/j.drugalcdep.2018.05.005

Berens, P. (2018). Overview of the postpartum period, physiology, complications and maternal care. https://www.uptodate.com/contents/overview-of-the-postpartumperiod-physiology-complications-and-maternal-care\#H1

Best, D., Segal, J., \& Day, E. (2009). Changing patterns of heroin and crack use during pregnancy and beyond. Journal of Substance Use, 14(2), 124-132.

Birkhauer, J., Gaab, J., Kossowsky, J., Hasler, S., Krummenacher, P., Werner C., \& Gerger, H. (2017). Trust in the health care professional and health outcome: A meta-analysis. PLoS ONE 12(2): e0170988.

https://doi.org//10.1371/journal.pone.0170988

Centers for Disease Control and Prevention (2007). CDC Congressional Testimony. http://www.cdc.gov/washington/testimony/2007/t20071024.htm.

Chan, C., \& Moriarty, H. (2010). A special type of hard-to-reach patient: Experiences of pregnant women on methadone. Journal of Primary Health Care, 2(1), 61-69. https://doi.org/10.1071/HC10061

Cleveland, L. M., \& Bonugli, R. (2014). Experiences of mothers of infants with neonatal abstinence syndrome in the neonatal intensive care unit. Journal of Obstetric, Gynecologic \& Neonatal Nursing, 43(3), 318-329. https://doi.org/10.1111/15526909.12306

Cleveland, L. M., Bonugli, R. J., \& McGlothen, K. S. (2016). The mothering experiences of women with substance use disorders. Advances in Nursing Science, 39(2), 119129. https://doi.org/10.1097/ANS.0000000000000118

Cleveland, L. M., \& Gill, S. L. (2013). 'Try not to judge' mothers of substance exposed infants. MCN: The American Journal of Maternal Child Nursing, 38(4), 200-205. https://doi.org/10.1097/NMC.0b013e31827816de

Compton, W. M., Thomas, Y. F., Stinson, F. S., \& Grant, B. F. (2007). Prevalence, correlates, disability, and comorbidity of DSM-IV drug abuse and dependence in the United States: Results from the national epidemiologic survey on alcohol and related conditions. Arch Gen Psychiatry, 64(5), 566-576

https://doi.org/10.1001/archpsyc.64.5.566 
Cook, J. L., Green, C. R., de la Ronde, S., Dell, C. A., Graves, L., Ordean, A., Ruiter, J., Steeves, M., \& Wong, S. (2017). Epidemiology and effects of substance use in pregnancy. Journal of Obstetrics and Gynaecology Canada, (39) 10, 906-915. https://doi.org/10.1016/j.jogc.2017.07.005

Cox, R. G., Zhang, L., Zotti, M. E., \& Graham, J. (2011). Prenatal care utilization in Mississippi: Racial disparities and implications for unfavorable birth outcomes. Maternal and Child Health Journal, 15(7), 931-942. https://doi.org/10.1007/s10995-009-0542-6

Cresswell, J. W. \& Plano Clark, V. L. (2011). Designing and conducting mixed method research ( $2^{\text {nd }}$ ed.). SAGE.

Delaney, K. R., Shattell, M., \& Johnson, M. E., (2017). Capturing the interpersonal process of psychiatric nurses: A model of engagement. Archives of Psychiatric Nursing, 31, 634-640.

Demirci, J. R., Bogen, D. L., \& Klionsky, Y. (2015). Breastfeeding and methadone therapy: The maternal experience. Substance Abuse, 36(2), 203-208. https://doi.org/10.1080/08897077.2014.902417

Desai, R. J., Hernandez-Diaz, S., Bateman, B. T., \& Huybrechts, K. F. (2014). Increase in prescription opioid use during pregnancy among medicaid-enrolled women. Obstetrics and Gynecology, 123(5), 997-1002. https://doi.org/10.1097/AOG.0000000000000208

Dinc, L. \& Gastmans, C. (2013). Trust in nurse-patient relationships: A literature review. Nursing Ethics, 20 (5), 501-516. https://doi.org/10.1177/0969733012468463

Elo, S., Kääriäinen, M., Kanste, O., Pölkki, T., Utriainen, K., \& Kyngäs, H. (2014). Qualitative content analysis: A focus on trustworthiness. SAGE Open, 4(1), 2158244014522633. https://doi.org/10.1177/2158244014522633

El-Mohandes, A., Herman, A. A., El-Khorazaty, M. N., Katta, P. S., White, D., Grylack, L. (2003). Prenatal care reduces the impact of illicit drug use on perinatal outcomes. Journal of Perinatology, 23, 354-360. https://doi.org10.1038/sj.jp.7210933

Elwyn, G., Coulter, A., Laitner, S., Walker, E., Watson, P., \& Thomson, R. (2010). Implementing shared decision making in the NHS. BMJ, 341(c5146).

Eunice Kennedy Shriver National Institute of Child Health and Human Development (2020). Pregnancy. https://www.nichd.nih.gov/health/topics/pregnancy

Falletta, L., Hamilton, K., Fischbein, R., Aultman, J., Kinney, B., \& Kenne, D. (2018). Perceptions of child protective services among pregnant or recently pregnant, opioid-using women in substance abuse treatment. Child Abuse \& Neglect, 79, 125-135. https://doi.org/10.1016/j.chiabu.2018.01.026

Fallin-Bennett, A., \& Ashford, K. (2017). Tailoring a NICU-based tobacco treatment program for mothers who are dependent on opioids. Journal of Obstetric, Gynecologic, and Neonatal Nursing: JOGNN, 46(5), 660-668. https://doi.org10.1016/j.jogn.2017.06.007

Fingar, K. R., Stocks C., Weiss, A. J., \& Owens, P. L. (2015). Neonatal and maternal hospital stays related to substance use, 2006-2012: Statistical brief \#193. 2015 Jul. In: Healthcare Cost and Utilization Project (HCUP) Statistical Briefs 
[Internet]. Rockville (MD): Agency for Healthcare Research and Quality (US); https://europepmc.org/books/NBK316155;jsessionid=BEC50D21EA7042

Forray, A. (2016). Substance use during pregnancy. F1000Research, 5, F1000 Faculty Reviews-1887. https://doi.org/10.12688/f1000research.7645.1

Fraser, J. A., Barnes, M., Biggs, H. C., \& Kain, V. J. (2007). Caring, chaos and the vulnerable family: Experiences in caring for newborns of drug-dependent parents. International Journal of Nursing Studies, 44(8), 1363-1370. https://doi.org/10.1016/j.ijnurstu.2006.06.004

Gilchrist, G., Cameron, J., Nicolson, S., Galbally, M., \& Moore, P. (2012). Reducing depression among perinatal drug users - what is needed? A triangulated study. Advances in Dual Diagnosis, 5(4), 164-175. https//doi.org/10.1108/17570971211281666

Goffman, E. (1963). Stigma: Notes on a spoiled identity. Jenkins, JH \& Carpenter.

Goler, N. C., Armstrong, M. A., Taillac, C. J., \& Osejo, V. M. (2008). Substance abuse treatment linked with prenatal visits improves perinatal outcomes: A new standard. Journal of Perinatology, 28, 597. https://doi.org/10.1038/jp.2008.70

Guttmacher Institute (2019). Substance use during pregnancy. https://www.guttmacher.org/state-policy/explore/substance-use-duringpregnancy.

Haight, S. C., Ko, J. Y., Tong, V. T., Bohm, M. K., \& Callaghan, W. M. (2018). Opioid use disorder documented at delivery hospitalization - United States, 1999-2014. MMWR Morbidity Mortality Weekly Report, 67:845-849. https://doi.org/10.15585/mmwr.mm6731a1

Hall, J. L., \& van Teijlingen, E. R. (2006). A qualitative study of an integrated maternity, drugs and social care service for drug-using women. BMC Pregnancy and Childbirth, 6(1), 19. https://doi.org/10.1186/1471-2393-6-19

Harvey, S., Schmied, V., Nicholls, D., \& Dahlen, H. (2015). Hope amidst judgement: The meaning mothers accessing opioid treatment programmes ascribe to interactions with health services in the perinatal period. Journal of Family Studies, 21(3), 282-304. https://doi.org/10.1080/13229400.2015.1110531

Hibbard, J. H., Stockard, J., Mahoney, E. R., \& Tusler, M. (2004). Development of the Patient Activation Measure (PAM): Conceptualizing and measuring activation in patients and consumers. Health Services Research. 39(4 Pt 1),1005-26.

Hicks, J., Morse, E., \& Wyant, D. K., (2018). Barriers and facilitators of breastfeeding reported by postpartum women in methadone maintenance therapy. Breastfeeding Medicine, 13(4), 259-265. https://doi.org10.1089/bfm.2017.0130

Holland, C. L., Nkumsah, M. A., Morrison, P., Tarr, J. A., Rubio, D., Rodriguez, K. L., Kraemer, K.L., Day, N., Arnold, R.M., \& Chang, J. C. (2016). “Anything above marijuana takes priority": Obstetric providers' attitudes and counseling strategies regarding perinatal marijuana use. Patient Education and Counseling, 99(9), 1446-1451. https://doi.org/10.1016/j.pec.2016.06.003

Howard, H. (2015). Reducing stigma: Lessons from opioid-dependent women. Journal of Social Work Practice in the Addictions, 15(4), 418-438. https://doi.org/10.1080/1533256X.2015.1091003 
Howard, H. (2016). Experiences of opioid-dependent women in their prenatal and postpartum care: Implications for social workers in health care. Social Work in Health Care, 55(1), 61-85. https://doi.org/10.1080/00981389.2015.1078427

Hsieh, H. F. \& Shannon, S. E. (2005). Three approaches to qualitative content analysis. Qualitative Health Research, 15(9), 1277-1288.

Hudak, M. L., \& Tan, R. C. (2012). Neonatal drug withdrawal. Pediatrics, 129(2), e540. https://doi.org/10.1542/peds.2011-3212

International Nurses Society of Addictions (n.d.). Examination and Recertification. https://www.intnsa.org/ancb/certification/

Jarlenski, M., Tarr, J. A., Holland, C. L., Farrell, D., \& Chang, J. C. (2016). Pregnant women's access to information about perinatal marijuana use: A qualitative study. Women's Health Issues : Official publication of the Jacobs Institute of Women's Health, 26(4), 452-459. https://doi.org/10.1016/j.whi.2016.03.010

Jessup, M.A., Humphreys, J. C., Brindis, C. D., \& Lee, K. A. (2003). Extrinsic barriers to substance abuse treatment among pregnant drug dependent women. Journal of Drug Issues, 33(2), 285-304. https://doi.org/10.1177/002204260303300202

Jones, C. M., Logan, J., Gladden, R. M., \& Bohm, M. K. (2015). Vital signs: demographic and substance use trends among heroin users - United States, 2002-2013. MMWR Morbidity and Mortality Weekly Report, 64(26), 719-725

Klaman, S., Isaacs, K., Leopold, A., Perpich, J., Hayashi, S., Vender, J., Campopiano, M., \& Jones, H. (2017). Treating women who are pregnant and parenting for opioid use disorder and the concurrent care of their infants and children: Literature review to support national guidance. Journal of addiction medicine, 11(3), 178-190. https://doi.org/10.1097/ADM.0000000000000308

Knaak, S., Mantler, E., \& Szeto, A. (2017). Mental illness-related stigma in healthcare: Barriers to access and care and evidence-based solutions. Healthcare Management Forum, 30(2), 111-116. https://doi.org/10.1177/0840470416679413

Ko, J.Y., Patrick, S. W., Tong, V. T., Patel, R., Lind, J. N., \& Barfield, W. D. (2016). Incidence of neonatal abstinence syndrome - 28 States, 1999-2013. MMWR Morbidity Mortality Weekly Report 65,799-802. https://doi.org/10.15585/mmwr.mm6531a2

Kotelchuck, M., Cheng, E. R., Belanoff, C., Cabral, H. J., Babakhanlou-Chase, H., Derrington, T. M., Diop, H., Evans, S. R., \& Bernstein, J. (2017). The prevalence and impact of substance use disorder and treatment on maternal obstetric experiences and birth outcomes among singleton deliveries in Massachusetts. Maternal Child Health Journal, 21(4), 893-902. https://doi.org/10.1007/s10995016-2190-y

Kramlich, D., Kronk, R., Marcellus, L., Colbert, A., \& Jakub, K. (2018). Rural postpartum women with substance use disorders. Qualitative Health Research, 28(9), 1449-1461. https://doi.org/10.1177/1049732318765720

Krans, E. E., \& Patrick, S. W. (2016). Opioid use disorder in pregnancy: Health policy and practice in the midst of an epidemic. Obstetrics and gynecology, 128(1), 410. https://doi.org/10.1097/AOG.0000000000001446

Kruk, E., \& Banga, P. S. (2011). Engagement of substance-using pregnant women in addiction recovery. Canadian Journal of Community Mental Health, 30(1), 79-91. https://doi.org/10.7870/cjcmh-2011-0006 
Kuo, C., Schonbrun, Y. C., Zlotnick, C., Bates, N., Todorova, R., Kao, J. C. W., \& Johnson, J. (2013). A qualitative study of treatment needs among pregnant and postpartum women with substance use and depression. Substance Use \& Misuse, 48(14), 1498-1508. https://doi.org/10.3109/10826084.2013.800116

Leppo, A. (2012). "Subutex is safe": Perceptions of risk in using illicit drugs during pregnancy. International Journal of Drug Policy, 23(5), 365-373. https://doi.org/10.1016/j.drugpo.2012.01.004

Lincoln, Y. S., \& Guba, E. G. (1985). Naturalistic inquiry. Sage Publications.

Lind, J. N., Interrante, J. D., Ailes, E. C., Gilboa, S. M., Khan, S., Frey, M. T., Dawson, A. L., Honein, M. A., Dowling, N. F., Razzaghi, H., Creanga, A. A., \& Broussard, C. S. (2017). Maternal use of opioids during pregnancy and congenital malformations: A systematic review. Pediatrics, 139 (6) e20164131. https://doi.org/10.1542/peds.2016-4131

Lyndon, A. (2009). Skillful anticipation: maternity nurses; perspectives on maintaining safety. Quality and Safety in Health Care. https://doi.org/10.1136/qshc.2007.024547.

Maguire, D., Webb, M., Passmore, D., \& Cline, G. (2012). NICU nurses' lived experience: Caring for infants with neonatal abstinence syndrome. Advances in Neonatal Care, 12(5), 281-285. https://doi.org10.1097/ANC.0b013e3182677bc1

Marshall, C. \& Rossman (2016). Designing Qualitative Research. Sage Publication, Inc.

Martin, C. E., Longinaker, N., \& Terplan, M. (2015). Recent trends in treatment admissions for prescription opioid abuse during pregnancy. Journal of Substance Abuse Treatment, 48(1), 37-42. https://doi.org/10.1016/j.jsat.2014.07.007

Mattocks, K. M., Clark, R., \& Weinreb, L. (2017). Initiation and engagement with methadone treatment among pregnant and postpartum women. Women's Health Issues, 27(6), 646-651. https://doi.org/10.1016/j.whi.2017.05.002

McGlothen, K. S., Cleveland, L. M., \& Gill, S. L. (2018). "I'm doing the best that I can for her": Infant-Feeding decisions of mothers receiving medication-assisted treatment for an opioid use disorder. Journal of Human Lactation, 34(3), 535-542. https://doi.org/10.1177/0890334417745521

Miles, M. B., Huberman, A. M., \& Saldaña, J. (2013). Qualitative data analysis: A methods sourcebook: SAGE Publications, Incorporated.

Milligan, K., Niccols, A., Sword, W., Thabane, L., Henderson, J., \& Smith, A. (2011). Birth outcomes for infants born to women participating in integrated substance abuse treatment programs: A meta-analytic review. Addiction Research and Theory, 19(6), 542-555. https://doi.org/10.3109/16066359.2010.545153

Moher, D., Liberati, A., Tetzlaff, J., Altman, D. G., \& the PRISMA Group. (2009). Preferred reporting items for systematic reviews and meta-analyses: The PRISMA statement. PLoS Medicine, 6(6). https://doi.org/10.1371/journal.pmed1000097

Murphy-Oikonen, J., Brownlee, K., Montelpare, W., \& Gerlach, K. (2010). The experiences of NICU nurses in caring for infants with neonatal abstinence syndrome. Neonatal Network, 29(5), 307-313.

Neergaard, M. A., Olesen, F., Andersen, R. S., \& Sondergaard, J. (2009). Qualitative description - the poor cousin of health research? BMC Medical Research Methodology, 9(1), 52. https://doi.org/10.1186/1471-2288-9-52 
Neville, K. \& Roan, N. (2014). Challenges in nursing practice: Nurses' perceptions in caring for hospitalized medical-surgical patients with substance abuse/dependence. Journal of Nursing Administration, 44 (6), 339-346. https://doi.org/10.1097/NNA.0000000000000079.

O’Leary, C., Jacoby, P., D’Antoine, H., Bartu, A., \& Bower, C. (2012). Heavy prenatal alcohol exposure and increased risk of stillbirth. BJOG: An International Journal of Obstetrics \& Gynaecology, 119(8), 945-952. https://doi.org/10.1111/j.14710528.2012.03333.x

Paterno, M. T., Low, M., Gubrium, A., \& Sanger, K. (2018). Mothers and mentors: Exploring perinatal addiction and recovery through digital storytelling. Qualitative Health Research, 1049732318777474. https://doi.org/10.1177/1049732318777474

Patrick, S. W., Bauer, A. M., Warren, M. D., Jones, T. F., \& Wester, C. (2017). Hepatitis $\mathrm{C}$ virus infection among women giving birth - Tennessee and United States, 20092014. MMWR: Morbidity \& Mortality Weekly Report, 66(18), 470-473. https://doi.org/10.15585/mmwr.mm6618a3

Patrick, S. W., Davis, M. M., Lehmann, C. U., \& Cooper, W. O. (2015). Increasing incidence and geographic distribution of neonatal abstinence syndrome: United States 2009 to 2012. Journal of Perinatology: Official Journal of the California Perinatal Association, 35(8), 650-655. https://doi.org/10.1038/jp.2015.36

Patrick, S. W., Schumacher, R. E., Benneyworth, B. D., Krans, E. E., McAllister, J. M., \& Davis, M. M. (2012). Neonatal abstinence syndrome and associated health care expenditures: United States, 2000-2009. JAMA, 307(18), 1934-1940.

Peplau, H.E. (1952). Interpersonal Relations in Nursing. G.P. Putnam and Sons.

Peplau, H.E. (1988). Interpersonal relations in nursing. Macmillan.

Peplau, H.E. (1997). Peplau's theory of interpersonal relations. Nursing Science Quarterly, 10(4), 162-167. https://doi:10.1177/089431849701000407

Pereira, C. M., Pacagnella, R. C., Parpinelli, M. A., Andreucci, C. B., Zanardi, D. M., Souza, R., Robles, Angelini, C., Silveira, C., \& Cecatti, J. G. (2018). Drug use during pregnancy and its consequences: A nested case control study on severe maternal morbidity. Rev Bras Ginecol Obstet, 40(09), 518-526. https://doi.org/10.1055/s-0038-1667291

Peterson, W. E., Sword, W., Charles, C., \& DiCenso, A. (2007). Adolescents' perceptions of inpatient postpartum nursing Care. Qualitative Health Research, 17(2), 201212. https://doi.org/10.1177/1049732306297414

Phillips, D., Thomas, K., Cox, H., Ricciardelli, L. A., Ogle, J., Love, V., \& Steele, A. (2007). Factors that influence women's disclosures of substance use during pregnancy: A qualitative study of ten midwives and ten pregnant women. Journal of Drug Issues, 37(2), 357-375.

Pineles, B. L., Hsu S., Park E., \& Samet, J. M. (2016). Systematic review and metaanalyses of perinatal death and maternal exposure to tobacco smoke during pregnancy. American Journal of Epidemiology, 184 (02) 87-97. https://doi.org/10.1093/aje/kwv301

Polit, D. F. and Beck, C. T. (2012). Nursing Research: Generating and Assessing Evidence for Nursing Practice (9th ed.). Lippincott, Williams \& Wilkins. 
Radcliffe, P. (2009). Drug use and motherhood: Strategies for managing identity. Drugs and Alcohol Today, 9(3), 17-21.

https://doi.org/10.1108/17459265200900026

Renbarger, K.M., Shieh, C., Moorman, M., Mintus-Latham, K., \& Draucker, C. (2019).

The health care encounters of pregnant and postpartum women with substance use disorders. Western Journal of Nursing Research.

https://doi.org/10.1177/0193945919893372.

Riihim€aki, O., Paavonen, J., Luukkaala, T., Gissler, M., Metsaranta, M., Andersson, S., Nuutila, M., Pukkala, E., Melin, J., \&Tikkanen, M. (2017). Mortality and causes of death among women with a history of placental abruption. Acta Obstetricia et Gynecologica Scandinavica (96), 1315-1321. https://doi.org/10.1111/aogs.13212

Roberts, S. C. M., \& Nuru-Jeter, A. (2010). Women's perspectives on screening for alcohol and drug use in prenatal care. Women's Health Issues, 20(3), 193-200. https://doi.org/10.1016/j.whi.2010.02.003

Roberts, S. C. M., \& Pies, C. (2011). Complex calculations: How drug use during pregnancy becomes a barrier to prenatal care. Maternal and Child Health Journal, 15(3), 333-341. https://doi.org/10.1007/s10995-010-0594-7

Rørtveit, K., Hansen, B. S., Leiknes, I., Joa, I., Testad, I., \& Severinsson, E. (2015). Patients' experiences of trust in the patient-nurse relationship-A systematic review of qualitative studies. Open Journal of Nurisng, 5, 195-209. https://doi.org/10.4236/ojn.2015.53024

Rosengren, K. E. (1981). Advances in Scandinavia content analysis: An introduction. In Rosengren, K.E. (Ed.), Advances in content analysis (pp. 9-19). Sage.

Salihu, H. M., \& Wilson, R. E. (2007). Epidemiology of prenatal smoking and perinatal outcomes. Early Human Development, 83(11), 713-720. https://doi.org/10.1016/j.earlhumdev.2007.08.002.

Salmon, M. M., Joseph, B. M., Saylor, C., \& Mann, R. J. (2000). Women's perception of provider, social, and program support in an outpatient drug treatment program. Journal of Substance Abuse Treatment, 19(3), 239-246. https://doi.org/10.1016/S0740-5472(00)00103-3

Sandelowski, M. (2000). Whatever happened to qualitative description? Research in Nursing \& Health, 23(4), 334-340.

Sandelowski, M., \& Barroso, J. (2003). Creating Metasummaries of Qualitative Findings. Nursing Research, 52(4), 226-233.

Sandelowski, M., \& Barroso, J. (2007). Handbook for synthesizing qualitative research. Springer Publishing Company, Inc.

Scott, L. F., Shieh, C., Umoren, R. A., \& Conard, T. (2017). Care experiences of women who used opioids and experienced fetal or infant loss. Journal of Obstetric, Gynecologic, and Neonatal Nursing : JOGNN, 46(6), 846-856. https://doi.org/10.1016/j.jogn.2017.08.006

Shankaran, S., Lester, B. M., Das, A., Bauer, C. R., Bada, H. S., Lagasse, L., \& Higgins, R. (2007). Impact of maternal substance use during pregnancy on childhood outcome. Seminars in fetal \& neonatal medicine, 12(2), 143-150. https://doi.org/10.1016/j.siny.2007.01.002 
Shattell, M. (2004). Nurse-patient interaction: A review of the literature. Journal of Clinical Nursing, 13, 714-722.

Shaw, M. R., Lederhos, C., Haberman, M., Howell, D., Fleming, S., \& Roll, J. (2016). Nurses' perceptions of caring for childbearing women who misuse opioids. $M C N$ : The American Journal of Maternal/Child Nursing, 41(1), 37-42. https://doi.org/10.1097/nmc.0000000000000208.

Shay, L. A., \& Lafata, J. E. (2015). Where is the evidence? A systematic review of shared decision making and patient outcomes. Medical Decision Making, 35(1), 114-131. https://doi.org/10.1177/0272989x14551638

Solis, J. M., Shadur, J. M., Burns, A. R., \& Hussong, A. M. (2012). Understanding the diverse needs of children whose parents abuse substances. Current drug abuse reviews, 5(2), 135-147

Stengel, C. (2014). The risk of being 'too honest': Drug use, stigma and pregnancy. Health, Risk \& Society, 16(1), 36-50. https://doi.org/10.1080/13698575.2013.868408

Stone, R. (2015). Pregnant women and substance use: Fear, stigma, and barriers to care. Health \& Justice, 3(1), 1-15. https://doi.org/10.1186/s40352-015-0015-5

Suarez, M. A., Horton-Bierema, W., \& Bodine, C. E. (2018). Challenges and resources available for mothers in opiate recovery: A qualitative study. The Open Journal of Occupational Therapy,6(4). https://doi.org/10.15453/2168-6408.1483

Sullivan-Bolyai, S., Bova, C., \& Harper, D. (2005). Developing and refining interventions in persons with health disparities: The use of qualitative description. Nursing Outlook, 53(3), 127-133. https://doi.org/10.1016/j.outlook.2005.03.005

U .S. Department of Health and Human Services. (2019). The AFCARS Report. Retrieved from Children's Bureau: www.acf.hhs.gov.

U.S. Department of Health and Human Services, Substance Abuse and Mental Health Services Administration, SAMHSA-HRSA Center for Intergrated Health Solutions (n.d). Making integrated care work. https://www.integration.samhsa.gov/workforce/education-training

U.S. Department of Health and Human Services, Substance Abuse and Mental Health Services Administration, Center for Behavioral Health Statistics and Quality. (2019). National Survey on Drug Use and Health 2018. https://www.samhsa.gov/data/nsduh/reports-detailed-tables-2018-NSDUH

van Boekel, L. C., Brouwers, E. P. M., van Weeghel, J., Garretsen, H. F. L. (2013). Stigma among health professionals towards patients with substance use disorders and its consequences for healthcare delivery: Systematic review. Drug and alcohol dependence, 131(1-2), 23-35. https://doi.org/10.1016/j.drugalcdep.2013.02.018

Van Brakel, W.H. (2006) Measuring health-related stigma-A literature review. Psychology, Health \& Medicine, 11(3), 307-334. https://doi.org/10.1080/13548500600595160

Van Scoyoc, A., Harrison, J. A., \& Fisher, P. A. (2016). Beliefs and behaviors of pregnant women with addictions awaiting treatment initiation. Child \& Adolescent Social Work Journal. https://doi.org/10.1007/s10560-016-0474-0

Weisner, C. M., Chi, F. W., Lu, Y., Ross, T. B., Wood, S. B., Hinman, A., Pating, D., Satre, D., \& Sterling, S. A. (2016). Examination of the effects of an intervention 
aiming to link patients receiving addiction treatment with health care: The LINKAGE clinical trial linking patients in addiction treatment to health care engagement, JAMA Psychiatry, 73(8), 804-814.

https://doi.org/10.1001/jamapsychiatry.2016.0970

Weiss, M.E., \& Lokken, L. (2009). Predictors and outcomes of postpartum mothers' perceptions of readiness for discharge after birth. Journal of Obstetric, Gynecologic, and Neonatal Nursing, 38(4),406-417.

World Health Organization (2019). Lexicon of alcohol and drug terms. https://apps.who.int/iris/bitstream/handle/10665/39461/9241544686_eng.pdf;jsess ionid=4CB8F790BC8878101C8A4CF18076CDC2? sequence $=1$

Winkelman, T. N. A., Villapiano, N., Kozhimannil, K. B., Davis, M. M., Patrick, S. W. (2018). Incidence and costs of neonatal abstinence syndrome among infants with Medicaid: 2004-2014. Pediatrics, 141 (4), e20173520; https://doi.org/10.1542/peds.2017-3520

Yazdy, M. M., Desai, R. J., \& Brogly, S. B. (2015). Prescription opioids in pregnancy and birth outcomes: A review of the literature. Journal of Pediatric Genetics, 4(2), 56-70. https://doi.org/10.1055/s-0035-1556740 


\title{
CURRICULUM VITAE
}

\section{Education}

\author{
Kalyn Marie Renbarger
}

- Doctor of Philosophy in Nursing Science (Minor-Sociology), Indiana University, earned at IUPUI, Indianapolis, IN (2016-2020)

- Master of Science in Nursing, Ball State University, Muncie, IN (2008-2010)

- Bachelor of Science in Nursing, Ball State University, Muncie, IN (1997-2001)

\section{Professional Experience}

- Indiana University Health Ball Memorial Hospital. Muncie, IN, Registered Nurse. Women and Children's Service Line (2002-2019)

- Indiana University Health Riley Children's Hospital (2002-2003)

- Ball State University, Muncie IN, Assistant Clinical Lecturer of Nursing (20092020)

\section{Professional Memberships}

- Association of Women's Health, Obstetric, and Neonatal Nursing (2015-2020)

- Sigma Theta Tau Nursing Society (2015-present)

- Midwest Nursing Research Society (2015-present)

- International Society of Psychiatric Nurses (2018-2020)

\section{Honors and Awards}

- Diane McCabe Scholarship, 2019

- Sherry Queener Graduate Student Excellence Award nominee, Indiana University, 2019

- Jonas Scholar, 2018-2020, American Association of Colleges of Nursing

- Meier/Lyon Dissertation Fellowship, Indiana University, 2018-2019 
- Irene Aycock Nursing Scholarship, Indiana University, 2018

- Customer Service Champion Award, Ball Memorial Hospital, 2006

- Clauser Award (Nursing GPA), Ball State University, 2001

\section{Presentations}

- Slater G., Thaller J., Place J., \& Renbarger, K. (2019). Considering trauma and trauma-informed care in opioid addiction recovery for pregnant and postpartum women. Fall 2019 scholarship series. Invited talk at College of Health, Ball State University, IN.

- Thaller J., Place J., Renbarger, K., \& Slater, G. Examining the strengths, weaknesses, opportunities, and threats of implementation of an in-patient opioid addiction recovery program for women and children, presentation at the International Congress of Qualitative Inquiry, University of Illinois at UrbanaChampaign, May 17, 2019.

- Slater, G., Renbarger, K., Schumacher, S., \& Woods, B. Innovative options in pregnant and postpartum addictions treatment and recovery: Pilot results of the Fresh Start Recovery Center at VOAOH-IN, Labor of Love Conference, Indianapolis, December 11, 2019.

- Place J., Thaller J., Slater, G., \& Renbarger, K. Examining the strengths, weaknesses, opportunities, and threats of implementation of an in-patient opioid addiction recovery program for women and children, poster presentation submitted to the Indiana Public Health Conference, Indianapolis, IN, October 11, 2018. 


\section{Publications-Refereed}

- $\quad$ Renbarger, K.M., Shieh, C., Moorman, M., Latham-Mintus, K., \& Draucker, C. (2019). The health care encounters of pregnant and postpartum women with substance use disorders. Western Journal of Nursing Research.

https://doi.org/10.1177/0193945919893372

- In Progress

○ Renbarger, K.M., Shieh, C., Moorman, M., Latham-Mintus, K., \& Draucker, C. (in preparation). Exploring the relationship between maternity nurses and pregnant and postpartum women with substance use disorders.

○ Thaller, J., Slater, G., Place, J.M., \& Renbarger, K.M. (in preparation). Trauma informed care in a maternal residential treatment center.

\section{Grants}

- $\quad$ Slater, G. (PI), Thaller, J. (Co-PI), Place, J.M. (Co-PI), \& Renbarger, K. (Co-PI). Volunteers of America of Indiana Fresh Start Recovery Center Expansion and Enhancement (Proposal A18-0090). Substance Abuse and Mental Health Services Administration [SAMHSA] (Grant \# G0001183A). September 30, 2017 - September 29, 2022, \$237,500. Funded.

- Slater, G. (PI), Trainor, K. (Co-PI), \& Renbarger, K. (Co-PI). Neonatal Abstinence Syndrome (NAS) Fresh Start Pilot Expansion Project (Proposal A180476), Indiana State Department of Health (Grant \# G0001183A). June 30, 2019 - July 1, 2020, \$60,000, Funded. 
- Renbarger, K. (P.I.), Joyce Fitzpatrick Psychiatric Nursing Research Grant, International Society of Psychiatric Nurses, April, 2019-2020, \$3,000, Funded.

- Slater, G. (PI), Thaller, J.(Co-PI), Place, J.M.(Co-PI), \& Renbarger, K. (Co-PI). Fresh Start Pilot Project (Proposal a. A18-0297), Indiana State Department of Health (Grant \#G0001183A). June 30, 2017 - July 1, 2019, \$59,779, Funded. 